\title{
Regulation of the Actin Cytoskeleton via Rho GTPase Signalling in Dictyostelium and Mammalian Cells: A Parallel Slalom
}

\author{
Vedrana Filić *, Lucija Mijanović, Darija Putar, Antea Talajić, Helena Ćetković and Igor Weber *(D)
}

Citation: Filić, V.; Mijanović, L.; Putar, D.; Talajić, A.; Ćetković, H.; Weber, I. Regulation of the Actin Cytoskeleton via Rho GTPase Signalling in Dictyostelium and Mammalian Cells: A Parallel Slalom. Cells 2021, 10, 1592. https:// doi.org/10.3390/cells10071592

Academic Editor: Francisco Rivero

Received: 28 May 2021

Accepted: 16 June 2021

Published: 24 June 2021

Publisher's Note: MDPI stays neutral with regard to jurisdictional claims in published maps and institutional affiliations.

Copyright: (c) 2021 by the authors. Licensee MDPI, Basel, Switzerland. This article is an open access article distributed under the terms and conditions of the Creative Commons Attribution (CC BY) license (https:// creativecommons.org/licenses/by/ $4.0 /)$.
Division of Molecular Biology, Ruđer Bošković Institute, Bijenička 54, HR-10000 Zagreb, Croatia; lucija.mijanovic@irb.hr (L.M.); darija.putar@irb.hr (D.P.); antea.talajic@irb.hr (A.T.); helena.cetkovic@irb.hr (H.Ć.) * Correspondence: vedrana.filic@irb.hr (V.F.); igor.weber@irb.hr (I.W.)

\begin{abstract}
Both Dictyostelium amoebae and mammalian cells are endowed with an elaborate actin cytoskeleton that enables them to perform a multitude of tasks essential for survival. Although these organisms diverged more than a billion years ago, their cells share the capability of chemotactic migration, large-scale endocytosis, binary division effected by actomyosin contraction, and various types of adhesions to other cells and to the extracellular environment. The composition and dynamics of the transient actin-based structures that are engaged in these processes are also astonishingly similar in these evolutionary distant organisms. The question arises whether this remarkable resemblance in the cellular motility hardware is accompanied by a similar correspondence in matching software, the signalling networks that govern the assembly of the actin cytoskeleton. Small GTPases from the Rho family play pivotal roles in the control of the actin cytoskeleton dynamics. Indicatively, Dictyostelium matches mammals in the number of these proteins. We give an overview of the Rho signalling pathways that regulate the actin dynamics in Dictyostelium and compare them with similar signalling networks in mammals. We also provide a phylogeny of Rho GTPases in Amoebozoa, which shows a variability of the Rho inventories across different clades found also in Metazoa.
\end{abstract}

Keywords: Rho; Rac; cell migration; cell motility; convergent evolution; Amoebozoa

\section{Introduction}

Small GTPases from the Rho family have continued to draw the attention of students of cell motility ever since the ground-breaking discovery of their paramount importance in the regulation of the actin cytoskeleton [1-3]. Initially demonstrated in mammalian and yeast cells, their role as the master switches in control of actin remodelling soon turned out to be universal among eukaryotes [4]. From an evolutionary perspective, it should be advantageous to compare Rho signalling in motile mammalian cells with cells of evolutionary distant organisms that share their major traits rooted in the actin cytoskeleton, such as the crawling locomotion, internalization of the extracellular material by large-scale endocytosis, intercellular and extracellular adhesion coupled with anchorage to their surroundings, and binary division by actomyosin-based constriction. Organisms belonging to nonflagellated amoebozoans fulfil these criteria rather well. Amoebozoa constitute a monophyletic clade that branched from Opisthokonta early in the evolution of eukaryotes, probably already in the Mesoproterozoic [5,6]. The lifestyle of these highly motile amoebae, e.g., of their best studied representative Dictyostelium discoideum, is remarkably reminiscent of the mammalian white blood cells, particularly neutrophils and phagocytes [7]. Similar to the cells that perform immune surveillance in complex multicellular organisms, Dictyostelium amoebae chase their microbial prey by chemotaxis and engulf it by phagocytosis [8,9]. During their starvation-induced aggregation, the amoebae adhere to each other and move in multicellular streams reminiscent of collective cell movements during animal embryogenesis [10-12]. The amoeboid locomotion of Dictyostelium cells and their capability 
to internalize nutrients by macropinocytosis very closely match the corresponding acquired traits of cancer cells [13-18] and, more generally, mirror the mesenchymal-amoeboid transition occurring during embryonal development $[13,19,20]$.

The shape and locomotion of Dictyostelium amoebae are astonishingly plastic. Although they predominantly move by protrusion of irregular pseudopodia similar to leukocytes, vegetative amoebae occasionally extend thin lamellipodia akin to fibroblasts in culture and even can assume a fan-like shape and migrate in a way that highly resembles the locomotion of skin keratocytes [21]. Dictyostelium cells also frequently extend numerous filopodia and under certain circumstances switch to a blebbing type of locomotion [22-24]. During aggregation, the amoebae move by protruding long cylindrical pseudopodia, a behaviour that augments their sensitivity to chemoattractant gradients [25]. Vegetative cells feed by large-scale endocytosis and are capable of generating phagocytic and macropinocytotic cups of various shapes and sizes, and at a high rate [26,27]. Since all these diverse protrusions are generated and supported by specifically orchestrated actin assemblies, it is not surprising that the Dictyostelium proteome includes representatives of major classes of actin polymerases, actin-binding proteins, and myosin motor proteins, which are the convergence points of signalling pathways that regulate the actin-based supramolecular structures $[28,29]$.

Coincidentally, the genomes of Dictyostelium discoideum and Homo sapiens both encode 20 Rho GTPases, although the two species diverged more than a billion years ago [5,6]. Given the similarities in the cellular and cytoskeletal dynamics between the two organisms, which are known to be governed by Rho GTPases, the parallel diversification of this protein family in the two lineages probably represents a prime example of convergent evolution $[30,31]$. Rho family genes occur in all examined eukaryotic supergroups, leading to the conclusion that Rho GTPases were already present in the last eukaryotic common ancestor (LECA). Phylogenetic analysis distributes the sequences of genes encoding 20 human Rho GTPases between the two stem groups: the Rac group includes Rac1/2/3/RhoG, Cdc42/RhoJ/Q, RhoU/V, RhoH, and RhoBTB1/2, whereas the Rho group includes RhoA/B/C, RhoD/F, and Rnd1/2/3 [4,32]. Since Rho GTPases in nonOpisthokont lineages are more closely related to Rac proteins, it is generally accepted that Rac is the founding member of the whole family. Indeed, it is usually argued that both Rho sensu stricto (s.s.) and Cdc42 are represented only in Opisthokonta [33]. The Rho family expanded rapidly in the Metazoa around 700 million years ago, probably as a result of multiple gene duplication and lateral gene transfer events $[4,34]$. For example, the time of emergence of Rnd and RhoU/V subgroups is consistent with their roles in the acquisition of muscle and nerve cells, while the Cdc42 isoforms, RhoJ/Q and RhoD/F, probably emerged at the time of origin of the vertebrate central nervous system [32].

Traditionally, Rho GTPases from D. discoideum were described either as Rac-like (6 members of the Rac stem group) or as RhoBTB-like (RacA), while others remained unclassified [35]. Here, we performed a phylogenetic analysis of Rho GTPases from representatives of four amoebozoan classes, with two basal metazoans and human included in the reference set (Figure 1; Table S1). Among the analysed amoebozoan genomes, 19 Rho GTPase genes were identified in the genome of Entamoeba histolytica, 5 in Acanthamoeba castellanii, and 6 in Planoprotostelium aurantium. This large variability in the number of Rho GTPases in amoebozoans is a sign of elevated evolutionary dynamics, similar to the high incidence of gain and loss of the Rho family members in different animal lineages [4,33]. We present evidence based on the published data that RacE and RacC GTPases from Amoebozoa, in particular from $D$. discoideum, represent bona fide functional equivalents of mammalian Rho and Cdc42 groups, respectively. It remains an open question, however, whether the Rac/Rho/Cdc42 trinity has been conserved from the common ancestor of Amoebozoa and Metazoa, or if it emerged independently in these two clades. 


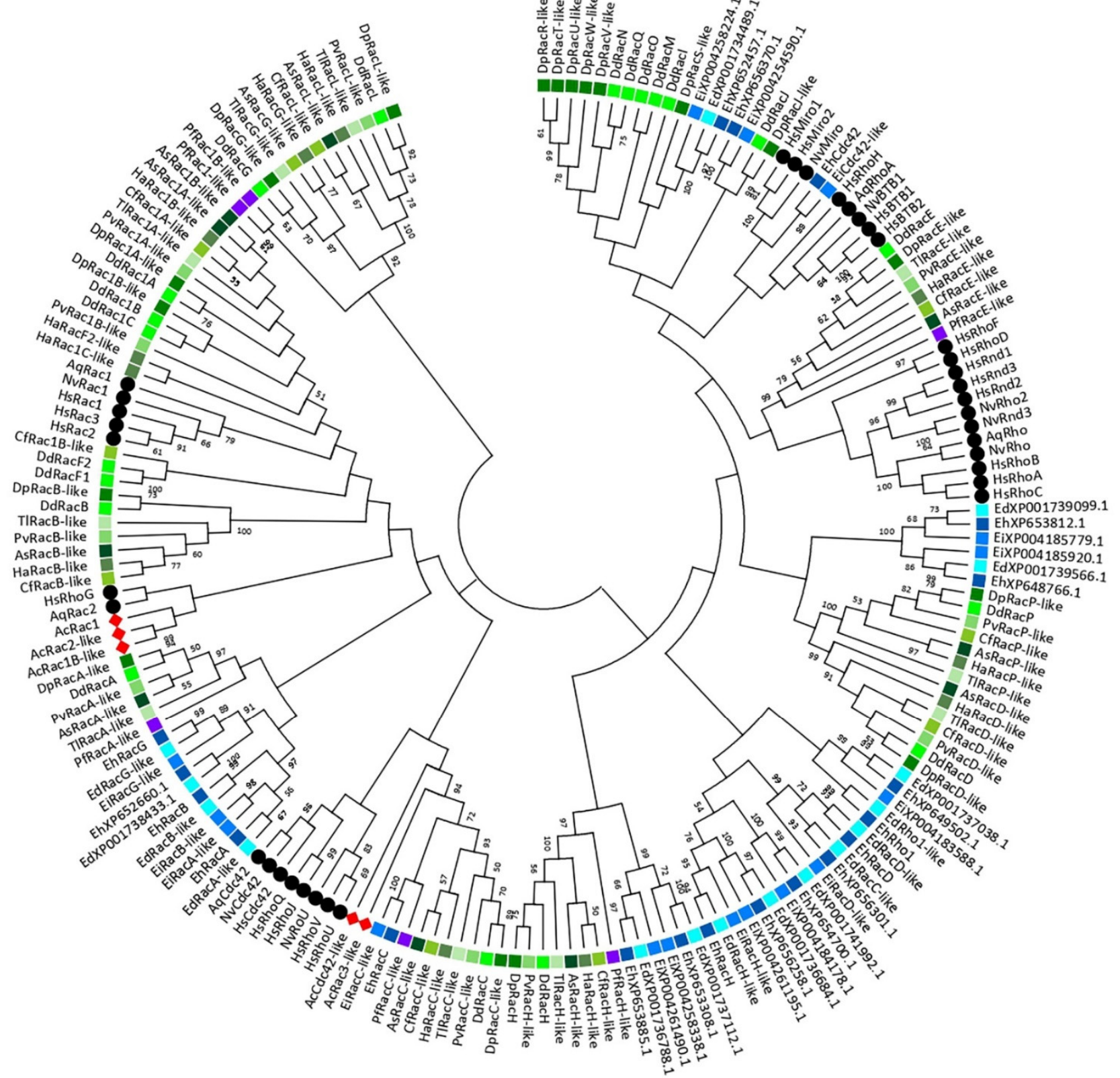

Figure 1. Phylogenetic tree of Rho GTPases in Amoebozoa. The evolutionary history was inferred using the maximum likelihood method and the Le_Gascuel_2008 model [36]. Evolutionary analyses were conducted in MEGAX [37], based on 186 amino acid sequences (accession numbers and sequences are presented in Supplementary File 2). Numbers at nodes are bootstrap percentages evaluated from 1000 bootstrapping replications (bootstrap values higher than 50 are indicated at the branching points). Rho GTPases from Metazoa are indicated by black circles. Amoebozoan Rho GTPases are marked as follows: subphylum Lobosa, class Discosea by red rhombus; subphylum Conosa, classes Archamoebea, Dictyostelia, and Variosea by blue, green, and purple squares, respectively.

It is remarkable that the cells of organisms so evolutionarily distant as cellular slime moulds and mammals share so many similar traits based on a highly dynamic actin cytoskeleton. This apparent conservation of the actin-dependent cellular processes poses the question of the conservation of upstream signalling mechanisms. In this review, we systematically present the known signalling pathways in Dictyostelium that start with the activation of specific Rho GTPases and finish with a particular actin cytoskeleton activity, while drawing parallels with the comparable signalling networks in mammals. We arrive at a complex overall picture: while some $D$. discoideum Rho GTPases appear to be partial functional equivalents of their mammalian counterparts and engage in related signalling 
pathways, there is no strict one-to-one correspondence between the two, as epitomized by several original solutions on how to convey signals triggered by amoebozoan Rho GTPases to induce rearrangements of the actin cytoskeleton. Moreover, the overall picture is sparse since the mechanistic modes of action of many Dictyostelium Rho GTPases are still not known in any detail, and their further investigation should therefore be encouraged.

\section{Rho GTPase Family in Dictyostelium discoideum}

Rho GTPases constitute one of the five families within the Ras superfamily of small monomeric $G$ proteins [38]. Ras proteins are commonly described as molecular switches, because they are active and transduce signals in the GTP-bound state [39]. They have high binding affinities for both GTP and GDP and most of them exert low intrinsic GTPase and nucleotide exchange activities. These conserved biochemical features are determined by the shared structural design of the guanine nucleotide-binding domain composed of five G-boxes [40,41]. Most Ras GTPases interact with their downstream target proteins, the so-called effectors, only in their active, GTP-bound state. Conversions between the inactive GDP-bound and the active GTP-bound conformations are catalysed by guanine nucleotide exchange factors (GEFs) that, under physiological conditions, promote GTPase activation and by GTPase activating proteins (GAPs) that promote inactivation by facilitating hydrolysis of the bound GTP [42]. Conformational differences between GDP- and GTP-bound Ras proteins are mostly confined to the two surface regions designated as switch I and switch II $[39,43]$. Switch regions coincide with the effector-binding domain that becomes exposed in the GTP-bound conformation.

Of note, half of the mammalian Rho family members do not conform to the classical regulation by GEFs and GAPs. These, so-called atypical Rho GTPases are predominantly present in the GTP-bound state, either because of a defective GTPase activity or due to an increased intrinsic GDP/GTP exchange activity, and are regulated by different means [44]. Rho GTPases are characterized by a 10-15 amino acid long insert that is not found in other Ras superfamily GTPases [45-47]. In addition, the activity of some Rho family members is further regulated by a third class of proteins, the Rho GDP-dissociation inhibitors (RhoGDIs) [48,49]. Rho effectors use various structural motifs to interact with Rho GTPases [50]. For example, some Rho effectors bind Rho GTPases via a leucine-zipperlike HR1 motif inside the Rho effector homology (REM) region, or via a ROK-kinectin homology (RKH) Rho binding domain, while many Cdc42 and Rac1 effectors bind to the cognate GTPases via a CRIB (Cdc42/Rac interactive binding) motif harboured within their GTPase binding domains (GBD) [51,52]. The GTPase-effector interaction often induces conformational changes in the effector that relieve its intramolecular autoinhibition [51]. For a comprehensive overview of the physiological functions of mammalian Rho proteins, the reader is referred to several reviews, some with a specific emphasis on the role of Rho GTPases in the regulation of the actin cytoskeleton [44,53-56].

$D$. discoideum genome contains $20 \mathrm{rac}$ genes $(\mathrm{rac} 1 \mathrm{~A}, \mathrm{rac} 1 \mathrm{~B}, \mathrm{rac} 1 \mathrm{C}, \mathrm{rac} A, \mathrm{racB}, \mathrm{racC}, \mathrm{racD}$, racE, racF1, racF2, racG, racH, racI, racJ, racL, racM, racN, racO, racP, and racQ) and 1 pseudogene (racK_ps) (http:/ / dictybase.org, accessed on 4 February 2021; [57]). Their protein products are usually divided into the Rac-like subfamily (Rac1A/1B/1C, RacB, RacF1, and RacF2), the RhoBTB-like RacA, and others, allegedly with no obvious orthologues of Cdc42 and Rho [58,59]. In the following, we provide an original phylogenetic analysis of a subset of amoebozoan Rho family members (Section 3) and a succinct overview of the pathways that transduce signals from small Rho GTPases to the actin cytoskeleton in D. discoideum (Section 4), drawing parallels, when possible, with the corresponding signalling routes and functional outcomes in mammalian cells. The presented data indicate that Rho and Cdc42 bona fide functional equivalents are present in D. discoideum and probably also other related amoebozoan species. 


\section{A Phylogeny of the Rho GTPase Family in Amoebozoa}

Although basic phylogenies of the Rho family GTPases in Dictyostelium discoideum and Entamoeba histolytica have been published [35,58,60,61], to the best of our knowledge no such analysis has been attempted at the level of Amoebozoa as a clade, i.e., by taking into account multiple species from different amoebozoan classes. Our comparative analysis of the Rho GTPase-mediated regulation of the actin cytoskeleton and cell motility in D. discoideum and mammalian cells (Section 4) pointed out complex functional analogies between the two systems that prompted us to construct a phylogenetic tree comprising Rho GTPases from 12 amoebozoan species belonging to two subphyla and five classes, in addition to three representative metazoans (Figure 1; Table S1). The tree and the supplementary multiple sequence alignments shed light on several hitherto neglected aspects of the variability of the Rho GTPase repertoire in Amoebozoa and exposed examples of potentially misleading misnomers in the currently utilized nomenclature.

A total set of 151 amino acid sequences from 12 different species of amoeboid protists were identified as corresponding to Rho GTPase homologs at the National Center for Biotechnology Information database (NCBI) using the blastp algorithm (https:/ /blast.ncbi. nlm.nih.gov/Blast.cgi, accessed on 11 February 2021) (Table S1). In order to visualize phylogenetic relationships of the Rho homologs among different species of Amoebozoa, a phylogenetic tree was constructed using the maximum likelihood algorithm in the MEGAX software (Figure 1; [37]). For this purpose, amino acid sequences were aligned using the multiple sequence alignment with high accuracy and high throughput algorithm MUSCLE [62] against the known Rho GTPase proteins from basal Metazoa (Nematostella vectensis and Amphimedon queenslandica) [34] and a representative of higher animals, Homo sapiens, which served as a reference. A multiple sequence alignment of Rho family GTPases was used to identify conserved domains, indicating that all members of the Rho, Rac, Cdc42, and RhoBTB subfamilies in Amoebozoa have domains responsible for nucleotide binding and hydrolysis (G1-5 boxes) together with both switch I and II regions that specifically bind regulators or effectors. Rho insert, the most characteristic Rho family signature, is present in all analysed amoebozoan proteins, although in some cases this insert is shorter than the typical 13 amino acids. Interestingly, an alignment of RacA proteins from Dictyostelia and Variosea against human RhoBTB GTPases verified the presence of two BTB domains and their affiliation to the RhoBTB subfamily (Figure S1). Since members of the RhoBTB subfamily were not identified in the genomes of basal metazoan such as sponges, placozoans, and ctenophores [34], their presence in Amoebozoa, a clade that predates Opisthokonta, supports the suggestion that RhoBTB is one of the eldest Rac paralogs [32].

Most amoebozoan species included in our analysis belong to the subphylum Conosa and only one to the subphylum Lobosa, class Discosea $[6,63,64]$. Within the Conosa subphylum, our phylogenetic analysis demonstrates a divergent evolution between Rho GTPases from Archamoebea (i.e., Entamoeba) and other classes, namely Dictyostelia and Variosea (Figure 1). Based on a proteomic analysis, Song et al. (2005) also reported a significant divergence between $E$. histolytica and $D$. discoideum that is even deeper than between animals and fungi, although they each represent one Amoebozoa subphylum. However, the evolutionary analysis shows that Dictyostelia and Variosea Rho GTPases are most closely related and grouped together, while proteins from Archamoeba are placed at distant positions forming a few relatively independent branches. According to the phylogenetic clusters and a varying number of homologs in Amoebozoa, this is probably a consequence of lineage-specific duplications that likely happened shortly after the Amoebozoa split from the Opisthokont lineage [65]. Acanthamoeba castellanii, a representative of the Lobosa lineage, has the smallest set of Rho GTPases comprising only Rac and Cdc42 subfamily members, which are not grouped into clearly defined common branches with other Amoebozoa.

The nomenclature of Rho GTPases in Amoebozoa was introduced independently for each organism, mainly in original publications where the corresponding genes were initially identified and was essentially retained by convention, resulting in several misleading 
labels. For example, E. histolytica XP_654488 was labelled as EhRho1, although it harbours critical mutations in the switch I and G5 box compared to archetypical Rho proteins, and even lacks the Rho insert, a hallmark of the entire Rho family (Figure S2; [66]). It was therefore even suggested that it should be reclassified to the Ras family, but structural and functional characterization has subsequently corroborated that its initial categorization as an E. histolytica Rho orthologue was warranted [67]. On the other hand, D. discoideum XP_640935.1 contains the Rho insert and conforms to the consensus primary structure of G1-G5 and both switch regions of mammalian Rhos (Figure S2), but was nevertheless designated as RacE, and its relatedness to mammalian Rhos s.s. was, until recently, ignored, probably due to two sizeable inserts at the $\mathrm{C}$ - and $\mathrm{N}$-termini that biased the global sequence similarity scores [68]. Whereas RacE is a clear amoebozoan counterpart of RhoA with several common functional roles, we note that amoebozoan $\mathrm{RacC}$ proteins might have a similar position in relation to mammalian $\mathrm{Cdc} 42$, although their functional similarity is less well supported by the available data (Figure S3; [69]).

In general, obtaining a clear insight into the evolutionary relationships between the analysed Rho GTPases from Amoebozoa and selected Metazoa (Porifera, Cnidaria and Mammalia) is quite daunting based on the available data, mainly due to their ancient divergence point and specific selective constraints in each of the taxonomic groups that shaped their respective Rho GTPase signalling pathways. These obstacles are reflected in low support values for most of the deeper nodes of the constructed evolutionary tree (Figure 1), indicating that the core of the tree topology is not very robust, and precluding any definitive statements regarding possible orthological relationships between the amoebozoan and mammalian Rho family GTPases: for instance, for RacE vs. RhoA and RacC vs. Cdc42. Interestingly, this statement also applies to the branches and nodes that link Dictyostelium Rac1A/B/C to human Rac1/2/3, which are short and poorly supported, indicating weak phylogenetic signals in favour of the specific orthology of the two groups. To obtain a better resolution of the evolutionary history of Rho GTPases in Amoebozoa, a more comprehensive phylogenetic analysis is required, covering the range of homologous proteins from other intermediately related organisms. Moreover, additional phylogenetic probabilistic algorithms should be employed in order to obtain robustness and support for the nodes [70]. It is also possible to remove uninformative sites from the multiple sequence alignments to get a more precise output [71].

\section{Comparative Analysis of the Rho Signalling in Dictyostelium and Mammalian Cells}

\subsection{Rac1 GTPases}

The three $D$. discoideum Rac1 GTPases are more than $90 \%$ identical in the amino acid sequence shared among themselves. After cloning in 1993, it became common to regard the three Rac1 isoforms as Dictyostelium orthologues of the human Rac1 GTPase, with whom they share around $80 \%$ amino acid sequence identity; hence, they were named Rac1A, Rac1B, and Rac1C [72]. Their expression shows an increase during multicellular development, with Rac1A being expressed much stronger than Rac1B and Rac1C, in both vegetative and developing cells [72-74]. Rac1B and Rac1C are induced during the sexual maturation of cells as well [75]. Early studies on cells overexpressing wild-type forms of $D$. discoideum Rac1 GTPases have demonstrated their involvement in the formation of filopodia, lamellipodia, and membrane ruffles and suggested their roles in the regulation of growth, motility, large-scale endocytosis, and development [76,77]. However, the deletion of individual rac1 genes did not induce any prominent phenotypic changes when knockout cells were grown in suspension or on bacterial lawns, suggesting their redundancy $[77,78]$. The most noticeable effects were slightly smaller plaques of $\mathrm{rac} 1 \mathrm{~B}$ - and $\mathrm{rac} 1 \mathrm{C}$-null cells and an apparent defect in early development of rac1B-null cells; however, these phenotypes have not been further investigated [78]. On the other hand, biochemical studies have identified several interactors, the so-called effectors, through which Rac1 GTPases exert their functions and affect the actin cytoskeleton. 
It has been recognized early on that a core group of Rac/Cdc42 effectors is conserved across eukaryotes, in particular fungi and Metazoa [79]. Most of the core effectors involved in the regulation of the actin cytoskeleton are also conserved in Dictyostelium and will be dealt with at length in the remainder of this review. Indicatively, several core effectors interact with GTPases from both Rac and Cdc42 groups in the same organism, while other effectors interact with Rac in some organisms and with Cdc42 in others [79]. We encounter a similar situation in Dictyostelium (Figure 2), where it is also not possible to draw a sharp dividing line between the pathways driven by individual GTPases, neither in interaction nor in functional assays. The yeast-two-hybrid (Y2H) and pull-down assays that use CRIB motifs from different effectors as baits are especially prone to show interactions with multiple GTPases, and vice versa [59,80-85]. Refining the existing map of functional interactions between individual GTPases and their effectors in Dictyostelium therefore remains an important task for future research.
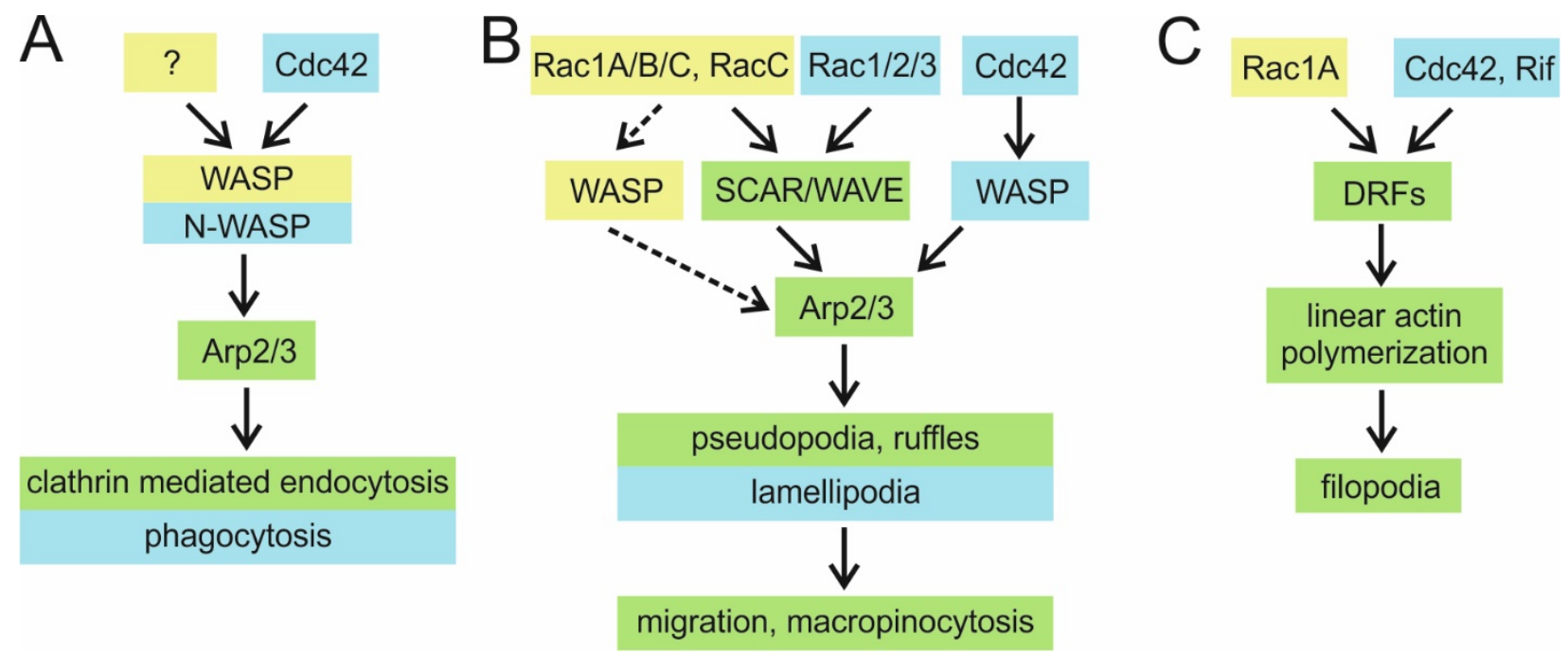

Figure 2. Parallel presentation of major signalling pathways starting from Rac1A/B/C and RacC in Dictyostelium (yellow) and Rac1/2/3 and Cdc42 in mammals (blue) and converging onto the actin cytoskeleton regulation. (A,B) Activation of the Arp2/3 complex via WASP family proteins, converging on the clathrin-mediated endocytosis and phagocytosis (A), or the protrusion of pseudopodia and macropinocytotic cups (B). (C) Activation of the DRF-mediated actin polymerization and protrusion of filopodia. The common elements shared by Dictyostelium and mammals are shown in green. The default active state of small GTPases is GTP-loaded.

\subsubsection{WASP Family Proteins as Rac1 Effectors}

A group of the most prominent effectors of mammalian Rac1 and Cdc42 are the actin filament nucleation promoting factors (NPFs) of the WASP family. NPFs stimulate the nucleation activity of the intrinsically almost inactive Arp $2 / 3$ complex that nucleates the branching actin filament on the sides of existing mother filaments [86,87]. WASP protein family in mammals encompasses at least six members that often have multiple isoforms: WASP, N-WASP, WAVE/SCAR, WASH, and metazoa-specific JMY and WHAMM, where WASPs and WAVEs are regulated by Rho GTPases. They all have a carboxyl terminal WCA domain that potently activates the Arp $2 / 3$ complex and a central PRD domain, whereas their amino termini differ, reflecting different modes of regulation and distinct means of spatiotemporal activation [88]. In general, in addition to Rho GTPases, various kinases and phosphoinositides regulate the activity of NPFs. In their unstimulated state, WASP and N-WASP are autoinhibited by an intramolecular interaction between the WCA and GBD domains, which precludes their interaction with the Arp2/3 complex [89-91]. The binding of activated Cdc42 or Rac1 relieves this autoinhibition and, in synergy with additional signals, stabilizes the active conformations of WASP and N-WASP [88,91-93]. 
Human and Dictyostelium WAVE proteins were cloned almost at the same time [94,95]. In both papers it was recognized that both central and C-terminal regions of the two proteins are typical for the WASP family, but their N-termini contained a novel motif. Thus, Miki et al. (1998b) named it WAVE, short for the WASP family verprolin-homologous protein, whereas Bear et al. (1998) dubbed it SCAR because it was identified in a genetic screen for suppressors of the $C A R 2$-null phenotype. WAVE/SCAR proteins are sequestered within the WAVE regulatory complex (WRC) that, besides WAVE, also contains the Sra1/Pir121, Nap1, Abi, and HSPC300 subunits [96-99]. While the activation of WASPs requires direct interaction with Cdc42, WAVE/SCAR proteins do not have a GBD and are regulated by Rac1 indirectly [95]. In an influential publication, it was claimed that the binding of the activated Rac1 to Pir121 in the WAVE1 complex induces the decoupling of the trans-inhibitory Pir121-Nap1-Abi2 subcomplex, thus releasing the active WAVE1-HSPC300 heterodimer [97]. Subsequent years have introduced much controversy into this matter, suggesting a constitutive activity of the WRC [100-102]. Finally, after realising that experimental conditions could have led to a nonphysiological activation of the WRC, the intrinsic inactivity of different WAVE complexes was strongly confirmed [103-105]. However, contrary to the original study of Eden et al. (2002), it was demonstrated that dissociation of the complex does not precede its activation and that Rac1 binding is not sufficient for the activation [105]. Full activation on the membrane requires simultaneous recruitment of the properly phosphorylated WAVE complex by the active Rac1 and acidic phospholipids $[105,106]$.

D. discoideum has five members of the WASP family: WASP encoded by was A [107], two unique WASP-related proteins encoded by wasB and wasC genes [108], SCAR [94], and WASH [109]. Dictyostelium WASP has the same domain organization as mammalian WASPs and is an orthologue of the ubiquitous N-WASP [108]. Both Dictyostelium WASP and mammalian N-WASP localize to the ventral plasma membrane where they transiently colocalize with clathrin puncta before the onset of the clathrin-coated vesicle (CCV) internalization [110-112]. It appears, therefore, that the main physiological role of WASP is to assist in clathrin-mediated endocytosis (CME) in both mammalian and Dictyostelium cells $[113,114]$. WASP is essential for CME in Dictyostelium [114], but neither its recruitment to clathrin-coated pits (CCPs) nor its ability to stimulate the Arp2/3-dependent F-actin assembly at the CCPs is dependent on a direct interaction with Rac GTPases (Figure 2A; [115]). CME is the least actin-dependent type of endocytosis in mammalian cells, requiring the support of actin filaments only to overcome high membrane tension or to internalize large cargo [116]. Contrary to the situation in Dictyostelium, mammalian $\mathrm{N}$-WASP is not essential for the actin assembly at CCPs since EGFR-mediated endocytosis in N-WASP knockout fibroblasts (devoid of haematopoietic WASP) is not blocked but only reduced [113]. However, an interaction between N-WASP and Cdc42 is required for efficient CME in mammalian cells [117]. Interestingly, both Rho and Rac1 negatively regulate CME [118,119].

In mammalian cells, WASPs are generally required for podosome formation, endocytosis, and phagocytosis, whereas WAVE proteins drive membrane protrusions in the form of lamellipodia and dorsal ruffles [88,120]. Analogously, Dictyostelium WASP is not needed for pseudopodia formation [114]. Yet, in addition to clathrin puncta, WASP is also scarcely visible in protrusions of vegetative cells and transiently enriched in the leading edge and the uropod of chemotactically competent cells $[107,121]$. Therefore, it is not entirely surprising that, in the absence of SCAR, WASP takes over its function by acquiring leading edge localization and driving pseudopodia protrusion to sustain efficient chemotaxis, and this function of WASP requires direct activation by Rac (Figure 2B; $[112,115])$. On the other hand, wasA-null cells exhibit somewhat reduced speed in the chemotaxis to folate due to an inefficient retraction of their enlarged trailing tails that accumulate active Rac and SCAR, which was interpreted as the source of their depolarization $[107,114,115]$. These authors speculate that WASP functions at CCPs, not only to drive the actin assembly to assist vesicle internalization, but also to remove active Rac from the cell rear via endocytosis, thus 
maintaining the front-rear polarity [115]. The proposed model therefore depicts WASP as a de facto regulator rather than an effector of Rac.

Due to the usage of a nonspecific Rac probe that interacts with several active Rac GTPases, including Rac1A/1B/1C and RacC [81], it was not determined which particular Rac GTPases interact with WASP in vivo. WASP GBD interacts with active Rac1, RacA, RacB, and RacC GTPases, but only RacC was shown to be capable of relieving WASP autoinhibition and thus activating F-actin polymerization in vitro and in vivo [82]. Fulllength recombinant WASP binds both active Rac1 and RacC [115]. As Rac1 seems to be the major regulator of the leading-edge structures in vegetative cells [122], WASP probably removes Rac1 from the rear, but it is conceivable that other Racs, especially RacC, contribute to front protrusions and/or other WASP-mediated processes. Namely, the phenotype of was A-null cells also implicated WASP activity in phagocytosis, cytokinesis, and starvationinduced aggregation [114], but its regulation in these processes has not been investigated in any detail. Of note, Fc $\gamma$ R-mediated phagocytosis in mammalian macrophages requires the Cdc42-induced activation of WASP and N-WASP [123,124].

Dictyostelium SCAR (scrA gene) is also a part of a heteropentameric inhibitory complex that contains orthologues of PIR121, Nap1, HSPC300, and Abi, each encoded by a single gene [125-127]. Although direct interaction between PIR121 and Rac1 (or any other Rac) in Dictyostelium has not been demonstrated, microscopy data show that the localization of WRC to active Rac regions at the leading edges of pseudopodia is abolished when wild-type PIR121 is replaced by the Rac1-nonbinding A-site mutant protein [128]. The determination of the structure of the Rac1-bound WRC revealed two Rac1 binding sites in Sra1 (A- and D-site), both required for the WAVE-mediated activation of the Arp2/3 complex [129]. These sites have different binding affinities for Rac1 and distinct functions in vivo, with A-site being a major contributor to the allosteric activation of the complex and crucial for lamellipodia formation $[129,130]$. The postulated role of Rac in the activation of Dicytostelium SCAR is further corroborated by the colocalization of active Rac and SCAR [112,128]. Moreover, the cellular distribution of a probe specific for Dicytostelium Rac1 GTPases [131] shows that SCAR localizes to the structures occupied by active Rac1: the leading edges of pseudopodia [112], macropinosomes, and phagosomes [132] and the protruding poles of incipient daughter cells during cell division [133]. Of note, more detailed analysis of macropinocytic and phagocytic cups revealed that Rac is located at the cup centre, while SCAR localizes to the rim of nascent cups [132]. Consistent with their role in F-actin polymerization [134], scrA-null cells have a significantly reduced F-actin content [94]. Furthermore, phenotypes of several null mutants generated independently in different genetic backgrounds demonstrate that SCAR plays a role in almost every aspect of cellular motility. Thus, SCAR regulates pseudopod extension and splitting, random cell migration, large-scale endocytosis and endosomal trafficking, cytokinesis, and some aspects of growth and development [94,132,135-137].

The best-studied and most prominent evolutionarily conserved role of WAVE/SCAR proteins is the Rac-induced formation of pseudopodia that enables cell migration [95]. Mammalian WAVEs localize to the leading edge of lamellipodia and peripheral ruffles and at the protruding tips of dorsal ruffles [95,138-140]. There is ample evidence, obtained from different cell lines, that WAVE proteins play an essential role in the generation of these structures [130,139-142]. Specifically, the ablation of WAVE, or other components of WRC such as Pir121 and Sra1, induces severe impairment in lamellipodia formation, motility, and directed cell migration, as also observed in Rac-deficient cells [143]. Similarly, Dictyostelium cells devoid of SCAR extend significantly fewer pseudopodia, membrane ruffles, and macropinocytic crowns and move at a considerably reduced speed $[114,135]$. However, the SCAR-deficient cells are capable of generating pseudopodia that support their migration by a WASP-dependent mechanism (Figure 2B; [112,114]). Only the deletion of both SCAR and WASP resulted in immobile cells entirely devoid of pseudopodia [114]. Interestingly, a recent study on acute myeloid leukaemia HL-60 cells showed that haematopoietic WASP also participates in the formation of pseudopodia and is required for the efficient migration 
of neutrophils [144]. Namely, whereas ubiquitously expressed N-WASP is dispensable for the lamellipodia and filopodia formation in various adherent fibroblast cells [145-147], WASP, expressed only in blood cells, is involved in pseudopodia protrusion and migration (Figure 2B; [144,148-151]). Thus, although being an orthologue of N-WASP, Dictyostelium WASP also shares functions with a mammalian N-WASP paralogue, the haematopoietic WASP, which emerged at the onset of vertebrate evolution [108].

Interestingly, Dictyostelium and mammalian cells share another Rac1 interactor, CYRI (CYFIP-related Rac interactor), which is a negative regulator of SCAR/WAVE activity [152]. CYRI is an evolutionary conserved protein that binds active Rac1 via its DUF1394 domain and competes with SCAR/WAVE for active Rac1 at the leading edge. Thus, CYRI locally buffers Rac1 activity and thereby inhibits the SCAR/WAVE-induced cell protrusions to achieve optimal actin dynamics for efficient cell polarization and steering during cell migration [152]. CYRI is also required to establish Rac1-dependent polarity during epithelial cyst formation $[152,153]$.

\subsubsection{Formins as Rac1 Effectors}

An early study has indicated that Dictyostelium Rac1 GTPases play a pivotal role in the protrusion of filopodia [76]. It was soon shown that this function is mediated through another actin nucleator, the Diaphanous-related formin H [23]. Indeed, the WASP family of NPFs are dispensable for the protrusion of filopodia in Dictyostelium and mammalian cells alike $[114,135,139,145,147,154]$. Formins constitute a distinct class of actin nucleators that, unlike the Arp2/3 complex, promote de novo nucleation of unbranched filaments and their rapid elongation, acting as processive actin polymerases [120]. Formins are characterized by the presence of an FH2 domain that is necessary and sufficient for actin assembly [155]. In most formins, the FH2 domain is preceded by an FH1 domain that accelerates actin polymerization by channelling the ATP-G-actin subunits $[156,157]$. For a detailed overview of formin-mediated actin assembly mechanisms the reader is referred to a recent review [158]. Diaphanous-related formins (DRFs) are a subgroup of formins characterized by additional regulatory elements flanking the FH1 and FH2 domains, Nterminal GBD and FH3 domains where FH3 contains a Diaphanous-inhibitory domain (DID), a dimerization domain (DD), and a C-terminal Diaphanous-autoregulatory domain (DAD) $[159,160]$. These regulatory domains enable a direct regulation of DRFs by Rho GTPases [161]. In its inactive state, DRF is autoinhibited by an intramolecular interaction between DAD and DID, and the binding of a Rho GTPase to GBD, in the presence of an additional cofactor, relieves this inhibition.

The $D$. discoideum formin family is comprised of ten proteins, ForA to J, and eight thereof belong to DRFs [162]. ForH is a canonical DRF with the typical GBD/FH3-FH1FH2-DAD domain organization and exerts typical formin activities [23]. ForH strongly binds to activated Rac1A in vivo, localizes to the tips of growing and mature filopodia, and is specifically required for the extension of filopodial actin filaments [23]. ForH is an orthologue of a mammalian $\mathrm{DRF}, \mathrm{mDia} 2$, hence its alternative name, $\mathrm{dDia} 2$ [23]. The roles of mammalian DRFs, notably mDia1 and mDia2, in generating long linear actin filaments in filopodia are well established [163-167]. mDia2 is required for the formation of filopodia downstream of two Rho GTPases, Cdc42, and Rif (RhoF). In addition to binding to RhoA-C, which are the major regulators of mammalian formins [161,168], mDia2 also binds the active Cdc42 via a CRIB motif in its GBD domain [169,170]. It localizes to the tips of Cdc42-induced filopodia and is required for Cdc42-induced filopodia formation [170]. In addition, $\mathrm{mDia} 2$ participates in a Cdc42-independent mechanism of filopodia formation that involves the small GTPase Rif (Rho in filopodia) and localizes to the tips of Rif-induced filopodia (Figure 2C; [171,172]).

\subsubsection{Coronins as Rac1 Interactors}

Coronins are another class of Rac interactors found in both Dicytostelium amoebae and mammalian cells. Coronins inhibit the Arp2/3-mediated actin filament nucleation directly 
by binding to Arp2/3 complex subunits [173]. They also indirectly promote the filament turnover in lamellipodia by regulating cofilin activity via Slingshot phosphatase and by antagonizing the activity of cortactin, a filament branch stabilizer [173-175]. Mammalian coronins are divided into three types, where types I (coronin $1 \mathrm{~A}, 1 \mathrm{~B}, 1 \mathrm{C}$ and 6 ) and II (coronin 2A and 2B) share the same basic structural organization containing one WDrepeat domain that folds into a $\beta$-propeller structure, while type III coronin 7 contains two $\beta$-propeller units in tandem [175]. The Dictyostelium genome codes for two coronins: conventional type I-like coronin (encoded by cor A), the founding member of the coronin protein family, and coronin 7 (encoded by corB), an orthologue of human coronin 7 [176,177]. In $D$. discoideum cells, coronin is involved in the regulation of phagocytosis, cytokinesis, cell polarization, motility, chemotaxis, and initiation of development [178-181]. It localizes to the phagocytic cups and the crown-shaped dorsal projections of growth-phase cells, i.e., the macropinosomes, and to pseudopodia of both vegetative and aggregation competent cells $[176,179]$. It is also enriched at the polar regions of nascent daughter cells during cell division but is excluded from the cleavage furrow [178]. Coronin 7 is also involved in phagocytosis, chemotaxis, and development and localizes to the leading front of both vegetative and aggregating cells $[177,180]$. It is also recruited to nascent phagocytic cups, with enrichment at its tips, and persists there until completion of the particle ingestion [177].

Coronin family members contain a CRIB motif, though it is only moderately conserved in Dictyostelium coronin 7 [121,182]. Nonetheless, direct interactions with Rac GTPases were demonstrated for both Dictyostelium coronins, but they preferentially bound to the GDP-loaded Rac GTPases; coronin to the Rac1 GTPases, RacB and, somewhat more weakly, RacC; and coronin 7 to RacA, RacC, RacE, and, weakly, to Rac1 GTPases [85,121]. These interactions appear to have a role in sequestering Rac and thus regulate the balance between active and inactive Rac GTPases in the cell. Based on increased levels of activated Rac GTPases and myosin II filaments in corA-null cells, a model was proposed wherein coronin regulates the Rac activity and prevents it from overly activating its downstream effector PAKa that promotes myosin II assembly by inhibiting myosin II heavy chain kinases (MHCKs) [85]. Apparently, coronin can also directly bind PAKa and regulate its activity [85]. A higher binding affinity towards GDP-bound Rac1 and a Rac-sequestering role was also demonstrated for mammalian coronin 1C [183]. Coronin 1C interacts with GDP-bound Rac1 and RCC2, a negative regulator of Rac1 activity, and prevents the mislocalized activation of Rac1. Coronin 1C redistributes inactive Rac1 from the lateral to the front membrane, where RCC2, which also binds Rac1 directly and prevents its activation by GEFs, takes on a sequestering role as long as activation signals are absent. Upon sufficient local activation of GEF, RCC2 becomes outcompeted, and local Rac1 activation leads to the formation of a single dominant protrusion [183]. The depletion of coronin 1A or 1B induces the formation of myosin II-dependent structures similar to Dictyostelium corA-null cells; however, both mammalian coronins are important for Rac1-induced cytoskeletal changes via the Rac1ArhGEF7-Pak2 signalling pathway [184]. Interestingly, and in contrast to Dictyostelium coronin, coronin $1 \mathrm{~A}$ favours Rac1 activation by promoting its translocation to the plasma membrane [185]. Coronin 1A forms a complex with PAK1 and RhoGDI $\alpha$ that facilitates the release of Rac1 from the RhoGDI $\alpha$ inhibitory grip via the Pak1-dependent phosphorylation of RhoGDI. Formation of the coronin 1A-Pak1-RhoGDI $\alpha$ complex is dependent on the coronin 1A interaction with the catalytically inactive ArhGEF7 and F-actin [185].

In contrast to corA-null cells, there was no significant increase in Rac activity in corBnull cells, which could be explained with a higher amount of coronin in the cell and its substantially more efficient binding to Racs compared to coronin 7 [121]. Still, the authors proposed that coronin 7 restricts the local activation of Rac in the regulation of phagocytosis and motility. Namely, WASP was found in a complex with coronin 7 and the expression of GFP-WASP in corB-null cells reverted a significantly increased uptake of yeast particles to wild-type levels. It was inferred, therefore, that coronin 7 regulates actin depolymerisation and WASP activation at the phagocytic cups. The same was suggested for SCAR in the coronin 7-mediated regulation of motility and development [121]. 
Ubiquitously expressed mammalian coronin 7 localizes to the Golgi apparatus and is crucial for the maintenance of the Golgi architecture and anterograde trafficking [186-188]. Similar to its Dictyostelium counterpart, mammalian coronin 7 preferentially binds to the GDP-loaded Cdc42 and considerably less to the GDP-loaded Rac1, and this interaction is necessary to support the Golgi structure, presumably by regulating the activity of the Golgi-associated Cdc42 [186]. Unexpectedly, the level of activated Cdc42 was markedly reduced in knockout cells, suggesting that the Golgi-associated coronin 7 activates the subpopulation of $\mathrm{Cdc} 42$ that regulates the Golgi apparatus structure. On the other hand, coronin 7 was shown to directly interact with the Cdc42 target N-WASP, thus suppressing the N-WASP-promoted formation of excessive actin filaments which could harm the integrity of the Golgi apparatus [186].

\subsubsection{PAK Kinases as Rac1 Effectors}

p21-activated kinases (PAKs) are serine/threonine protein kinases that act as effectors of small GTPases and regulate the actin cytoskeleton via phosphorylation and interaction with numerous proteins involved in cytoskeletal rearrangements, motility, cell cycle, and survival $[189,190]$. PAKs can be found from protozoa to mammals, and all have a $\mathrm{N}$-terminal regulatory GBD (a.k.a. PBD—p21 binding domain) that contains the CRIB motif and a conserved C-terminal kinase catalytic domain $[190,191]$. The six PAK isoforms in humans are divided into two groups [189]. Group I PAKs (1-3) harbour an autoinhibitory domain (AID) at the N-terminal region that, following a GTPase-dependent or independent activation, separates from the kinase domain, allowing the autophosphorylation of PAK [189-191]. Interaction with Rac/Cdc42 leads to the translocation of group II PAKs to different cellular compartments where they phosphorylate the target proteins [190-192].

The Rac/Cdc42-mediated activation of PAK1 induces the formation of lamellipodia and filopodia during directional cell migration by regulating F-actin localization at the leading edge of the cell $[189,191,193,194]$. Furthermore, Rac/Cdc42-activated PAK1 and PAK2 regulate the actin-myosin contractility by phosphorylation and inhibition of the myosin light chain kinase (MLCK) activity $[195,196]$. PAK1 and PAK2 also participate in a positive feedback loop by phosphorylating RhoGDI1, which leads to the activation of Rac1 and Cdc42 [197,198]. PAK3 and 4 are known to preferentially bind Cdc42 rather than Rac [192]. PAK3 activated by Cdc42 phosphorylates paxillin $\alpha$ is involved in the formation of integrin-dependent focal adhesions [199]. PAK4 activation by Cdc42 regulates the formation of filopodia [200].

D. discoideum genome contains nine genes encoding eight PAKs that can be divided into two groups based on the similarity of their catalytic domains: PAKa-d and PAKe-h [35]. $\mathrm{PAKa}, \mathrm{PAKb}, \mathrm{PAKc}$, and PAKd play roles in chemotaxis, cell polarity, and endocytosis, but an interaction with Rho GTPases was shown only for the first three [81,84]. PAKa is expressed during vegetative and early developmental stages, with a maximum during aggregation. PAKa localizes to the rear of migrating cells and pakA-null cells show diminished directionality during chemotaxis, suggesting that PAKa plays a role in the suppression of lateral pseudopodia and retraction of the cell tail [201,202]. An initially indicated involvement of PAKa in cytokinesis [201], however, was later disputed [202,203]. Interaction studies showed that PAKa interacts in vitro with active forms of Rac1A/B/C, RacB, RacA, and human Cdc42 and Rac1, as well as with PKBa, coronin, and 14-3-3 protein $[84,85,202,204]$. Interestingly, coimmunoprecipitation and pull-down assays showed that coronin interacts with PAKa through its CRIB motif (see Section 4.1.3; [85]). cAMP-mediated PAKa activation and translocation to the cell rear is regulated via a direct phosphorylation by PKB/Akt, as opposed to an indirect activation of mammalian PAK1 through Akt [202,205]. PAKa regulates the myosin II assembly by inhibiting MHCKs A and C or by activating MHC phosphatase $[85,201,206]$.

Although no clear functional significance of the PAKa interaction with Rac GTPases has been deciphered yet, its GBD was successfully used to track and quantify the spatiotemporal activity of Rac1 in Dictyostelium cells [131]. Y2H, pull-down, and fluorescence 
resonance energy transfer (FRET) assays showed that PAKa GBD specifically interacts with the active Rac1A, and the fluorescently labelled probe localizes to the leading edge of migrating cells and to endocytic cups [131]. In comparison to previously used fluorescent Rac-GTP probes based on the GBDs of PAKb [81,112] and mammalian PAK1 [122], the PAKa GBD probe produces much less background, and its expression level also remains adequate during aggregation and introduces no overexpression artefacts [131].

$\mathrm{PAKb}$ was first purified as a myosin I heavy chain kinase (MIHCK) responsible for myosin ID (MyoD) activation [207]. Furthermore, Y2H, pull-down, and coimmunoprecipitation assays showed that, besides MyoD, PAKb binds MyoK and the actin-binding protein 1 (Abp1) [207-209]. PAKb increases the motor activity of MyoK and MyoD by phosphorylating their TED sites $[207,208]$. It was suggested that MyoK and PAKb together with Abp1 form a loop to regulate phagocytosis [208]. PAKb localizes to the leading edge of migrating cells and to phagocytic and macropinocytic cups by its proline-rich N-terminal region, which largely coincides with the localization of several myosin I proteins [81]. Interestingly, however, no specific significant defects in any of the myosin I-dependent processes could be detected in cells lacking $\mathrm{PAKb}$, but they have a mild chemotaxis defect, suffer from the loss of polarity, and produce superfluous lateral pseudopodia [81,83]. PAKb binds to actin filaments by its actin filament-binding module at the N-terminal part of the protein, and it was suggested that a PAKb-Abp1 complex has a role in the cross linking of actin filaments [209]. A Y2H assay showed that the PAKb PBD binds the active Rac1A/B/C, F1, B, C, and GTPase domain of RacA [81] Interestingly, human Cdc42 and Rac1, but not RhoA, also interact with $\mathrm{PAKb}$ and stimulate its activity, indicating a conserved regulatory mechanism [210]. Acidic phospholipids can stimulate the PAKb autophosphorylation and kinase activities as effectively as active Rac1, but this activation mechanism becomes inhibited by the binding of $\mathrm{Ca}^{2+}$-calmodulin to PAKb [211].

Similar to $\mathrm{PAKa}$ and $\mathrm{PAKb}, \mathrm{PAKc}$ is required for proper chemotaxis since pakC-null cells exhibit a loss of polarity and produce excessive lateral pseudopodia [83]. Cells lacking both $\mathrm{PAKb}$ and $\mathrm{PAKc}$ have an even stronger chemotaxis defect with a greatly reduced speed, suggesting that PAKb and PAKc may have multiple overlapping functions. The overexpression of PAKc in wild-type cells also leads to a reduced speed and directionality [83]. A rapid, transient activation and translocation of PAKc from the cytosol to the plasma membrane occurs upon chemoattractant stimulation. In addition to the typical PAK domains, PAKc also contains an N-terminal pleckstrin homology $(\mathrm{PH})$ domain interacting primarily with $\mathrm{PI}(3,4) \mathrm{P} 2$ and a $\mathrm{C}$ - terminal extension related to the $\mathrm{G} \beta \gamma$ binding domain of the Saccharomyces cerevisiae Ste20 kinase and mammalian PAK1 [83]. It was shown that the PAKc GBD interacts with the constitutively active RacB, point mutations in the CRIB motif cause the loss of binding to active RacB and abolish PAKc activation, and racB-null cells exhibit no activation of $\mathrm{PAKc}$, jointly suggesting that RacB is required for chemoattractantmediated PAKc activation (see Section 4.2; $[83,84]$ ). It was also shown that the proper PAKc activation and translocation to the plasma membrane in vivo requires all its domains [83].

PAKd is involved in the regulation of actin dynamics in both vegetative and aggregating cells [212,213]. During cell migration, PAKd localizes to a single punctum within the cell and occasionally to the rear cortex in vegetative cells [212], whereas it translocates to pseudopods and uropods in response to cAMP gradients [213]. Consistently, pakD-null cells exhibit defects in chemotaxis to cAMP and are unable to form proper aggregates upon starvation [213]. PAKd is also important for the inhibition of cell proliferation at high cell densities and for growth-to-differentiation signalling [212,214,215]. PAKd has not yet been investigated in the context of regulation by Racs.

\subsubsection{IQGAP-Related Proteins as Rac1 Effectors}

IQGAP (IQ-IQ domain; GAP — domain with sequence similarity to the catalytic domain of RasGAPs, also known as GRD, GAP-related domain) proteins are well-established effectors of both mammalian and Dictyostelium Rho GTPases. Initially, they were considered to function as RasGAP proteins, but early experiments demonstrated that they do not bind Ras GTPases 
or have a RasGAP activity [216-220]. Instead, mammalian IQGAP1 and IQGAP3 interacted with activated Cdc42 and Rac1, with a higher affinity for Cdc42 [217-219,221], while IQGAP2 interacted with these two GTPases without discriminating their GTP- and GDP-bound forms [216,219]. Furthermore, it was demonstrated that not only do IQGAPs lack a GAP activity towards any small GTPase, but they also can stabilize Cdc42 and Rac1 in their active states by inhibiting their intrinsic and RhoGAP-stimulated GTPase activity [216,217,219].

IQGAP proteins are evolutionarily conserved proteins that have three family members in the majority of vertebrates [222]. These are relatively large proteins (human IQGAPs have around 1600 amino acid residues) containing several domains and motifs that enable them to interact with various binding partners and act as scaffolds to integrate and modulate different signalling pathways [223]. All three isoforms share the same domain organization from the $\mathrm{N}$ - to the C-terminus: a single F-actin-binding CHD [224-226], an IQGAP-specific repeat responsible for dimerization [226], a WW motif that binds ERK1/2 [227,228], a calmodulinbinding IQ domain [217,229,230], a GRD that binds Cdc42 and Rac1 [217,231,232], and a RGCT domain unique to IQGAPs that binds $\beta$-catenin, E-cadherin, and CLIP-170 [233,234]. Here, we have included only a subset of prominent IQGAP-interacting proteins; for an exhaustive list the reader is referred to recent reviews [222,235]. Mammalian IQGAPs participate in diverse cellular processes; they cross link actin filaments, regulate actin dynamics and actin-microtubule crosstalk, and are involved in the regulation of higher order processes, such as cell polarization and directional migration, cytokinesis, cadherinmediated cell-cell adhesion, vesicle trafficking, intracellular signalling, cell proliferation, and gene expression [223,235-239].

D. discoideum has four IQGAP-related proteins: DGAP1/DdIQGAP1, GAPA/DdIQGA P2, IqgC/DdIQGAP3, and IqgD/DdIQGAP4. They are half the size of mammalian IQGAPs (817-860 amino acids), aside from IqgD, which is larger (1385 amino acids). Basically, they are homologous to the C-terminal half of mammalian IQGAPs containing the juxtaposed GRD and RGCT domains [240]. Since they lack the N-terminal half of mammalian IQGAPs, Dictyostelium IQGAPs cannot bind F-actin directly. The only exception is IqgD, which harbours a CHD duplex at its longer N-terminus [241], but IqgD still awaits functional characterization. Of the three studied IQGAP-related proteins, DGAP1 and GAPA show features of typical IQGAP family members [242,243], while IqgC is not a typical IQGAP. IqgC has conserved residues in its GRD domain critical for the GAP activity that are mutated in other IQGAPs, and it was demonstrated to be a genuine RasGAP that binds to and inactivates RasG [244,245]. DGAP1 and GAPA interact with Rac GTPases and do not have a GAP activity, but, as opposed to their mammalian counterparts, they cannot stabilize the GTP-forms of bound GTPases [76,243,246,247].

All three Dictyostelium Rac1 GTPases interact strongly with DGAP1 [76], and it was shown that DGAP1 recruited by activated Rac1A promotes the formation of a tetrameric complex with the cortexillin I (CI)/cortexillin II (CII) heterodimer [246]. Cortexillins are actin-binding proteins that organize actin filaments preferentially into antiparallel bundles, associate them into meshwork, and stabilize cell shape by supporting the intrinsic stiffness of the cell cortex $[248,249]$. Subsequently it was demonstrated that all three Rac1 GTPases can participate in a complex formation with either DGAP1 or GAPA, and yet another cortexillin III was identified in a complex with DGAP1 but not GAPA [250]. Therefore, both DGAP1 and GAPA activated by Rac1 can promote complex formation, but in the absence of both proteins, the complex cannot be assembled [246]. DGAP1, GAPA, CI, and $\mathrm{CII}$ localize to the lateral and rear parts of the cortex in interphase cells and to the cleavage furrow in dividing cells [122,246-248]. Moreover, activated Rac1 can be seen in the cortex of the incipient cleavage furrow during cytokinesis, although it is significantly enriched at the polar regions of the nascent daughter cells [131]. The localization of active Rac1 during cytokinesis is highly reminiscent of the localization of another Rac1-binding partner, filamin, which, interestingly, binds both Rac1 and GAPA (see Section 4.1.6; [247]).

Phenotypes of single and double knockout mutants of the two IQGAPs and the two cortexillins have demonstrated the crucial role of their quaternary complexes for efficient 
cytokinesis $[242,246,248]$. They also play a role in the establishment of cell polarity and motility during chemotaxis by supressing lateral pseudopodia [250], and in the intercellular cAMP signal relay, which is important for cell streaming and development [251]. In late development, the DGAP1-CI-CII complex is involved in securing the apical localization of myosin II in the tip epithelial cells surrounding the stalk tube, thus promoting apical actomyosin ring constriction to ensure normal culmination of the fruiting body [252].

Drawing a parallel between the actin-targeted functions of mammalian IQGAPs and Dictyostelium IQGAP-related proteins is not straightforward. Besides binding directly to and crosslinking actin filaments, mammalian IQGAP1 also promotes actin filament assembly via its interactions with N-WASP, the Arp2/3 complex, and formin mDia1 [253-255]. Dictyostelium DGAP1 and GAPA do not directly bind F-actin, and no interactions with NPFs or actin polymerases have been reported. In line with these data, IQGAP1 localizes to the leading edge of polarized cells and to membrane ruffles $[217,218]$, whereas DGAP1 and GAPA are mostly confined to the rear and lateral structures in polarized cells [122,247]. However, Rac1-bound DGAP1 and GAPA interact with F-actin-binding cortexillins and thus indirectly promote F-actin bundling similar to mammalian IQGAPs. It is, therefore, still possible to compare the final functional outputs of the signalling pathways mediated by mammalian IQGAPs and Dictyostelium IQGAP-cortexillin complexes.

Both Dictyostelium and mammalian IQGAPs are required for cytokinesis completion $[236,242,246]$. The knockdown of IQGAP1 or IQGAP3 moderately increased the number of multinucleated HeLa cells, while the simultaneous knockdown of both proteins induced a more severe multinucleated phenotype, similar to the cumulative effect of the dgap1/gapA double knockout $[236,246]$. IQGAP3 accumulates in the contractile ring region where it interacts with the scaffold protein anillin, while IQGAP1 retains its cortical localization throughout cytokinesis. IQGAP1 and IQGAP3 thus appear to have nonredundant roles in cytokinesis, similar to the nonredundant roles ascribed to DGAP1 and GAPA [246]. Interestingly, the downregulation of RhoA, but not Cdc42, inhibited the proper localization of IQGAP3. Reciprocally, RhoA accumulation in the cleavage furrow was significantly reduced and/or disturbed in the absence of IQGAP1 and IQGAP3. However, neither of the IQGAPs was shown to interact with RhoA directly $[217,218,221,231,236]$.

Maintenance of cell polarity during the directed cell migration involves an asymmetric distribution of signalling molecules and cytoskeletal components. dgap1-null cells show a mild, and gapA-null cells a moderate, decrease in the ability to supress lateral pseudopodia, whereas the dgap1/gap $A$ double knockout cells exhibit markedly decreased migration speed, directionality, and cell polarity [250]. This effect was attributed to disturbed cortical mechanics and highly elevated and extended PI3K/PKB signalling in the cortex of mutant cells. Thus, the Dictyostelium DGAP1-cortexillin complex is involved in the establishment of cell polarity by restricting the leading-edge functions to the cell front. Similarly, mammalian IQGAP1 is involved in the regulation of cell polarity via the microtubule plus-end binding protein CLIP-170. Activated Rac1 or Cdc42 form a tripartite complex with IQGAP1 and CLIP-170, and IQGAP1 serves as a linker between the actin cytoskeleton and the microtubules, helping to capture microtubules at the leading edge and the base of filopodia, thus facilitating the establishment of a polarized cell morphology [233].

Besides its involvement in the regulation of cell polarity during migration, the DGAP1cortexillin complex is also required for the apico-basolateral polarity of the tip tubular epithelia during multicellular development [252]. $\alpha$-catenin together with DGAP1 and cortexillins act to exclude myosin II from the basolateral membranes and ensure its apical localization, where an actomyosin ring responsible for apical constriction is assembled. Such epithelial tubes, with apical membranes facing the lumen, are found in many tissues in our body and use apical actomyosin constriction to oppose luminal pressure [256]. Although direct evidence for an IQGAP-mediated myosin II exclusion from the basolateral membranes in animal cells is missing, IQGAP1 is still important for basolateral polarity during epithelial tube morphogenesis. In mitotic cells, IQGAP1 localizes to basolateral membranes, and this EGFR-mediated polarized distribution of IQGAP1 is required for an- 
choring of the astral microtubules to junctional plasma membranes and a correct orientation of the mitotic spindle during epithelial tube formation [257].

\subsubsection{Filamins as Rac1 Effectors}

As already mentioned, Rac1 interacts with the F-actin binding protein filamin [247]. Filamins are cross linking proteins that orthogonally connect actin filaments to stabilize their three-dimensional network, which provides elastic and strain-stiffening properties to the cell $[258,259]$. Two actin-binding domains (ABDs) required to connect neighbouring filaments are provided by the dimerization of two self-associating filamin subunits. Filamins also act as scaffolds that, e.g., link the actin cytoskeleton to membrane receptors and facilitate the colocalization of various signalling proteins $[258,260]$.

Being substantially shorter than mammalian filamins, Dictyostelium filamin, ddFLN (or actin binding protein $\mathrm{C}(\mathrm{ABP} 120)$, or gelation factor) is considered to represent an ancestral form of human filamins [241,259]. It is involved in the pseudopod formation and motility in response to cAMP stimulation and in phagocytosis and cytokinesis [247,261-263]. It is also essential for the normal phototaxis and thermotaxis of slugs during multicellular development [264]. Dictyostelium filamin interacts and, for the most part, colocalizes with GAPA at the cortex of interphase cells and partially rescues the phenotype of gapA-null cells [247]. Although it is found in the complex with GAPA and Rac1A, filamin can also interact with Rac1A in the absence of GAPA, and it was suggested that it acts as a scaffold for Rac1-GAPA signalling to the actin cytoskeleton [247].

Similar scaffolding roles in Rac1 signalling have been described for mammalian filamins A and B [265-268]. For example, filamin A is involved in the integrin-mediated Rac1 deactivation to constrain its activity during cell migration [266]. Filamin A and IQGAP1 are recruited to the activated $\beta 1$ integrin in early adhesion structures in lamellipodia, and subsequently, the filamin A-IQGAP1 complex recruits RacGAP1 to suppress Rac1 activity [266]. Filamin B is implicated in the regulation of endothelial cell migration and angiogenesis [265]. In a basal state, Rac1 and its GEF Vav2 are in a complex with filamin B, and following VEGF stimulation, VEGFR2 and proangiogenic integrin $\alpha v \beta 5$ are recruited to the complex. This complex built around filamin B appears to modulate both Rac1 activity and its intracellular localization [265].

\subsection{RacF1, RacF2, and RacB}

RacF1 and RacF2 proteins are expressed throughout the asexual Dictyostelium life cycle and also during sexual development induced under dark and submerged conditions $[75,269]$. In particular, the gene for RacF2 shows extremely high expression levels in gametes during sexual reproduction. RacF2 affects sexual cell fusion and, presumably, also asexual development by regulating EDTA-sensitive cell-cell adhesion. RacF1 is enriched at the plasma membrane, pseudopodia, early macropinosomes and phagosomes, and the sites of cell-cell contacts [269]. However, racF1-null, racF2-null, and double knockout cells do not show any serious defects in the vegetative phase or asexual development, suggesting that they are dispensable, or their activity is compensated for by other Racs $[75,78,269]$. Since RacF1 and RacF2 are 94\% identical, they are likely to have redundant roles in sexual cell fusion.

Similar to RacF1 and RacF2, RacB from $D$. discoideum is closely related to the Rac1 group (Figure 1) but is mostly expressed during the vegetative phase and in early development [72]. RacB has been shown to play a role in endocytosis, chemotaxis, and morphogenesis $[84,270]$. Cells with overexpressed wild-type RacB have a flattened and round morphology, significantly reduced fluid phase uptake, slightly reduced phagocytosis, and exocytosis and, over time, show signs of lysis, suggesting that high levels of RacB could be toxic $[270,271]$. The kinetics of the cAMP-stimulated RacB activation closely correspond to the kinetics of actin polymerization, and racB-null cells exhibit significantly reduced chemoattractant-induced polymerization peaks of F-actin, suggesting that RacB is involved in this process [84]. racB-null cells also show significantly dimin- 
ished chemoattractant-induced myosin II assembly; show no activation of PAKc; show a chemotaxis defect with reduced speed, polarity, and directionality; and have a significant developmental delay [84].

Interaction studies using $\mathrm{Y} 2 \mathrm{H}$ and pull-down assays identified GAPA, PAKa, $\mathrm{PAKb}$, PAKc, WASP, and WASP-B as binding partners of RacB-GTP [80-84,247]. It was shown by these assays that activated RacB strongly interacts with the CRIB motifs of PAKa and PAKc, which might explain the diminished myosin II assembly in racB-null cells, since PAKa is known to be required for the assembly of myosin II filaments [84]. Additionally, point mutations in the PAKc CRIB abrogate its binding to RacB-GTP, which leads to chemotaxis defects similar to the reduced polarization and directionality of pakC-null cells [83]. It has been suggested that $\mathrm{RacB}$ and $\mathrm{RacC}$ are involved in the regulation of actin polymerization by competing for interaction with the WASP CRIB [82]. It has also been suggested that coronin is involved in the sequestration of RacB, similar to the coronin-mediated Rac1 sequestration (see Section 4.1.3; [85]).

\subsection{RacA}

RacA is expressed throughout the vegetative phase and development and reaches the maximum level of expression after $12 \mathrm{~h}$ of starvation [72,272]. In addition to the G1-G5 and the two switch regions, RacA has a proline-rich region, two BTB (broad-complex, tamtrack, bric à brac) domains, and a specific $\mathrm{C}$-terminal region, which are all characteristic for the mammalian RhoBTB subfamily GTPases (Figure S1). Similar to mammalian RhoBTB1 and RhoBTB2, RacA also lacks the CAAX prenylation motif and is twice as large as other Rho GTPases from $D$. discoideum. It has therefore been suggested early on that RacA should be considered as a member of the RhoBTB subfamily [272]. Among the human RhoBTB GTPases, RhoBTB1 and RhoBTB2 are closely related to each other, whereas RhoBTB3 lacks most parts of the GTPase domain and has the conserved CAAX motif, but the structure of its BTB1 domain is more similar to RacA [273]. All three human RhoBTB proteins are considered to be tumour suppressors [274]. BTB domains are involved in protein-protein interactions and have a role in the formation of cullin3-dependent ubiquitin ligase complexes, thus possibly targeting proteins for degradation $[275,276]$. According to the data reported as preliminary, racA-null cells have a severe growth defect, which is apparently not a consequence of impaired cytokinesis or endocytosis [59]. Interaction studies using a $\mathrm{Y} 2 \mathrm{H}$ assay identified PAKa, PAKb, PAKc, WASP, and WASP-B as binding partners of RacA-GTP, which are also effectors of Rac1 and RacB, and some of them also for RacC and RacF1 [80-82,84]. An interaction study by a pull-down assay also identified GAPA as a possible binding partner of RacA [247].

\section{4. $\mathrm{RacC}$}

Our phylogenetic analysis shows that the amoebozoan RacC group, identified in all analysed amoebozoan classes, represents a sister clade to the metazoan group consisting of Cdc42 and a number of related GTPases including human RhoJ, Q, U, and V (Figure 1 and Figure S3; [277-279]). Functional data regarding the RacC from $D$. discoideum show that its roles in the regulation of the actin cytoskeleton are interwoven with the roles of Rac1 and other Rac subfamily GTPases in an intricate way, somewhat resembling a partial overlap between the roles of Cdc42 and Rac GTPases in mammals (Figure 2; [79]). Cdc42 is traditionally best known for its involvement in filopodia formation [280], acting predominantly through DRFs [161,170], but also by activating the Arp2/3 complex through N-WASP [91]. Over time, it was realized that Cdc42 is involved in many different aspects of cell polarity by regulating the formation of cytoskeletal structures $[281,282]$ and thus also influences the cellular migration and invasion processes underlying tumour formation [283]. Active Cdc42 thus regulates cell polarity in migrating cells via MRCKs (myotonic dystrophyrelated Cdc42-binding kinases), which regulate the actin-myosin contraction involved in the reorientation of the cell nuclei relative to the microtubule-organizing centres [284], and by activating the PKC $\zeta$-mPar6 complex [285]. The recruitment of mPar6 and PKC $\zeta$ 
(protein kinase $\mathrm{C}$ zeta) by Cdc42 leads to the GSK-3 $\beta$ phosphorylation at the leading edge, inducing association of the Apc protein with microtubules, which is essential for cell polarization [286].

D. discoideum RacC shows a steady expression during growth and development [72-74]. RacC was shown to associate with the plasma membrane in vegetative cells $[287,288]$, and to accumulate in the areas of F-actin assembly at the leading edge of chemotactically competent cells [80,82]. It was also found on cytoplasmic vesicles in both vegetative [122] and aggregation competent cells [82]. Similarly, Cdc42 was shown to partially localize to the plasma membrane, but a significant fraction was associated with Golgi vesicles [289]. racC-null cells exhibit motility defects during chemotaxis due to a lack of polarized F-actin organisation and a well-defined leading edge [82]. In addition, they also have a cytokinesis defect $[78,82]$ but show no significant alterations of the Golgi morphology in comparison to wild-type cells [69]. The overexpression of wild-type RacC induces the formation of irregular actin structures on the cell dorsal surface, named petalopodia [288]. It also strongly upregulates phagocytosis, while inhibiting macropinocytosis and exocytosis [288]. While the deletion of RacC leads to defects in both speed and directionality during chemotaxis of Dictyostelium cells, the effects of Cdc42 deletion are cell-type specific. For example, cdc42null mouse embryonic fibroblasts (MEFs) are impaired both in motility and directionality during chemotaxis [290], while some cancer cells still migrate with normal speed, only randomly [291].

Cdc42 is able to activate more than 45 effector/adaptor proteins encoded in the human genome, including PAKs, IQGAPs, N-WASP, PI3Ks, and others [282,283,292]. Interaction studies identified WASP [82,115], WASP-B [80], coronin [85], PAKc [84], and PAKb [81] as binding partners of RacC, but only interactions with WASP and WASP-B have been further investigated. As already mentioned, RacC activates WASP and promotes F-actin assembly in a PI3K-dependent manner (see Section 4.1.1; [82]). On the other hand, RacC is required for PI3K activation and translocation to the plasma membrane since both basal and chemoattractant-stimulated levels of PI3K at the plasma membrane are decreased in racC-null cells [82]. Besides WASP, Dictyostelium expresses two additional proteins from the WASP group, WASP-B and WASP-C [108]. Although their domain topology is unconventional, they both contain WCA and GBD domains and, like WASP, localize to clathrin puncta, suggesting an involvement in CME [108]. Furthermore, wasB-null cells are defective in chemotaxis due to a lack of polarized F-actin distribution, leading to the formation of pseudopodia at the rear and lateral parts of the cells [80]. This phenotype is highly reminiscent of a diminished cell polarity observed in wasA-null cells [114]. Interestingly, $\mathrm{RacC}$ activation is increased but RacC is mislocalized in the absence of WASP-B. Of note, WASP-B GBD also interacted with constitutively active Rac1B, RacA, and RacB, but the functional significance of these interactions was not further examined [80]. WASP-C is implicated in the regulation of actin cytoskeleton, the cell-substratum adhesion, and phagocytosis, but its regulation has not been investigated so far [293].

Adenylyl cyclase A (ACA) is a RacC interactor that is responsible for cAMP synthesis and localizes to the uropod during stream formation $[69,294,295]$. Since racC-null cells are defective in stream formation and ACA in these cells is found at the intracellular vesicles instead of on the plasma membrane, it was inferred that RacC is important for ACA vesicle trafficking [69]. Similar to this potential role of RacC in vesicle trafficking, Cdc42 is involved in vesicle formation and trafficking, which was shown to be mediated by the regulation of actin dynamics through N-WASP and Arp2/3 [296,297]. RacC was also shown to be essential for the autocrine proliferation repressor AprA-induced chemorepulsion [298,299]. Vegetative cells continuously secrete AprA, and its secretion from the cells at the colony edge signals to adjacent cells to move away [299]. Specifically, AprA inhibits the formation of new pseudopodia at the side of the cells closest to the colony. The racC-null cells were unable to respond to this chemorepellent [299]. 


\section{5. $\mathrm{RacH}, \mathrm{RacD}$ and RacP}

In the phylogenetic tree, $\mathrm{RacH}, \mathrm{D}$, and $\mathrm{P}$ from Dictyostelia occupy a position between the $\mathrm{Cdc} 42 / \mathrm{RacC}$ group and the Rho/RacE group but are more closely related to the latter (Figure 1). Lacking any obvious homologues in Metazoa, these proteins are also abundantly represented in Archamoebae, and can thus be regarded as a truly amoebozoan innovation.

Dictyostelium $\mathrm{RacH}$ is expressed throughout the life cycle, with the highest level in the aggregation stage [272,300]. It localizes to the nuclear envelope, endoplasmatic reticulum, and Golgi membranes [301]. racH-null cells grow moderately slower in suspension and show impaired macropinocytosis and a slight decrease in the acidification of early endosomes [301]. Their exocytosis efficiency is also reduced, probably due to an aberrant distribution of vacuolin [301]. Therefore, it has been proposed that $\mathrm{RacH}$ acts as a regulator of vesicle sorting. Furthermore, $\mathrm{RacH}$ also plays an important role in host-pathogen interactions, as it was shown that $\mathrm{racH}$-null cells are more susceptible to infection by Mycobacterium marinum or Legionella pneumophila: the bacteria proliferate more easily in $\mathrm{racH}$-null cells, which was attributed to a defect in endosome acidification [302,303]. On the other hand, the depletion of $\mathrm{RacH}$ has a deteriorating impact on bacterial transmission between Dictyostelium cells, since the release of bacteria from $\mathrm{racH}$-null cells is almost completely abrogated [303]. The ejectosome, an F-actin based structure crucial for nonlytic bacterial release, was shown to be absent in racH-null cells [304]. Consistently, it was shown that $\mathrm{RacH}$ can induce actin polymerization in a cell-free system [301].

The roles of $\mathrm{RacH}$ in the actin-based trafficking of vesicles and pathogen motility are reminiscent of the involvement of Cdc42 in the actin-based motility of pathogens in mammalian host cells [305]. Cdc42 has been shown to stimulate formation of the actin comet tail, which is important for intercellular and intracellular motility of various viral and bacterial pathogens [306]. For example, during Vaccinia virus infection, the pathogen activates host Cdc42 via RhoGEF intersectin-1, leading to the stabilization of the N-WASP activity and stimulation of the actin comet tail formation, which enhances the cell-to-cell infection spreading [305]. This Cdc42 activity parallels the role of RacH in the formation of the ejectosome. The main difference is that RacH is essential for the ejectosome formation [304], while actin comet tails can still be formed in the absence of an interaction between Cdc42 and N-WASP, albeit with a lower efficiency: the number of actin tails per cell is reduced [305].

RacD is $54 \%$ homologous to human Rac1, lacks the CAAX prenylation motif, and harbours serine-rich insertions close to the $\mathrm{C}$-terminal membrane-association domain. The expression of RacD is present in vegetative cells, rises slightly during early development, and then decreases again [72,272]. Available data show a steady increase of the RacP expression over the first $8 \mathrm{~h}$ of development [73,74].

\subsection{RacE}

The most extensively studied Dictyostelium Rho GTPase outside of the Rac subfamily is RacE. The racE gene was originally isolated in a genetic screen developed to identify genes required for cytokinesis [68]. Activated RacE proved to be essential for cytokinesis in unattached cells [68,287], and it was shown by a pipette aspiration assay that racE-null cells have a strongly diminished cortical tension [307]. A molecular mechanism responsible for the RacE involvement in the regulation of cortical integrity was first indicated by the finding that the cortical distribution of actin-binding proteins dynacortin and coronin was altered in racE-null cells [308]. More substantial evidence associated RacE with the regulation of 14-3-3 protein, which links the microtubule network to the actin cortex and modulates cortical contractility in cytokinesis via an interaction with the myosin II heavy chain $[309,310]$. The cortical localization and solubility of 14-3-3 were shown to depend on RacE, whereas the overexpression of 14-3-3 in racE-null cells partially rescued their growth, cortical tension, and cytokinesis defects. Although a direct binding between 143-3 and RacE was not demonstrated, these data indicated that the RacE/14-3-3 pathway regulates the remodelling and distribution of myosin II bipolar thick filaments and might 
be partly responsible for the cytokinesis defect of racE-null cells [310]. Interestingly, an interaction between RacE and the IQGAP-related protein DGAP1 was also reported, which was independent of the guanine nucleotide bound to RacE [243]. This finding suggests that RacE is instrumental in the regulation of a mechanosensory system that governs myosin II accumulation in the posterior cortex of polarized cells and in the cleavage furrow [311].

As already elaborated in Section 4.1.2, the intramolecular autoinhibition of DRFs is commonly released by the binding of activated Rho-family GTPases [161]. In Dictyostelium, it was shown that the mDia1-related DRF ForA contributes to the integrity of the cortical actin layer and localizes to the posterior cortex of polarized interphase cells and to the cleavage furrow of dividing cells [312]. RacE-GTP was identified as the GTPase that binds to and activates ForA, and it was subsequently shown that it also regulates the related cortical DRFs ForE and ForH [313]. Consistently, RacE-GTP localizes to the cell rear and to the cleavage furrow of mitotic cells and is essential for the cortical localization of ForA and ForE. The elimination of all three formins, or of RacE, induced comparable extensive defects in rigidity and architecture of the actin cortex, as demonstrated by aspiration assays and electron microscopy. This resulted in drastic defects in cytokinesis, development, cortical actin flow, and cell polarization, especially under the condition of two-dimensional confinement [313].

Serious defects in the migration and chemotaxis of $r a c E$-null cells were also identified in an independent line of investigation, focusing initially on the GEF and GAP proteins that regulate RacE $[78,314]$. It was shown, using a palette of genetic mutations and chemical inhibitors, that RacE and its regulators influence the accuracy of cell orientation in chemotactic gradients and, importantly, that RacE exerts its regulatory role upstream of Ras activation and PIP3 production. How exactly this comes about was revealed when this group uncovered an unexpected mechanism by which the GDP-bound RacE modulates the mTORC2/AKT signalling in GPCR-mediated directed cell migration [315]. The stimulation of cells by a chemoattractant induces the phosphorylation of RacE-GDP at S192 by the GSK3 serine protein kinase. Thereupon, the phosphorylated RacE-GDP assembles with RasC-GTP and mTORC2 into a signalling supercomplex that phosphorylates and thereby activates an important serine/threonine kinase PKB, which in turn phosphorylates multiple substrates that control the dynamics of the actin cytoskeleton and the cell-substratum adhesion [316,317]. In a follow-up study, it was shown that chemoattractant stimulation enables GDP-RacE to oligomerize and to recruit GTP-RasC to assemble RacE-RasC heterooligomers that activate mTORC2 [318]. Interestingly, unphosphorylated GTP-RacE inhibits the role of phospho-GDP-RacE in mTORC2 activation by competing with the interaction between phospho-GDP-RacE and GTP-RasC.

RacE shows considerable sequence similarities with Rho proteins from Metazoa, and it was suggested that it represents an orthologue of mammalian RhoA in Dictyostelium (Figure 1 and Figure S2; [35,315]). In particular, the amino acid sequence of the Switch I region, important for the interaction with effectors, which is specific to each type of Rho GTPases, is identical between human RhoA and Dictyostelium RacE [50]. Most transduction pathways that convey signals from RacE to the actin cytoskeleton in Dictyostelium appear to have their counterparts commencing from RhoA in mammals (Figure 3). RhoA binds to and activates the DRFs mDia1, 2, and 3 in vitro [319,320], and their loss compromised the ultrastructure of the cortical actin cytoskeleton and led to substantial defects in cell polarization and migration [313,321]. Given the alleged interaction between RacE and the IQGAP-related protein DGAP1 in Dictyostelium, it is interesting to note that mammalian IQGAP1 is required to target mDia1 to the plasma membrane [254] and enhances the RhoA-mediated activation of mDia1 [322]. 

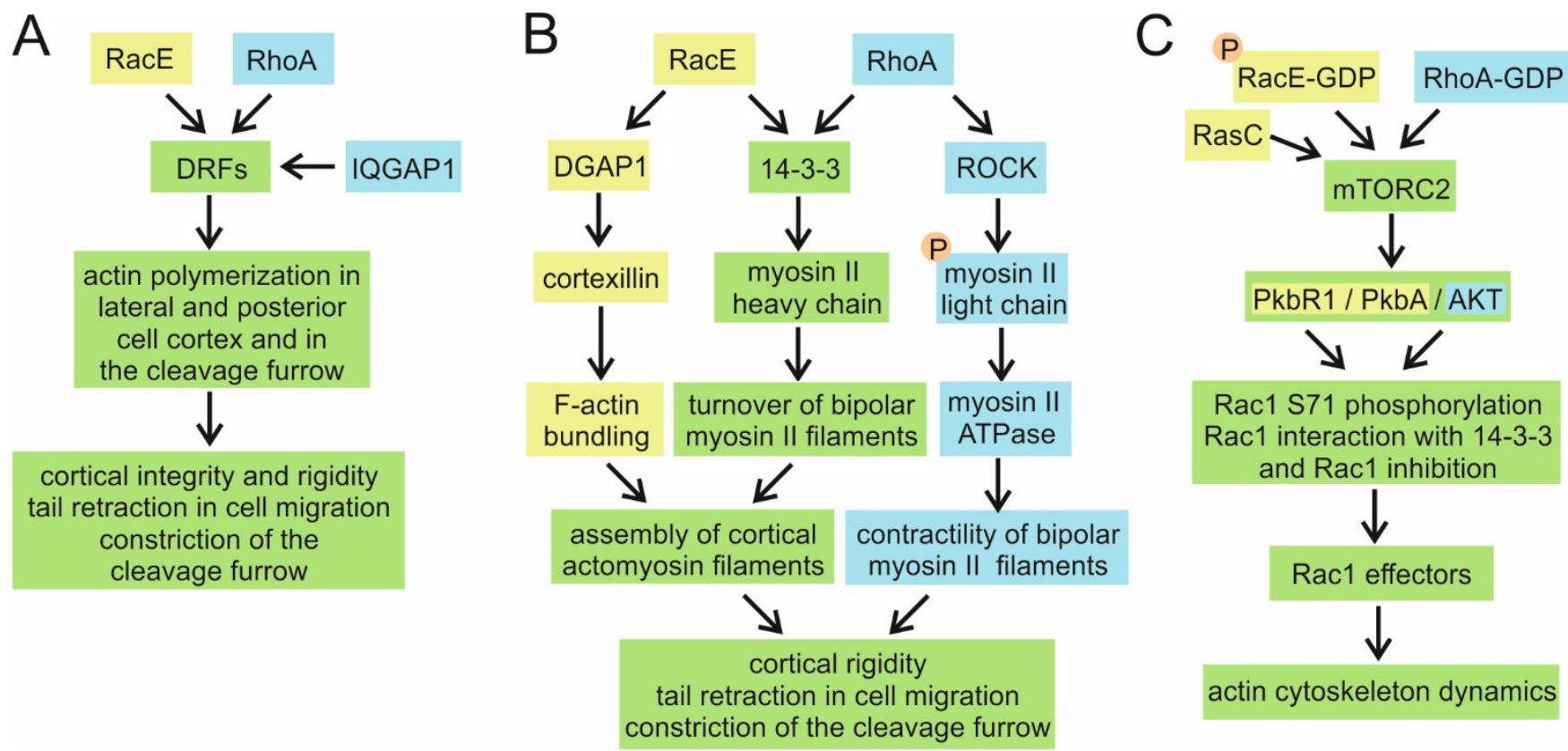

Figure 3. Parallel presentation of major signalling pathways starting from RacE in Dictyostelium (yellow) and RhoA in mammals (blue) and converging onto the actin cytoskeleton regulation. (A) Activation of the DRF-mediated actin polymerization. (B) Assembly of the actomyosin filaments and activation of their contractility. (C) Activation of the mTORC2-AKT signalling pathway. The common elements shared by Dictyostelium and mammals are shown in green. The default active state of small GTPases is GTP-loaded, except when shown otherwise. Red encircled "P" indicates phosphorylated proteins.

Mammalian 14-3-3 family proteins function by binding preferentially to Ser/Thr phosphorylated intracellular proteins, which alters the conformation, activity, and subcellular localization of their binding partners. Until recently, all the data regarding the interaction between Rho GTPases and 14-3-3 proteins were indirect, and it was suggested that 14-3-3 proteins either regulate Rho GTPases through the interaction with RhoGEFs and RhoGAPs or that Rho GTPases control 14-3-3 proteins through PAK1 [323]. However, a direct interaction was recently demonstrated between 14-3-3 and Rac1 that is facilitated by the AKT-mediated phosphorylation of Rac1 at S71 [324]. A similar interaction between 14-3-3 proteins and RhoA has not been shown yet, but it is interesting to note that both RhoA and RacE share the RPLpSYP motif with Rac1, which is very close to the type I consensus motif for the binding of 14-3-3 proteins [325], suggesting that S73 phosphorylation could regulate the interaction of RhoA with 14-3-3 proteins. In Dictyostelium and humans alike, 14-3-3 proteins bind directly to the tail of nonmuscle myosin II and inhibit its assembly into bipolar filaments, which increases the soluble fraction of myosin in the cell and promotes myosin turnover [309]. 14-3-3 proteins in mammalian and Dictyostelium cells could therefore serve as scaffolds that interact with RhoA and myosin II, thereby promoting the turnover of bipolar myosin II filaments and their reassembly at appropriate intracellular locations.

Interestingly, an archetypal signalling axis leading from the RhoA-mediated activation of Rho-dependent kinases to the contraction of F-actin-supported bipolar myosin II filaments appears not to be preserved in Dictyostelium, although it is apparently preserved in E. histolytica [326]. In mammals, the serine/threonine kinase ROCK regulates the phosphorylation of the myosin light chain (MLC) by the direct phosphorylation of MLC and by the inactivation of myosin phosphatase through the phosphorylation of its myosin-binding subunit [327]. Rho kinase and myosin phosphatase thus jointly regulate the MLC phosphorylation, which stimulates cross linking of actin by myosin and enhances actomyosin contractility and stress fibre formation in nonmuscle cells [328]. In Dictyostelium, myosin motor activity is regulated by the phosphorylation of the regulatory light chain through MLCK A [329]. Unlike conventional light chain kinases, this enzyme is not regulated by 
calcium but is activated by cGMP-induced phosphorylation via an upstream kinase and subsequent autophosphorylation. No Rho-dependent kinases involved in the regulation of the actomyosin contraction were identified in Dictyostelium. On the other hand, the unusual involvement of RacE-GDP in the regulation of the mTORC2-AKT pathway does appear to have its equivalent in mammalian cells, although additional work is needed to elucidate this pathway involving RhoA-GDP in more detail [315].

In summary, although RacE and RhoA probably diverged independently from the core Rac group in LECA, they participate in remarkably conserved signalling pathways in Amoebozoa and animals (Figure 3). One of these pathways activates actin polymerases from the DRF group (Figure $3 \mathrm{~A}$ ), whereas the other regulates the contractile machinery propelled by myosin II (Figure 3B). Both pathways are essential for the regulation of cell polarization, since the constitutive proteins localize in the lateral and the posterior nonprotrusive cell cortex and determine its ultrastructure, rigidity, and contractility. It appears, therefore, that in the two systems, RhoA and its functional counterpart RacE are involved in setting up an appropriate organization of the actin-myosin contractile filamentous structures, e.g., the retractile tail of migrating cells, the contractile cytokinetic ring, and the stress fibres anchored in focal adhesions. Consequently, the inhibition of RhoA leads to severe defects in the cortical rigidity, cell migration, and cell division in mammalian cells [330-332], resembling the aforementioned consequences of the racE knockout in Dictyostelium. Importantly, RacE/RhoA participate in the posterior/central pathways in their GTP-bound form and regulate effectors closely associated with the actin cytoskeleton (RacE-DRFs—actin, RacE-14-3-3 - myosin II/actin). On the other hand, they also participate in an anterior pathway close to the protruding cell front in their GDP-bound form and transduce the signal by oligomerizing with Ras much more upstream from actin (RacE/RasC - mTORC2-AKT-intermediates-actin cytoskeleton) (Figure 3C). Therefore, the two modes of RacE/RhoA action are separated spatially, temporally, and biochemically from each other. This dual role of RacE/RhoA is therefore somewhat reminiscent of the dual role played by Rac1 GTPases in the front and the back of polarized Dictyostelium cells [122,333].

\subsection{Other Rho GTPases ( $G, L, I, J, M, N, O$, and $Q$ )}

There is very little information available about the remaining eight Rho GTPases from D. discoideum, a group somewhat related to mammalian Miro and BTB GTPases (RacI, J, M, $\mathrm{N}, \mathrm{O}$, and $\mathrm{Q}$ ), and an unrelated group of mutually similar RacG and RacL (Figure 1).

RacG is constitutively expressed in growing and developing cells, with a decrease in expression after the slug stage [272,300]. Its expression is also induced during sexual maturation followed by a reduction immediately after the gamete fusion, suggesting that it may have a specific role in interactions between sexually competent cells [75]. RacG is localized uniformly in the cell cortex, and it is also found in long, highly motile filopodia induced by its overexpression [334]. It is also enriched at the rim of the nascent phagocytic cups, and its overexpression enhances phagocytosis efficiency [334]. However, racG-null cells did not show any defects in growth, large-scale endocytosis, cytokinesis, or development. The only observed defect was an impaired migration of mutant cells in the cAMP gradient, suggesting that RacG likely shares its roles in the regulation of cell morphology, phagocytosis, and chemotaxis with other Rac proteins [334].

RacI, Racj, and RacL are expressed throughout the life cycle, and while the expression of RacI culminates in early development, RacJ and RacL reach their maximum expression in the late stages of development [72-74,272]. It has therefore been suggested that RacJ and RacL, together with RacG, may have a role in the regulation of the multicellular development of D. discoideum [75]. Remarkably, RacJ has a divergent switch I region [272]. The expression levels of RacM and RacQ are highest at the first hour of development, whereas RacN and $\mathrm{RacO}$ have the highest expression at the fifth hour of development [73,74]. 


\section{Concluding Remarks}

The actin cytoskeleton is an ancient constituent of living cells and epitomizes the fundamental principle of the noncovalent "polymerization" of globular protein units into "cytomotive" filamentous structures, already present in prokaryotes [335-338]. The recent discovery of a protoactin along with a subset of proteins involved in actin polymerization and depolymerization in Asgard archaea established that a dynamic actin cytoskeleton predates the advent of eukaryotes [339-343]. This and other related findings [144,344] strongly support the view that the basic constitutive and regulatory elements of the actin cytoskeleton, the principles of its organization and polarity, as well as the actin-dependent phenotypes, were already established in the common ancestor of all eukaryotes $[343,345]$. Starting from there, eukaryotic clades have infused a vast variety of ecological niches and adopted a wide repertoire of lifestyles, adjusting the composition and functionality of their actin cytoskeleton accordingly [346]. Among them, remarkably similar traits reliant on the actin cytoskeleton have evolved in some representatives of Amoebozoa and in several classes of animals, in particular mammalian cells, and primarily motile cells of the immune system $[347,348]$. It appears, therefore, that the functional modules that shape the actin cytoskeleton, encompassing actin-binding proteins and upstream signalling proteins, coevolved in a similar manner in Amoebozoa and Metazoa and, although differing in details, share fundamental structural and operational principles.

A large number of small GTPases, including putative representatives of the Rho family, were identified in Lokiarchea [349,350]. These RhoLs, however, lack some typical signatures of eukaryotic Rhos, e.g., the CAAX motif essential for prenylation and binding to the membrane, and no obvious orthologues of eukaryotic GEFs and GAPs have been detected in archaeal genomes so far [350,351]. Since Rho GTPases are also present in all major extant eukaryotic clades, there is little doubt that they were also present in LECA [4]. In Metazoa, the number of Rho GTPases and the cellular processes in which they participate grew with the increase of complexity and the number of cell types in multicellular animals, leading to the present repertoire of Rho GTPases in mammals [4,34]. Somewhat surprisingly, our analysis indicates that a similar, but independent, diversification took place in dominantly unicellular Amoebozoa (Figure 1). Although they evolved independently, many of these proteins perform similar tasks and are involved in the regulation of similar signalling pathways as in animals. Whereas many of the cytoskeletal functional modules were already present in the last common ancestor of Amoebozoa and Metazoa, the functional equivalence of at least some independently evolved GTPases, e.g., of RhoA in human and RacE in Dictyostelium, is remarkable (Figure 3).

We analysed the phylogeny of Rho GTPases from 12 amoebozoan species belonging to four classes: Eumycetozoa (seven species, e.g., Dictyostelium discoideum, social amoeba undergoing aggregation into a transient multicellular form; [352,353]), Archamoeba (three species, e.g., Entamoeba histolytica, human pathogen and an obligate amitochondriate anaerobe; [354]), Centramoebia (Acanthamoeba castellanii, an ubiquitously distributed solitary amoeba and an opportunistic parasite; [355]), and Variosea (Planoprotostelium aurantium var. fungivorum, unicellular amoebozoon that sporulates by making an unicellular sporocarp; [356]). The number of Rho GTPases encoded in the genomes of typical representatives of the examined amoebozoan classes correlates roughly with their lifestyles. D. discoideum, as a free-living aerobic amoeba whose life cycle encompasses unicellular and multicellular stages, several modes of migration, and large-scale endocytosis, cell differentiation, and sporulation [357], and E. histolytica, which interacts with the complex environment of the host organisms and features a rich repertoire of actin-based structures [358], encode 20 and 19 Rho GTPase proteins, respectively, comparable to 20 Rho GTPases in humans. On the other hand, the free-living, solitary A. castellanii and P. aurantium encode only five and six Rho GTPases, respectively, comparable to five in the sponge Amphimedon queenslandica (Porifera) and seven in the sea anemone Nematostella vectensis (Cnidaria). It should be emphasized that the divergence of the surveyed amoeba classes is ancient, and even the branching of D. discoideum and E. histolytica, which are both classified into the Conosa sub- 
phylum, has been estimated to be greater than between animals and fungi [65]. It appears, therefore, that a correlation between the complexity of cellular processes involving the actin cytoskeleton and richness of the Rho GTPase repertoire has general validity across eukaryotes. In accord with this notion, the genome of the free-living amoeboflagellate Naegleria gruberi, which belongs to a varied and ubiquitous protist clade of Heterolobosea that diverged from other eukaryotic lineages over a billion years ago, encodes at least 23 and possibly more Rho GTPases [33,359]. On the other hand, the mammalian intestinal parasite from another deep-branching eukaryotic lineage, Giardia lamblia, contains a highly reduced actin cytoskeleton, lacking canonical actin-binding proteins, and a single Rho GTPase, glRac [360]. Intriguingly, glRac appears to exert effects on the Giardia actin cytoskeleton via a 14-3-3 orthologue [361]. Consistent with the expansion of Rho family GTPases in Amoebozoa and Heterolobosea, the species belonging to these and other clades that share the amoeboid phenotype also encode an excess of Dbl-RhoGEFs [362]. It has been shown that this expansion appeared independently in Amoebozoa, Heterolobosea, Parabasalia, and Rhizaria, indicating a convergent evolution of Dbl-like RhoGEFs, probably driven by diversity of extracellular stimuli that these amoeboid protists were exposed to. The authors conclude that Dbl-like RhoGEFs are functionally involved in the acquisition of the amoeboid phenotype [362].

Finally, we would like to comment on an enduring perception that $D$. discoideum contains only members of one out of the three archetypical small Rho GTPase classes, the Rac group [35], although suggestions have been made, mainly on the basis of functional data alone, that RacE and RacC represent bona fide orthologues of Rho and Cdc42, respectively $[69,82,313,315,363,364]$. As elaborated in Section 3, our phylogenetic analysis does not sufficiently support a homology even between the Dictyostelium and mammalian Rac proteins, and the dilemma between their common ancestry or convergent evolution remains unsolved. The numerous parallelisms between the signalling pathways that involve the corresponding GTPase classes in these organisms, however, suggest that they represent functional equivalents or counterparts, regardless of their evolutionary relationships. Bona fide functional equivalents of Rac1, RhoA, and Cdc42 are also present in E. histolytica and $P$. aurantium, whereas $A$. castellanii apparently lacks a typical Rho s.s. While the Cdc42, Rho, and BTB groups underwent considerable expansion in mammals, the most remarkable feature in D. discoideum, other eumycetozoans, and E. histolytica is the appearance of a group of closely related $\mathrm{RacH}, \mathrm{D}$, and $\mathrm{P}$, which have no obvious mammalian equivalents. Despite the differences between individual taxa, the combined evidence from the sequenced and analysed genomes of basal Metazoa [34], Amoebozoa (this work), other early branching eukaryotes [359], and Asgard archaea [349,350] suggests that the archetypical Rho family GTPases were already present in LECA, together with other basic structural and regulatory elements of the actin cytoskeleton [343,346,365].

Supplementary Materials: The following are available online at https://www.mdpi.com/article/ 10.3390/cells10071592/s1, Supplementary File 1: Figures S1-S3: Multiple sequence alignments of Rho GTPases, Table S1: Rho GTPases in Amoebozoa; Supplementary File 2: Accession numbers and amino acid sequences of Rho proteins from selected species.

Author Contributions: Conceptualization, V.F. and I.W.; bioinformatics analyses, A.T. and H.Ć.; review of the literature, V.F., L.M., D.P., A.T., H.Ć., and I.W.; writing-original draft preparation, V.F. and I.W.; writing—review and editing, V.F., L.M., D.P., A.T., H.Ć., and I.W.; funding acquisition, H.Ć. and I.W. All authors have read and agreed to the published version of the manuscript.

Funding: This work has been partly supported by the Croatian Science Foundation under the projects IP-2014-09-4753 and IP-2019-04-5382. The work of doctoral student Lucija Mijanović has been fully supported by the "Young researchers' career development project-training of doctoral students" of the Croatian Science Foundation funded by the European Union from the European Social Fund. The work of doctoral student Darija Putar is financed within the Croatian-Swiss Research Program of the Croatian Science Foundation and the Swiss National Science Foundation with funds obtained from the Swiss-Croatian Cooperation Program. 
Acknowledgments: The authors would like to thank the anonymous reviewer whose constructive suggestions strongly contributed to improvement of the manuscript.

Conflicts of Interest: The authors declare no conflict of interest.

\section{Abbreviations}

$\begin{array}{ll}\text { ABD } & \text { actin-binding domain } \\ \text { ABI } & \text { ABL interactor } \\ \text { Abp1 } & \text { actin-binding protein 1 } \\ \text { ACA } & \text { adenylyl cyclase A } \\ \text { AID } & \text { autoinhibitory domain } \\ \text { Arp2/3 } & \text { actin related protein 2/3 } \\ \text { BTB } & \text { broad-complex, tamtrack, bric à brac } \\ \text { CCP } & \text { clathrin-coated pit } \\ \text { CCV } & \text { clathrin-coated vesicle } \\ \text { CHD } & \text { calponin homology domain } \\ \text { CI } & \text { cortexillin I } \\ \text { CII } & \text { cortexillin II } \\ \text { CLIP-170 } & \text { cytoplasmic linker protein-170 } \\ \text { CME } & \text { clathrin-mediated endocytosis } \\ \text { CRIB } & \text { Cdc42/ Rac interactive binding } \\ \text { CYRI } & \text { CYFIP-related Rac interactor } \\ \text { DAD } & \text { Diaphanous-autoregulatory domain } \\ \text { DD } & \text { dimerization domain } \\ \text { DID } & \text { Diaphanous-inhibitory domain } \\ \text { DRF } & \text { Diaphanous-related formin } \\ \text { DUF1394 } & \text { domain of unknown function } \\ \text { EGFR } & \text { epidermal growth factor receptor } \\ \text { ERK } & \text { extracellular signal-regulated kinase } \\ \text { Fc } \gamma \text { R } & \text { Fc } \gamma \text { receptor } \\ \text { FH1 } & \text { formin homology 1 } \\ \text { FH2 } & \text { formin homology 2 } \\ \text { FH3 } & \text { formin homology 3 } \\ \text { FRET } & \text { fluorescence resonance energy transfer } \\ \text { GAP } & \text { GTPase activating protein } \\ \text { GEF } & \text { guanine-nucleotide exchange factor } \\ \text { GBD } & \text { GTPase binding domain } \\ \text { GPCR } & \text { G protein-coupled receptor } \\ \text { GRD } & \text { GAP-related domain } \\ \text { HSPC300 } & \text { hematopoietic stem/progenitor cell protein } 300 \\ \text { JMY } & \text { junction-mediating and -regulatory protein } \\ \text { MEF } & \text { mouse embryonic fibroblast } \\ \text { MHCK } & \text { myosin II heavy chain kinase } \\ \text { MIHCK } & \text { myosin I heavy chain kinase } \\ \text { MLC } & \text { myosin II light chain } \\ \text { MLCK } & \text { MLC kinase } \\ \text { NAP1 } & \text { Nck-associated protein 1 } \\ \text { NPF } & \text { nucleation promoting factor } \\ \text { N-WASP } & \text { neural WASP } \\ \text { PAK } & \text { p21-activated kinase } \\ \text { PBD } & \text { p21 binding domain } \\ \text { PH } & \text { pleckstrin homology } \\ \text { phosphatidylinositol (3,4)-bisphosphate } \\ \text { phosphatidylinositol 3-kinase }\end{array}$




$\begin{array}{ll}\text { PIP3 } & \text { phosphatidylinositol }(3,4,5) \text {-trisphosphate } \\ \text { PIR121 } & \text { 121F-specific p53 inducible RNA } \\ \text { PKB } & \text { protein kinase B } \\ \text { PRD } & \text { proline rich domain } \\ \text { REM } & \text { Rho effector homology } \\ \text { RGCT } & \text { RasGAP C-terminus } \\ \text { RhoGDI } & \text { Rho GDP-dissociation inhibitor } \\ \text { Rif } & \text { Rho in filopodia } \\ \text { RKH } & \text { ROK-kinectin homology } \\ \text { SRA1 } & \text { specifically RAC1-associated protein 1 } \\ \text { VEGF } & \text { vascular endothelial growth factor } \\ \text { VEGFR2 } & \text { VEGF receptor 2 } \\ \text { WASH } & \text { WASP and SCAR homologue } \\ \text { WASP } & \text { Wiskott-Aldrich syndrome protein } \\ \text { WAVE/SCAR } & \text { WASP family verprolin-homologous protein/suppressor of } \\ & \text { cAMP receptor } \\ \text { WCA } & \text { WASP-homology-2, also known as verprolin-homology, } \\ \text { WHAMM } & \text { cofilin-homology, or connecting or central, acidic } \\ \text { WRC } & \text { WASP homolog associated with actin, membranes, and microtubules } \\ \text { Y2H } & \text { WAVE regulatory complex }\end{array}$

\section{References}

1. Ridley, A.J.; Hall, A. The small GTP-binding protein rho regulates the assembly of focal adhesions and actin stress fibers in response to growth factors. Cell 1992, 70, 389-399. [CrossRef]

2. Ridley, A.J.; Paterson, H.F.; Johnston, C.L.; Diekmann, D.; Hall, A. The small GTP-binding protein rac regulates growth factorinduced membrane ruffling. Cell 1992, 70, 401-410. [CrossRef]

3. Ridley, A.J. Historical Overview of Rho GTPases. Methods Mol. Biol. 2012, 827, 3-12. [CrossRef] [PubMed]

4. Boureux, A.; Vignal, E.; Faure, S.; Fort, P. Evolution of the Rho Family of Ras-Like GTPases in Eukaryotes. Mol. Biol. Evol. 2007, 24, 203-216. [CrossRef] [PubMed]

5. Eme, L.; Sharpe, S.C.; Brown, M.W.; Roger, A.J. On the Age of Eukaryotes: Evaluating Evidence from Fossils and Molecular Clocks. Cold Spring Harb. Perspect. Biol. 2014, 6, a016139. [CrossRef] [PubMed]

6. Kang, S.; Tice, A.K.; Spiegel, F.W.; Silberman, J.D.; Pánek, T.; Čepička, I.; Kostka, M.; Kosakyan, A.; Alcântara, D.M.C.; Roger, A.J.; et al. Between a Pod and a Hard Test: The Deep Evolution of Amoebae. Mol. Biol. Evol. 2017, 34, 2258-2270. [CrossRef]

7. Artemenko, Y.; Lampert, T.J.; Devreotes, P.N. Moving towards a paradigm: Common mechanisms of chemotactic signaling in Dictyostelium and mammalian leukocytes. Cell. Mol. Life Sci. 2014, 71, 3711-3747. [CrossRef]

8. Bozzaro, S.; Bucci, C.; Steinert, M. Phagocytosis and Host-Pathogen Interactions in Dictyostelium with a Look at Macrophages. Int. Rev. Cell Mol. Biol. 2008, 271, 253-300. [CrossRef] [PubMed]

9. Dunn, J.D.; Bosmani, C.; Barisch, C.; Raykov, L.; Lefrancois, L.H.; Muñoz, E.C.; López-Jiménez, A.T.; Soldati, T. Eat Prey, Live: Dictyostelium discoideum as a Model for Cell-Autonomous Defenses. Front. Immunol. 2018, 8, 1906. [CrossRef]

10. Dickinson, D.J.; Nelson, W.J.; Weis, W.I. Studying Epithelial Morphogenesis in Dictyostelium. Methods Mol. Biol. 2015, 1189, 267-281. [CrossRef]

11. Loomis, W.F. Genetic control of morphogenesis in Dictyostelium. Dev. Biol. 2015, 402, 146-161. [CrossRef] [PubMed]

12. Weijer, C.J. Dictyostelium morphogenesis. Curr. Opin. Genet. Dev. 2004, 14, 392-398. [CrossRef]

13. Alexandrova, A.Y.; Chikina, A.S.; Svitkina, T.M. Actin Cytoskeleton in Mesenchymal-to-Amoeboid Transition of Cancer Cells. Int. Rev. Cell Mol. Biol. 2020, 356, 197-256. [CrossRef] [PubMed]

14. Commisso, C.; Davidson, S.M.; Soydaner-Azeloglu, R.G.; Parker, S.J.; Kamphorst, J.; Hackett, S.; Grabocka, E.; Nofal, M.; Drebin, J.A.; Thompson, C.B.; et al. Macropinocytosis of protein is an amino acid supply route in Ras-transformed cells. Nature 2013, 497, 633-637. [CrossRef]

15. King, J.S.; Kay, R.R. The origins and evolution of macropinocytosis. Philos. Trans. R. Soc. B Biol. Sci. 2019, $374,20180158$. [CrossRef]

16. Palm, W.; Thompson, C.B. Nutrient acquisition strategies of mammalian cells. Nature 2017, 546, 234-242. [CrossRef] [PubMed]

17. Stuelten, C.; Parent, C.A.; Montell, D.J. Cell motility in cancer invasion and metastasis: Insights from simple model organisms. Nat. Rev. Cancer 2018, 18, 296-312. [CrossRef] [PubMed]

18. Williams, T.D.; Paschke, P.I.; Kay, R.R. Function of small GTPases in Dictyostelium macropinocytosis. Philos. Trans. R. Soc. B Biol. Sci. 2019, 374, 20180150. [CrossRef] [PubMed] 
19. Liu, Y.-J.; Le Berre, M.; Lautenschläger, F.; Maiuri, P.; Callan-Jones, A.; Heuzé, M.; Takaki, T.; Voituriez, R.; Piel, M. Confinement and Low Adhesion Induce Fast Amoeboid Migration of Slow Mesenchymal Cells. Cell 2015, 160, 659-672. [CrossRef] [PubMed]

20. Yamada, K.M.; Sixt, M. Mechanisms of 3D cell migration. Nat. Rev. Mol. Cell Biol. 2019, 20, 738-752. [CrossRef] [PubMed]

21. Miao, Y.; Bhattacharya, S.; Edwards, M.; Cai, H.; Inoue, T.; Iglesias, P.A.; Devreotes, P.N. Altering the threshold of an excitable signal transduction network changes cell migratory modes. Nat. Cell Biol. 2017, 19, 329-340. [CrossRef] [PubMed]

22. Medalia, O.; Beck, M.; Ecke, M.; Weber, I.; Neujahr, R.; Baumeister, W.; Gerisch, G. Organization of Actin Networks in Intact Filopodia. Curr. Biol. 2007, 17, 79-84. [CrossRef] [PubMed]

23. Schirenbeck, A.; Bretschneider, T.; Arasada, R.; Schleicher, M.; Faix, J. The Diaphanous-related formin dDia2 is required for the formation and maintenance of filopodia. Nat. Cell Biol. 2005, 7, 619-625. [CrossRef] [PubMed]

24. Zatulovskiy, E.; Tyson, R.; Bretschneider, T.; Kay, R.R. Bleb-driven chemotaxis of Dictyostelium cells. J. Cell Biol. 2014, 204, 1027-1044. [CrossRef] [PubMed]

25. Weber, I. Is there a pilot in a pseudopod? Eur. J. Cell Biol. 2006, 85, 915-924. [CrossRef]

26. Cardelli, J. Phagocytosis and Macropinocytosis in Dictyostelium: Phosphoinositide-Based Processes, Biochemically Distinct. Traffic 2001, 2, 311-320. [CrossRef] [PubMed]

27. Rivero, F. Endocytosis and the Actin Cytoskeleton in Dictyostelium discoideum. Int. Rev. Cell Mol. Biol. 2008, 267, 343-397. [CrossRef] [PubMed]

28. Lee, E.; Pang, K.-M.; Knecht, D. The regulation of actin polymerization and cross-linking in Dictyostelium. Biochim. Biophys. Acta (BBA) Gen. Subj. 2001, 1525, 217-227. [CrossRef]

29. Noegel, A.; Schleicher, M. The actin cytoskeleton of Dictyostelium: A story told by mutants. J. Cell Sci. 2000, 113 Pt 5, 759-766. [CrossRef]

30. Rosenblum, E.B.; Parent, C.E.; Brandt, E.E. The Molecular Basis of Phenotypic Convergence. Annu. Rev. Ecol. Evol. Syst. 2014, 45, 203-226. [CrossRef]

31. Speed, M.P.; Arbuckle, K. Quantification provides a conceptual basis for convergent evolution. Biol. Rev. 2016, 92, 815-829. [CrossRef]

32. Fort, P. Rho signaling: An historical and evolutionary perspective. In Rho Signaling: Molecular Biology in Health and Disease; Fort, P., Blangy, A., Eds.; World Scientific: Singapore, 2018; pp. 3-18.

33. Eliáš, M.; Klimes, V. Rho GTPases: Deciphering the Evolutionary History of a Complex Protein Family. Methods Mol. Biol. 2012, 827, 13-34. [CrossRef]

34. Beljan, S.; Bosnar, M.H.; Ćetković, H. Rho Family of Ras-Like GTPases in Early-Branching Animals. Cells 2020, 9, 2279. [CrossRef] [PubMed]

35. Vlahou, G.; Rivero, F. Rho GTPase signaling in Dictyostelium discoideum: Insights from the genome. Eur. J. Cell Biol. 2006, 85, 947-959. [CrossRef]

36. Le, Q.; Gascuel, O. An Improved General Amino Acid Replacement Matrix. Mol. Biol. Evol. 2008, 25, 1307-1320. [CrossRef] [PubMed]

37. Kumar, S.; Stecher, G.; Li, M.; Knyaz, C.; Tamura, K. MEGA X: Molecular evolutionary genetics analysis across computing platforms. Mol. Biol. Evol. 2018, 35, 1547-1549. [CrossRef]

38. Wennerberg, K.; Rossman, K.L.; Der, C.J. The Ras superfamily at a glance. J. Cell Sci. 2005, 118, 843-846. [CrossRef] [PubMed]

39. Vetter, I.R. The Guanine Nucleotide-Binding Switch in Three Dimensions. Science 2001, 294, 1299-1304. [CrossRef] [PubMed]

40. Bourne, H.R.; Sanders, D.A.; McCormick, F. The GTPase superfamily: Conserved structure and molecular mechanism. Nature 1991, 349, 117-127. [CrossRef]

41. Dever, T.E.; Glynias, M.J.; Merrick, W.C. GTP-binding domain: Three consensus sequence elements with distinct spacing. Proc. Natl. Acad. Sci. USA 1987, 84, 1814-1818. [CrossRef] [PubMed]

42. Bos, J.L.; Rehmann, H.; Wittinghofer, A. GEFs and GAPs: Critical Elements in the Control of Small G Proteins. Cell 2007, 129, 865-877. [CrossRef] [PubMed]

43. Milburn, M.V.; Tong, L.; Devos, A.M.; Brunger, A.; Yamaizumi, Z.; Nishimura, S.; Kim, S.H. Molecular switch for signal transduction: Structural differences between active and inactive forms of protooncogenic ras proteins. Science 1990, 247, 939-945. [CrossRef] [PubMed]

44. Aspenström, P. Fast-cycling Rho GTPases. Small GTPases 2020, 11, 248-255. [CrossRef] [PubMed]

45. Colicelli, J. Human RAS Superfamily Proteins and Related GTPases. Sci. STKE 2004, 2004, re13. [CrossRef] [PubMed]

46. Dvorský, R.; Ahmadian, M.R. Always look on the bright site of Rho: Structural implications for a conserved intermolecular interface. EMBO Rep. 2004, 5, 1130-1136. [CrossRef]

47. Schaefer, A.; Reinhard, N.R.; Hordijk, P.L. Toward understanding RhoGTPase specificity: Structure, function and local activation. Small GTPases 2014, 5, e968004. [CrossRef]

48. Dovas, A.; Couchman, J.R. RhoGDI: Multiple functions in the regulation of Rho family GTPase activities. Biochem. J. 2005, 390, 1-9. [CrossRef]

49. Garcia-Mata, R.; Boulter, E.; Burridge, K. The 'invisible hand': Regulation of RHO GTPases by RHOGDIs. Nat. Rev. Mol. Cell Biol. 2011, 12, 493-504. [CrossRef]

50. Mott, H.; Owen, D. Structures of Ras superfamily effector complexes: What have we learnt in two decades? Crit. Rev. Biochem. Mol. Biol. 2015, 50, 85-133. [CrossRef] 
51. Bishop, A.L.; Hall, A. Rho GTPases and Their Effector Proteins. Biochem. J. 2000, 348 Pt 2, 241-255. [CrossRef]

52. Burbelo, P.D.; Drechsel, D.; Hall, A. A Conserved Binding Motif Defines Numerous Candidate Target Proteins for Both Cdc42 and Rac GTPases. J. Biol. Chem. 1995, 270, 29071-29074. [CrossRef]

53. Heasman, S.J.; Ridley, A.J. Mammalian Rho GTPases: New insights into their functions from in vivo studies. Nat. Rev. Mol. Cell Biol. 2008, 9, 690-701. [CrossRef] [PubMed]

54. Lawson, C.D.; Ridley, A.J. Rho GTPase signaling complexes in cell migration and invasion. J. Cell Biol. 2018, $217,447-457$. [CrossRef]

55. Phuyal, S.; Farhan, H. Multifaceted Rho GTPase Signaling at the Endomembranes. Front. Cell Dev. Biol. 2019, 7, 127. [CrossRef] [PubMed]

56. Sit, S.-T.; Manser, E. Rho GTPases and their role in organizing the actin cytoskeleton. J. Cell Sci. 2011, 124, 679-683. [CrossRef] [PubMed]

57. Basu, S.; Fey, P.; Jimenez-Morales, D.; Dodson, R.J.; Chisholm, R.L. dictyBase 2015: Expanding data and annotations in a new software environment. Genesis 2015, 53, 523-534. [CrossRef]

58. Rivero, F.; Somesh, B.P. Signal transduction pathways regulated by Rho GTPases in Dictyostelium. J. Muscle Res. Cell Motil. 2002, 23, 737-749. [CrossRef] [PubMed]

59. Rivero, F.; Xiong, H. Rho Signaling in Dictyostelium discoideum. In International Review of Cell and Molecular Biology; Jeon, K.W., Ed.; Elsevier Inc.: Oxford, UK, 2016; Volume 322, pp. 61-181.

60. Franco-Barraza, J.; Zamudio-Meza, H.; Franco, E.; Domínguez-Robles, M.D.C.; Villegas-Sepúlveda, N.; Meza, I. Rho signaling in Entamoeba histolytica modulates actomyosin-dependent activities stimulated during invasive behavior. Cell Motil. Cytoskelet. 2006, 63, 117-131. [CrossRef] [PubMed]

61. Lohia, A.; Samuelson, J. Heterogeneity of Entamoeba histolytica rac genes encoding p21rac homologues. Gene 1996, 173, 205-208. [CrossRef]

62. Edgar, R.C. MUSCLE: Multiple sequence alignment with high accuracy and high throughput. Nucleic Acids Res. 2004, 32, 1792-1797. [CrossRef]

63. Cavalier-Smith, T.; Fiore-Donno, A.M.; Chao, E.; Kudryavtsev, A.; Berney, C.; Snell, E.A.; Lewis, R. Multigene phylogeny resolves deep branching of Amoebozoa. Mol. Phylogenet. Evol. 2015, 83, 293-304. [CrossRef] [PubMed]

64. Schilde, C.; Schaap, P. The Amoebozoa. In Dictyostelium Discoideum Protocols, 2nd ed.; Eichinger, L., Rivero, F., Eds.; Methods in Molecular Biology Series 983; Humana Press: Totowa, NJ, USA, 2013; pp. 1-15.

65. Song, J.; Xu, Q.; Olsen, R.; Loomis, W.F.; Shaulsky, G.; Kuspa, A.; Sucgang, R. Comparing the Dictyostelium and Entamoeba Genomes Reveals an Ancient Split in the Conosa Lineage. PLoS Comput. Biol. 2005, 1, e71. [CrossRef]

66. Godbold, G.D.; Corbett, K.D.; Mann, B.J. A Rho-like small GTPase of Entamoeba histolytica contains an unusual amino acid residue in a conserved GDP-stabilization region and is not a substrate for C3 exoenzyme. Exp. Parasitol. 2002, 101, 107-110. [CrossRef]

67. Bosch, D.E.; Wittchen, E.S.; Qiu, C.; Burridge, K.; Siderovski, D. Unique Structural and Nucleotide Exchange Features of the Rho1 GTPase of Entamoeba histolytica. J. Biol. Chem. 2011, 286, 39236-39246. [CrossRef]

68. Larochelle, D.A.; Vithalani, K.K.; De Lozanne, A. A novel member of the rho family of small GTP-binding proteins is specifically required for cytokinesis. J. Cell Biol. 1996, 133, 1321-1329. [CrossRef] [PubMed]

69. Wang, C.; Jung, D.; Cao, Z.; Chung, C.Y. Adenylyl cyclase localization to the uropod of aggregating Dictyostelium cells requires RacC. Biochem. Biophys. Res. Commun. 2015, 465, 613-619. [CrossRef] [PubMed]

70. Ronquist, F.; Teslenko, M.; Van Der Mark, P.; Ayres, D.L.; Darling, A.; Hoehna, S.; Larget, B.; Liu, L.; Suchard, M.A.; Huelsenbeck, J.P. MrBayes 3.2: Efficient Bayesian Phylogenetic Inference and Model Choice Across a Large Model Space. Syst. Biol. 2012, 61, 539-542. [CrossRef]

71. Criscuolo, A.; Gribaldo, S. BMGE (Block Mapping and Gathering with Entropy): A new software for selection of phylogenetic informative regions from multiple sequence alignments. BMC Evol. Biol. 2010, 10, 210. [CrossRef]

72. Bush, J.; Franek, K.; Cardelli, J. Cloning and characterization of seven novel Dictyostelium discoideum rac-related genes belonging to the rho family of GTPases. Gene 1993, 136, 61-68. [CrossRef]

73. Santhanam, B.; Cai, H.; Devreotes, P.N.; Shaulsky, G.; Katoh-Kurasawa, M. The GATA transcription factor GtaC regulates early developmental gene expression dynamics in Dictyostelium. Nat. Commun. 2015, 6, 7551. [CrossRef] [PubMed]

74. Stajdohar, M.; Jeran, L.; Kokosar, J.; Blenkus, D.; Janez, T.; Kuspa, A.; Shaulsky, G.; Zupan, B. DictyExpress: Visual Analytics of NGS Gene Expression in Dictyostelium. 2015. Available online: https:/ / www.dictyexpress.org (accessed on 4 February 2021).

75. Muramoto, T.; Urushihara, H. Small GTPase RacF2 affects sexual cell fusion and asexual development in Dictyostelium discoideum through the regulation of cell adhesion. Dev. Growth Differ. 2006, 48, 199-208. [CrossRef] [PubMed]

76. Dumontier, M.; Hocht, P.; Mintert, U.; Faix, J. Rac1 GTPases control filopodia formation, cell motility, endocytosis, cytokinesis and development in Dictyostelium. J. Cell Sci. 2000, 113 Pt 12, 2253-2265. [CrossRef]

77. Palmieri, S.J.; Nebl, T.; Pope, R.K.; Seastone, D.J.; Lee, E.; Hinchcliffe, E.H.; Sluder, G.; Knecht, D.; Cardelli, J.; Luna, E.J. Mutant Rac1B expression in Dictyostelium: Effects on morphology, growth, endocytosis, development, and the actin cytoskeleton. Cell Motil. Cytoskelet. 2000, 46, 285-304. [CrossRef]

78. Wang, Y.; Senoo, H.; Sesaki, H.; Iijima, M. Rho GTPases orient directional sensing in chemotaxis. Proc. Natl. Acad. Sci. USA 2013, 110, E4723-E4732. [CrossRef] 
79. Cotteret, S.; Chernoff, J. The evolutionary history of effectors downstream of Cdc42 and Rac. Genome Biol. 2002, 3, REVIEWS0002. [CrossRef]

80. Chung, C.Y.; Feoktistov, A.; Hollingsworth, R.J.; Rivero, F.; Mandel, N.S. An attenuating role of a WASP-related protein, WASP-B, in the regulation of F-actin polymerization and pseudopod formation via the regulation of RacC during Dictyostelium chemotaxis. Biochem. Biophys. Res. Commun. 2013, 436, 719-724. [CrossRef] [PubMed]

81. De La Roche, M.; Mahasneh, A.; Lee, S.-F.; Rivero, F.; Côté, G.P. Cellular Distribution and Functions of Wild-Type and Constitutively Activated Dictyostelium PakB. Mol. Biol. Cell 2005, 16, 238-247. [CrossRef]

82. Han, J.W.; Leeper, L.; Rivero, F.; Chung, C.Y. Role of RacC for the Regulation of WASP and Phosphatidylinositol 3-Kinase during Chemotaxis of Dictyostelium. J. Biol. Chem. 2006, 281, 35224-35234. [CrossRef] [PubMed]

83. Lee, S.; Rivero, F.; Park, K.C.; Huang, E.; Funamoto, S.; Firtel, R.A. Dictyostelium PAKc Is Required for Proper Chemotaxis. Mol. Biol. Cell 2004, 15, 5456-5469. [CrossRef] [PubMed]

84. Park, K.C.; Rivero, F.; Meili, R.; Lee, S.; Apone, F.; Firtel, R.A. Rac regulation of chemotaxis and morphogenesis in Dictyostelium. EMBO J. 2004, 23, 4177-4189. [CrossRef] [PubMed]

85. Swaminathan, K.; Müller-Taubenberger, A.; Faix, J.; Rivero, F.; Noegel, A.A. A Cdc42- and Rac-interactive binding (CRIB) domain mediates functions of coronin. Proc. Natl. Acad. Sci. USA 2014, 111, E25-E33. [CrossRef] [PubMed]

86. Mullins, R.D.; Heuser, J.A.; Pollard, T.D. The interaction of Arp2/3 complex with actin: Nucleation, high affinity pointed end capping, and formation of branching networks of filaments. Proc. Natl. Acad. Sci. USA 1998, 95, 6181-6186. [CrossRef] [PubMed]

87. Pollard, T.D.; Borisy, G.G. Cellular Motility Driven by Assembly and Disassembly of Actin Filaments. Cell 2003, 112, 453-465. [CrossRef]

88. Burianek, L.E.; Soderling, S.H. Under lock and key: Spatiotemporal regulation of WASP family proteins coordinates separate dynamic cellular processes. Semin. Cell Dev. Biol. 2013, 24, 258-266. [CrossRef] [PubMed]

89. Kim, A.S.; Kakalis, L.T.; Abdul-Manan, N.; Liu, G.A.; Rosen, M.K. Autoinhibition and activation mechanisms of the WiskottAldrich syndrome protein. Nature 2000, 404, 151-158. [CrossRef] [PubMed]

90. Miki, H.; Sasaki, T.; Takai, Y.; Takenawa, T. Induction of filopodium formation by a WASP-related actin-depolymerizing protein N-WASP. Nature 1998, 391, 93-96. [CrossRef] [PubMed]

91. Rohatgi, R.; Ma, L.; Miki, H.; Lopez, M.; Kirchhausen, T.; Takenawa, T.; Kirschner, M.W. The Interaction between N-WASP and the Arp2/3 Complex Links Cdc42-Dependent Signals to Actin Assembly. Cell 1999, 97, 221-231. [CrossRef]

92. Rotty, J.D.; Wu, C.; Bear, J.E. New insights into the regulation and cellular functions of the ARP2/3 complex. Nat. Rev. Mol. Cell Biol. 2012, 14, 7-12. [CrossRef]

93. Tomasevic, N.; Jia, Z.; Russell, A.; Fujii, T.; Hartman, J.J.; Clancy, S.; Wang, M.; Beraud, C.; Wood, K.W.; Sakowicz, R. Differential Regulation of WASP and N-WASP by Cdc42, Rac1, Nck, and PI(4,5)P2. Biochemistry 2007, 46, 3494-3502. [CrossRef]

94. Bear, J.E.; Rawls, J.; Saxe, C.L. SCAR, a WASP-related Protein, Isolated as a Suppressor of Receptor Defects in Late Dictyostelium Development. J. Cell Biol. 1998, 142, 1325-1335. [CrossRef] [PubMed]

95. Miki, H.; Suetsugu, S.; Takenawa, T. WAVE, a novel WASP-family protein involved in actin reorganization induced by Rac. EMBO J. 1998, 17, 6932-6941. [CrossRef] [PubMed]

96. Chen, Z.; Borek, D.; Padrick, S.; Gomez, T.S.; Metlagel, Z.; Ismail, A.M.; Umetani, J.; Billadeau, D.D.; Otwinowski, Z.; Rosen, M.K. Structure and control of the actin regulatory WAVE complex. Nature 2010, 468, 533-538. [CrossRef]

97. Eden, S.; Rohatgi, R.; Podtelejnikov, A.V.; Mann, M.; Kirschner, M.W. Mechanism of regulation of WAVE1-induced actin nucleation by Rac1 and Nck. Nature 2002, 418, 790-793. [CrossRef] [PubMed]

98. Gautreau, A.; Ho, H.-Y.H.; Li, J.; Steen, H.; Gygi, S.P.; Kirschner, M.W. Purification and architecture of the ubiquitous Wave complex. Proc. Natl. Acad. Sci. USA 2004, 101, 4379-4383. [CrossRef] [PubMed]

99. Stovold, C.F.; Millard, T.H.; Machesky, L.M. Inclusion of Scar/WAVE3 in a similar complex to Scar/WAVE1 and 2. BMC Cell Biol. 2005, 6, 11. [CrossRef]

100. Innocenti, M.; Zucconi, A.; Disanza, A.; Frittoli, E.; Areces, L.B.; Steffen, A.; Stradal, T.; Di Fiore, P.P.; Carlier, M.-F.; Scita, G. Abi1 is essential for the formation and activation of a WAVE2 signalling complex. Nature 2004, 6, 319-327. [CrossRef]

101. Kim, Y.; Sung, J.Y.; Ceglia, I.; Lee, K.-W.; Ahn, J.-H.; Halford, J.M.; Kim, A.M.; Kwak, S.P.; Park, J.B.; Ryu, S.H.; et al. Phosphorylation of WAVE1 regulates actin polymerization and dendritic spine morphology. Nature 2006, 442, 814-817. [CrossRef]

102. Suetsugu, S.; Kurisu, S.; Oikawa, T.; Yamazaki, D.; Oda, A.; Takenawa, T. Optimization of WAVE2 complex-induced actin polymerization by membrane-bound IRSp53, PIP3, and Rac. J. Cell Biol. 2006, 173, 571-585. [CrossRef] [PubMed]

103. Derivery, E.; Lombard, B.; Loew, D.; Gautreau, A. The Wave complex is intrinsically inactive. Cell Motil. Cytoskelet. 2009, 66, 777-790. [CrossRef]

104. Ismail, A.M.; Padrick, S.; Chen, B.; Umetani, J.; Rosen, M.K. The WAVE regulatory complex is inhibited. Nat. Struct. Mol. Biol. 2009, 16, 561-563. [CrossRef] [PubMed]

105. Lebensohn, A.M.; Kirschner, M.W. Activation of the WAVE Complex by Coincident Signals Controls Actin Assembly. Mol. Cell 2009, 36, 512-524. [CrossRef]

106. Oikawa, T.; Yamaguchi, H.; Itoh, T.; Kato, M.; Ijuin, T.; Yamazaki, D.; Suetsugu, S.; Takenawa, T. PtdIns(3,4,5)P3 binding is necessary for WAVE2-induced formation of lamellipodia. Nature 2004, 6, 420-426. [CrossRef]

107. Myers, S.A.; Han, J.W.; Lee, Y.; Firtel, R.A.; Chung, C.Y. ADictyosteliumHomologue of WASP Is Required for Polarized F-Actin Assembly during Chemotaxis. Mol. Biol. Cell 2005, 16, 2191-2206. [CrossRef] 
108. Veltman, D.M.; Insall, R.H. WASP Family Proteins: Their Evolution and Its Physiological Implications. Mol. Biol. Cell 2010, 21, 2880-2893. [CrossRef]

109. Carnell, M.; Zech, T.; Calaminus, S.D.; Ura, S.; Hagedorn, M.; Johnston, S.A.; May, R.C.; Soldati, T.; Machesky, L.M.; Insall, R.H. Actin polymerization driven by WASH causes V-ATPase retrieval and vesicle neutralization before exocytosis. J. Cell Biol. 2011, 193, 831-839. [CrossRef] [PubMed]

110. Merrifield, C.J.; Qualmann, B.; Kessels, M.M.; Almers, W. Neural Wiskott Aldrich Syndrome Protein (N-WASP) and the Arp2/3 complex are recruited to sites of clathrin-mediated endocytosis in cultured fibroblasts. Eur. J. Cell Biol. 2004, 83, 13-18. [CrossRef] [PubMed]

111. Veltman, D.M.; Auciello, G.; Spence, H.J.; Machesky, L.M.; Rappoport, J.Z.; Insall, R.H. Functional analysis of Dictyostelium IBARa reveals a conserved role of the I-BAR domain in endocytosis. Biochem. J. 2011, 436, 45-52. [CrossRef] [PubMed]

112. Veltman, D.M.; King, J.; Machesky, L.M.; Insall, R.H. SCAR knockouts in Dictyostelium: WASP assumes SCAR's position and upstream regulators in pseudopods. J. Cell Biol. 2012, 198, 501-508. [CrossRef]

113. Benesch, S.; Polo, S.; Lai, F.P.L.; Anderson, K.I.; Stradal, T.; Wehland, J.; Rottner, K. N-WASP deficiency impairs EGF internalization and actin assembly at clathrin-coated pits. J. Cell Sci. 2005, 118, 3103-3115. [CrossRef] [PubMed]

114. Davidson, A.J.; Amato, C.; Thomason, P.A.; Insall, R.H. WASP family proteins and formins compete in pseudopod- and bleb-based migration. J. Cell Biol. 2018, 217, 701-714. [CrossRef]

115. Amato, C.; Thomason, P.; Davidson, A.J.; Swaminathan, K.; Ismail, S.; Machesky, L.M.; Insall, R.H. WASP Restricts Active Rac to Maintain Cells' Front-Rear Polarization. Curr. Biol. 2019, 29, 4169-4182.e4. [CrossRef] [PubMed]

116. Hinze, C.; Boucrot, E. Local actin polymerization during endocytic carrier formation. Biochem. Soc. Trans. 2018, 46, 565-576. [CrossRef] [PubMed]

117. Innocenti, M.; Gerboth, S.; Rottner, K.; Lai, F.P.L.; Hertzog, M.; Stradal, T.; Frittoli, E.; Didry, D.; Polo, S.; Disanza, A.; et al. Abi1 regulates the activity of N-WASP and WAVE in distinct actin-based processes. Nat. Cell Biol. 2005, 7, 969-976. [CrossRef]

118. Croisé, P.; Estay-Ahumada, C.; Gasman, S.; Ory, S. Rho GTPases, phosphoinositides, and actin: A Tripartite Framework for Efficient Vesicular Trafficking. Small GTPases 2014, 5, e29469. [CrossRef]

119. Lamaze, C.; Chuang, T.-H.; Terlecky, L.J.; Bokoch, G.M.; Schmid, S.L. Regulation of receptor-mediated endocytosis by Rho and Rac. Nature 1996, 382, 177-179. [CrossRef] [PubMed]

120. Campellone, K.G.; Welch, M.D. A Nucleator Arms Race: Cellular Control of Actin Assembly. Nat. Rev. Mol. Cell Biol. 2010, 11, 237-251. [CrossRef]

121. Swaminathan, K.; Stumpf, M.; Müller, R.; Horn, A.-C.; Schmidbauer, J.; Eichinger, L.; Müller-Taubenberger, A.; Faix, J.; Noegel, A.A. Coronin7 regulates WASP and SCAR through CRIB mediated interaction with Rac proteins. Sci. Rep. 2015, 5 , 14437. [CrossRef]

122. Filić, V.; Marinović, M.; Faix, J.; Weber, I. A dual role for Rac1 GTPases in the regulation of cell motility. J. Cell Sci. 2012, 125, 387-398. [CrossRef]

123. Niedergang, F.; Grinstein, S. How to build a phagosome: New concepts for an old process. Curr. Opin. Cell Biol. 2018, 50, 57-63. [CrossRef] [PubMed]

124. Park, H.; Cox, D. Cdc42 Regulates Fc $\gamma$ Receptor-mediated Phagocytosis through the Activation and Phosphorylation of WiskottAldrich Syndrome Protein (WASP) and Neural-WASP. Mol. Biol. Cell 2009, 20, 4500-4508. [CrossRef]

125. Blagg, S.L.; Stewart, M.; Sambles, C.; Insall, R.H. PIR121 Regulates Pseudopod Dynamics and SCAR Activity in Dictyostelium. Curr. Biol. 2003, 13, 1480-1487. [CrossRef]

126. Caracino, D.; Jones, C.; Compton, M.; Saxe, C.L. The N-Terminus ofDictyosteliumScar Interacts with Abi and HSPC300 and Is Essential for Proper Regulation and Function. Mol. Biol. Cell 2007, 18, 1609-1620. [CrossRef] [PubMed]

127. Ibarra, N.; Blagg, S.L.; Vazquez, F.; Insall, R. Nap1 Regulates Dictyostelium Cell Motility and Adhesion through SCAR-Dependent and -Independent Pathways. Curr. Biol. 2006, 16, 717-722. [CrossRef] [PubMed]

128. Singh, S.P.; Thomason, P.A.; Lilla, S.; Schaks, M.; Tang, Q.; Goode, B.L.; Machesky, L.M.; Rottner, K.; Insall, R.H. Cell-substrate adhesion drives Scar/WAVE activation and phosphorylation by a Ste20-family kinase, which controls pseudopod lifetime. PLoS Biol. 2020, 18, e3000774. [CrossRef]

129. Chen, B.; Chou, H.-T.; Brautigam, C.A.; Xing, W.; Yang, S.; Henry, L.; Doolittle, L.K.; Walz, T.; Rosen, M.K. Rac1 GTPase activates the WAVE regulatory complex through two distinct binding sites. eLife 2017, 6, 6. [CrossRef]

130. Schaks, M.; Singh, S.P.; Kage, F.; Thomason, P.; Klünemann, T.; Steffen, A.; Blankenfeldt, W.; Stradal, T.E.; Insall, R.H.; Rottner, K. Distinct Interaction Sites of Rac GTPase with WAVE Regulatory Complex Have Non-Redundant Functions In Vivo. Curr. Biol. 2018, 28, 3674-3684.e6. [CrossRef]

131. Marinović, M.; Šoštar, M.; Filić, V.; Antolović, V.; Weber, I. Quantitative imaging of Rac1 activity in Dictyostelium cells with a fluorescently labelled GTPase-binding domain from DPAKa kinase. Histochem. Cell Biol. 2016, 146, 267-279. [CrossRef]

132. Veltman, D.M.; Williams, T.D.; Bloomfield, G.; Chen, B.-C.; Betzig, E.; Insall, R.; Kay, R.R. A plasma membrane template for macropinocytic cups. eLife 2016, 5, e20085. [CrossRef] [PubMed]

133. King, J.S.; Veltman, D.M.; Georgiou, M.; Baum, B.; Insall, R. SCAR/WAVE is activated at mitosis and drives myosin-independent cytokinesis. J. Cell Sci. 2010, 123, 2246-2255. [CrossRef]

134. Machesky, L.M.; Mullins, R.D.; Higgs, H.N.; Kaiser, D.A.; Blanchoin, L.; May, R.C.; Hall, M.E.; Pollard, T.D. Scar, a WASp-related protein, activates nucleation of actin filaments by the Arp2/3 complex. Proc. Natl. Acad. Sci. USA 1999, 96, 3739-3744. [CrossRef] 
135. Litschko, C.; Linkner, J.; Brühmann, S.; Stradal, T.E.; Reinl, T.; Jänsch, L.; Rottner, K.; Faix, J. Differential functions of WAVE regulatory complex subunits in the regulation of actin-driven processes. Eur. J. Cell Biol. 2017, 96, 715-727. [CrossRef]

136. Seastone, D.J.; Harris, E.; Temesvari, L.A.; Bear, J.E.; Saxe, C.L.; Cardelli, J. The WASp-like protein Scar regulates macropinocytosis, phagocytosis and endosomal membrane flow in Dictyostelium. J. Cell Sci. 2001, 114, 2673-2683. [CrossRef] [PubMed]

137. Ura, S.; Pollitt, A.Y.; Veltman, D.M.; Morrice, N.A.; Machesky, L.M.; Insall, R.H. Pseudopod Growth and Evolution during Cell Movement Is Controlled through SCAR/WAVE Dephosphorylation. Curr. Biol. 2012, 22, 553-561. [CrossRef] [PubMed]

138. Hahne, P.; Sechi, A.; Benesch, S.; Small, J. Scar/WAVE is localised at the tips of protruding lamellipodia in living cells. FEBS Lett. 2001, 492, 215-220. [CrossRef]

139. Suetsugu, S.; Yamazaki, D.; Kurisu, S.; Takenawa, T. Differential Roles of WAVE1 and WAVE2 in Dorsal and Peripheral Ruffle Formation for Fibroblast Cell Migration. Dev. Cell 2003, 5, 595-609. [CrossRef]

140. Yamazaki, D.; Suetsugu, S.; Miki, H.; Kataoka, Y.; Nishikawa, S.-I.; Fujiwara, T.; Yoshida, N.; Takenawa, T. WAVE2 is required for directed cell migration and cardiovascular development. Nature 2003, 424, 452-456. [CrossRef]

141. Steffen, A.; Rottner, K.; Ehinger, J.; Innocenti, M.; Scita, G.; Wehland, J.; Stradal, T.E.B. Sra-1 and Nap1 link Rac to actin assembly driving lamellipodia formation. EMBO J. 2004, 23, 749-759. [CrossRef]

142. Yan, C.; Martinez-Quiles, N.; Eden, S.; Shibata, T.; Takeshima, F.; Shinkura, R.; Fujiwara, Y.; Bronson, R.; Snapper, S.B.; Kirschner, M.W.; et al. WAVE2 deficiency reveals distinct roles in embryogenesis and Rac-mediated actin-based motility. EMBO J. 2003, 22, 3602-3612. [CrossRef]

143. Steffen, A.; Ladwein, M.; Dimchev, G.A.; Hein, A.; Schwenkmezger, L.; Arens, S.; Ladwein, K.I.; Holleboom, J.M.; Schur, F.; Small, J.V.; et al. Rac function is critical for cell migration but not required for spreading and focal adhesion formation. J. Cell Sci. 2013, 126, 4572-4588. [CrossRef]

144. Fritz-Laylin, L.K.; Lord, S.J.; Mullins, R.D. WASP and SCAR are evolutionarily conserved in actin-filled pseudopod-based motility. J. Cell Biol. 2017, 216, 1673-1688. [CrossRef] [PubMed]

145. Lommel, S.; Benesch, S.; Rottner, K.; Franz, T.; Wehland, J.; Kühn, R. Actin pedestal formation by enteropathogenicEscherichia coliand intracellular motility ofShigella flexneriare abolished in N-WASP-defective cells. EMBO Rep. 2001, 2, 850-857. [CrossRef] [PubMed]

146. Sarmiento, C.; Wang, W.; Dovas, A.; Yamaguchi, H.; Sidani, M.; El-Sibai, M.; Desmarais, V.; Holman, H.A.; Kitchen, S.; Backer, J.M.; et al. WASP family members and formin proteins coordinate regulation of cell protrusions in carcinoma cells. J. Cell Biol. 2008, 180, 1245-1260. [CrossRef] [PubMed]

147. Snapper, S.B.; Takeshima, F.; Antón, I.; Liu, C.-H.; Thomas, S.M.; Nguyen, D.; Dudley, D.; Fraser, H.; Purich, D.; Lopez-Ilasaca, M.; et al. N-WASP deficiency reveals distinct pathways for cell surface projections and microbial actin-based motility. Nat. Cell Biol. 2001, 3, 897-904. [CrossRef] [PubMed]

148. Badolato, R.; Sozzani, S.; Malacarne, F.; Bresciani, S.; Fiorini, M.; Borsatti, A.; Albertini, A.; Mantovani, A.; Ugazio, A.G.; Notarangelo, L.D. Monocytes from Wiskott-Aldrich patients display reduced chemotaxis and lack of cell polarization in response to monocyte chemoattractant protein-1 and formyl-methionyl-leucyl-phenylalanine. J. Immunol. 1998, 161, 1026-1033. [PubMed]

149. Burns, S.; Thrasher, A.J.; Blundell, M.P.; Machesky, L.; Jones, G.E. Configuration of human dendritic cell cytoskeleton by Rho GTPases, the WAS protein, and differentiation. Blood 2001, 98, 1142-1149. [CrossRef]

150. Ishihara, D.; Dovas, A.; Park, H.; Isaac, B.M.; Cox, D. The Chemotactic Defect in Wiskott-Aldrich Syndrome Macrophages Is Due to the Reduced Persistence of Directional Protrusions. PLoS ONE 2012, 7, e30033. [CrossRef]

151. Snapper, S.B.; Meelu, P.; Nguyen, D.; Stockton, B.M.; Bozza, P.; Alt, F.W.; Rosen, F.S.; Von Andrian, U.H.; Klein, C. WASP deficiency leads to global defects of directed leukocyte migration in vitro and in vivo. J. Leukoc. Biol. 2005, 77, 993-998. [CrossRef]

152. Fort, L.; Batista, J.M.; Thomason, P.A.; Spence, H.J.; Whitelaw, J.A.; Tweedy, L.; Greaves, J.; Martin, K.J.; Anderson, K.I.; Brown, P.; et al. Fam49/CYRI interacts with Rac1 and locally suppresses protrusions. Nat. Cell Biol. 2018, 20, 1159-1171. [CrossRef]

153. Yagi, S.; Matsuda, M.; Kiyokawa, E. Suppression of Rac1 activity at the apical membrane of MDCK cells is essential for cyst structure maintenance. EMBO Rep. 2012, 13, 237-243. [CrossRef]

154. Steffen, A.; Faix, J.; Resch, G.P.; Linkner, J.; Wehland, J.; Small, J.V.; Rottner, K.; Stradal, T.E. Filopodia Formation in the Absence of Functional WAVE- and Arp2/3-Complexes. Mol. Biol. Cell 2006, 17, 2581-2591. [CrossRef]

155. Pruyne, D.; Evangelista, M.; Yang, C.; Bi, E.; Zigmond, S.; Bretscher, A.; Boone, C. Role of Formins in Actin Assembly: Nucleation and Barbed-End Association. Science 2002, 297, 612-615. [CrossRef] [PubMed]

156. Kovar, D.R.; Harris, E.S.; Mahaffy, R.; Higgs, H.N.; Pollard, T.D. Control of the Assembly of ATP-and ADP-Actin by Formins and Profilin. Cell 2006, 124, 423-435. [CrossRef]

157. Sagot, I.; Rodal, A.A.; Moseley, J.B.; Goode, B.L.; Pellman, D. An actin nucleation mechanism mediated by Bni1 and Profilin. Nat. Cell Biol. 2002, 4, 626-631. [CrossRef] [PubMed]

158. Courtemanche, N. Mechanisms of formin-mediated actin assembly and dynamics. Biophys. Rev. 2018, 10, 1553-1569. [CrossRef]

159. Faix, J.; Grosse, R. Staying in Shape with Formins. Dev. Cell 2006, 10, 693-706. [CrossRef]

160. Pruyne, D. Revisiting the Phylogeny of the Animal Formins: Two New Subtypes, Relationships with Multiple Wing Hairs Proteins, and a Lost Human Formin. PLoS ONE 2016, 11, e0164067. [CrossRef]

161. Kühn, S.; Geyer, M. Formins as effector proteins of Rho GTPases. Small GTPases 2014, 5, e983876. [CrossRef] [PubMed] 
162. Rivero, F.; Muramoto, T.; Meyer, A.-K.; Urushihara, H.; Uyeda, T.Q.P.; Kitayama, C. A comparative sequence analysis reveals a common GBD/FH3-FH1-FH2-DAD architecture in formins from Dictyostelium, fungi and metazoa. BMC Genom. 2005, 6, 28. [CrossRef] [PubMed]

163. Bogdan, S.; Schultz, J.; Grosshans, J. Formin' cellular structures: Physiological Roles of Diaphanous (Dia) in Actin Dynamics. Commun. Integr. Biol. 2013, 6, e27634. [CrossRef] [PubMed]

164. Gallop, J. Filopodia and their links with membrane traffic and cell adhesion. Semin. Cell Dev. Biol. 2020, 102, 81-89. [CrossRef]

165. Goh, W.I.; Sudhaharan, T.; Lim, K.B.; Sem, K.P.; Lau, C.L.; Ahmed, S. Rif-mDia1 Interaction Is Involved in Filopodium Formation Independent of Cdc42 and Rac Effectors. J. Biol. Chem. 2011, 286, 13681-13694. [CrossRef] [PubMed]

166. Goh, W.I.; Lim, K.B.; Sudhaharan, T.; Sem, K.P.; Bu, W.; Chou, A.M.; Ahmed, S. mDia1 and WAVE2 Proteins Interact Directly with IRSp53 in Filopodia and Are Involved in Filopodium Formation. J. Biol. Chem. 2012, 287, 4702-4714. [CrossRef] [PubMed]

167. Yang, C.; Czech, L.; Gerboth, S.; Kojima, S.-I.; Scita, G.; Svitkina, T. Novel Roles of Formin mDia2 in Lamellipodia and Filopodia Formation in Motile Cells. PLoS Biol. 2007, 5, e317. [CrossRef]

168. Mellor, H. The Role of Formins in Filopodia Formation. Biochim. Biophys. Acta 2010, 1803, 191-200. [CrossRef] [PubMed]

169. Alberts, A.S.; Bouquin, N.; Johnston, L.H.; Treisman, R. Analysis of RhoA-binding Proteins Reveals an Interaction Domain Conserved in Heterotrimeric G Protein $\beta$ Subunits and the Yeast Response Regulator Protein Skn7. J. Biol. Chem. 1998, 273, 8616-8622. [CrossRef] [PubMed]

170. Peng, J.; Wallar, B.J.; Flanders, A.; Swiatek, P.J.; Alberts, A.S. Disruption of the Diaphanous-Related Formin Drf1 Gene Encoding mDia1 Reveals a Role for Drf3 as an Effector for Cdc42. Curr. Biol. 2003, 13, 534-545. [CrossRef]

171. Ellis, S.; Mellor, H. The novel Rho-family GTPase Rif regulates coordinated actin-based membrane rearrangements. Curr. Biol. 2000, 10, 1387-1390. [CrossRef]

172. Pellegrin, S.; Mellor, H. The Rho Family GTPase Rif Induces Filopodia through mDia2. Curr. Biol. 2005, 15, 129-133. [CrossRef] [PubMed]

173. Cai, L.; Marshall, T.W.; Uetrecht, A.C.; Schafer, D.A.; Bear, J.E. Coronin 1B Coordinates Arp2/3 Complex and Cofilin Activities at the Leading Edge. Cell 2007, 128, 915-929. [CrossRef] [PubMed]

174. Cai, L.; Makhov, A.M.; Schafer, D.A.; Bear, J.E. Coronin 1B Antagonizes Cortactin and Remodels Arp2/3-Containing Actin Branches in Lamellipodia. Cell 2008, 134, 828-842. [CrossRef]

175. Chan, K.T.; Creed, S.J.; Bear, J.E. Unraveling the enigma: Progress towards understanding the coronin family of actin regulators. Trends Cell Biol. 2011, 21, 481-488. [CrossRef] [PubMed]

176. De Hostos, E.; Bradtke, B.; Lottspeich, F.; Guggenheim, R.; Gerisch, G. Coronin, an actin binding protein of Dictyostelium discoideum localized to cell surface projections, has sequence similarities to $G$ protein beta subunits. EMBO J. 1991, 10, 4097-4104. [CrossRef]

177. Shina, M.C.; Ünal, C.; Eichinger, L.; Müller-Taubenberger, A.; Schleicher, M.; Steinert, M.; Noegel, A.A. A Coronin7 Homolog with Functions in Actin-driven Processes. J. Biol. Chem. 2010, 285, 9249-9261. [CrossRef] [PubMed]

178. De Hostos, E.L.; Rehfuess, C.; Bradtke, B.; Waddell, D.R.; Albrecht, R.; Murphy, J.; Gerisch, G. Dictyostelium mutants lacking the cytoskeletal protein coronin are defective in cytokinesis and cell motility. J. Cell Biol. 1993, 120, 163-173. [CrossRef] [PubMed]

179. Maniak, M.; Rauchenberger, R.; Albrecht, R.; Murphy, J.; Gerisch, G. Coronin involved in phagocytosis: Dynamics of particleinduced relocalization visualized by a green fluorescent protein tag. Cell 1995, 83, 915-924. [CrossRef]

180. Shina, M.C.; Müller-Taubenberger, A.; Unal, C.; Schleicher, M.; Steinert, M.; Eichinger, L.; Müller, R.; Blau-Wasser, R.; Glöckner, G.; Noegel, A.A. Redundant and unique roles of coronin proteins in Dictyostelium. Cell. Mol. Life Sci. 2010, 68, 303-313. [CrossRef] [PubMed]

181. Vinet, A.F.; Fiedler, T.; Studer, V.; Froquet, R.; Dardel, A.; Cosson, P.; Pieters, J. Initiation of multicellular differentiation in Dictyostelium discoideum is regulated by coronin A. Mol. Biol. Cell 2014, 25, 688-701. [CrossRef] [PubMed]

182. Xavier, C.-P.; Eichinger, L.; Fernandez, M.P.; Morgan, R.O.; Clemen, C.S. Evolutionary and Functional Diversity of Coronin Proteins. Subcell. Biochem. 2008, 48, 98-109. [CrossRef]

183. Williamson, R.C.; Cowell, C.A.M.; Hammond, C.L.; Bergen, D.J.M.; Roper, J.A.; Feng, Y.; Rendall, T.; Race, P.R.; Bass, M.D. Coronin-1C and RCC2 guide mesenchymal migration by trafficking Rac1 and controlling GEF exposure. J. Cell Sci. 2014, 127, 4292-4307. [CrossRef]

184. Ojeda, V.; Castro-Castro, A.; Bustelo, X.R. Coronin1 Proteins Dictate Rac1 Intracellular Dynamics and Cytoskeletal Output. Mol. Cell. Biol. 2014, 34, 3388-3406. [CrossRef]

185. Castro-Castro, A.; Ojeda, V.; Barreira, M.; Sauzeau, V.; Navarro-Lérida, I.; Muriel, O.; Couceiro, J.R.; Pimentel-Muíños, F.X.; Del Pozo, M.A.; Bustelo, X.R. Coronin 1A promotes a cytoskeletal-based feedback loop that facilitates Rac1 translocation and activation. EMBO J. 2011, 30, 3913-3927. [CrossRef] [PubMed]

186. Bhattacharya, K.; Swaminathan, K.; Peche, V.S.; Clemen, C.S.; Knyphausen, P.; Lammers, M.; Noegel, A.A.; Rastetter, R.H. Novel Coronin7 interactions with Cdc42 and N-WASP regulate actin organization and Golgi morphology. Sci. Rep. 2016, 6, 25411. [CrossRef]

187. Rybakin, V.; Stumpf, M.; Schulze, A.; Majoul, I.V.; Noegel, A.A.; Hasse, A. Coronin 7, the mammalian POD-1 homologue, localizes to the Golgi apparatus. FEBS Lett. 2004, 573, 161-167. [CrossRef] [PubMed]

188. Rybakin, V.; Gounko, N.; Späte, K.; Höning, S.; Majoul, I.V.; Duden, R.; Noegel, A.A. Crn7 Interacts with AP-1 and Is Required for the Maintenance of Golgi Morphology and Protein Export from the Golgi. J. Biol. Chem. 2006, 281, 31070-31078. [CrossRef]

189. Bokoch, G.M. Biology of the p21-Activated Kinases. Annu. Rev. Biochem. 2003, 72, 743-781. [CrossRef] 
190. Kumar, A.; Molli, P.R.; Pakala, S.B.; Nguyen, T.M.B.; Rayala, S.; Kumar, R. PAK thread from amoeba to mammals. J. Cell. Biochem. 2009, 107, 579-585. [CrossRef] [PubMed]

191. Szczepanowska, J. Involvement of Rac/Cdc42/PAK pathway in cytoskeletal rearrangements. Acta Biochim. Pol. 2009, 56, 225-234. [CrossRef]

192. Rane, C.K.; Minden, A. P21 activated kinases: Structure, Regulation, and Functions. Small GTPases 2014, 5, e28003. [CrossRef] [PubMed]

193. Li, Z.; Hannigan, M.; Mo, Z.; Liu, B.; Lu, W.; Wu, Y.; Smrcka, A.V.; Wu, G.; Li, L.; Liu, M.; et al. Directional Sensing Requires G Beta Gamma-Mediated PAK1 and PIX Alpha-Dependent Activation of Cdc42. Cell 2003, 114, 215-227. [CrossRef]

194. Sells, M.A.; Knaus, U.G.; Bagrodia, S.; Ambrose, D.M.; Bokoch, G.M.; Chernoff, J. Human p21-activated kinase (Pak1) regulates actin organization in mammalian cells. Curr. Biol. 1997, 7, 202-210. [CrossRef]

195. Goeckeler, Z.M.; Masaracchia, R.A.; Zeng, Q.; Chew, T.-L.; Gallagher, P.; Wysolmerski, R.B. Phosphorylation of Myosin Light Chain Kinase by p21-activated Kinase PAK2. J. Biol. Chem. 2000, 275, 18366-18374. [CrossRef] [PubMed]

196. Sanders, L.C.; Matsumura, F.; Bokoch, G.M.; De Lanerolle, P. Inhibition of Myosin Light Chain Kinase by p21-Activated Kinase. Science 1999, 283, 2083-2085. [CrossRef] [PubMed]

197. DerMardirossian, C.; Schnelzer, A.; Bokoch, G.M. Phosphorylation of RhoGDI by Pak1 Mediates Dissociation of Rac GTPase. Mol. Cell 2004, 15, 117-127. [CrossRef]

198. Shin, E.-Y.; Shim, E.-S.; Lee, C.-S.; Kim, H.K.; Kim, E.-G. Phosphorylation of RhoGDI1 by p21-activated kinase 2 mediates basic fibroblast growth factor-stimulated neurite outgrowth in PC12 cells. Biochem. Biophys. Res. Commun. 2009, 379, 384-389. [CrossRef]

199. Hashimoto, S.; Tsubouchi, A.; Mazaki, Y.; Sabe, H. Interaction of Paxillin with P21-Activated Kinase (PAK). Association of Paxillin Alpha with the Kinase-Inactive and the Cdc42-Activated Forms of PAK3. J. Biol. Chem. 2001, 276, 6037-6045. [CrossRef]

200. Abo, A.; Qu, J.; Cammarano, M.S.; Dan, C.; Fritsch, A.; Baud, V.; Belisle, B.; Minden, A. PAK4, a novel effector for Cdc42Hs, is implicated in the reorganization of the actin cytoskeleton and in the formation of filopodia. EMBO J. 1998, 17, 6527-6540. [CrossRef]

201. Chung, C.Y.; Firtel, R.A. Paka, a Putative Pak Family Member, Is Required for Cytokinesis and the Regulation of the Cytoskeleton in Dictyostelium discoideum Cells during Chemotaxis. J. Cell Biol. 1999, 147, 559-576. [CrossRef]

202. Tang, M.; Iijima, M.; Kamimura, Y.; Chen, L.; Long, Y.; Devreotes, P. Disruption of PKB signaling restores polarity to cells lacking tumor suppressor PTEN. Mol. Biol. Cell 2011, 22, 437-447. [CrossRef]

203. Müller-Taubenberger, A.; Bretschneider, T.; Faix, J.; Konzok, A.; Simmeth, E.; Weber, I. Differential localization of the Dictyostelium kinase DPAKa during cytokinesis and cell migration. J. Muscle Res. Cell Motil. 2002, 23, 751-763. [CrossRef]

204. Li, M.; Quan, C.; Chen, S.; Wang, H.Y. The 14-3-3 protein is an essential component of cyclic AMP signaling for regulation of chemotaxis and development in Dictyostelium. Cell. Signal. 2020, 75, 109739. [CrossRef]

205. Chung, C.Y.; Potikyan, G.; Firtel, R.A. Control of Cell Polarity and Chemotaxis by Akt/PKB and PI3 Kinase through the Regulation of PAKa. Mol. Cell 2001, 7, 937-947. [CrossRef]

206. De la Roche, M.A.; Côté, G.P. Regulation of Dictyostelium Myosin I and II. Biochim. Biophys. Acta (BBA) Gen. Subj. 2001, 1525, 245-261. [CrossRef]

207. Lee, S.-F.; Té, G.P.C. Purification and Characterization of a Dictyostelium Protein Kinase Required for Actin Activation of the $\mathrm{Mg}^{2+}$ ATPase Activity of Dictyostelium Myosin ID. J. Biol. Chem. 1995, 270, 11776-11782. [CrossRef] [PubMed]

208. Dieckmann, R.; Von Heyden, Y.; Kistler, C.; Gopaldass, N.A.; Hausherr, S.; Crawley, S.W.; Schwarz, E.C.; Diensthuber, R.P.; Côté, G.P.; Tsiavaliaris, G.; et al. A Myosin IK-Abp1-PakB Circuit Acts as a Switch to Regulate Phagocytosis Efficiency. Mol. Biol. Cell 2010, 21, 1505-1518. [CrossRef] [PubMed]

209. Yang, Y.; De La Roche, M.; Crawley, S.W.; Li, Z.; Furmaniak-Kazmierczak, E.; Côté, G.P. PakB binds to the SH3 domain of Dictyostelium Abp1 and regulates its effects on cell polarity and early development. Mol. Biol. Cell 2013, 24, 2216-2227. [CrossRef]

210. Lee, S.-F.; Egelhoff, T.T.; Mahasneh, A.; Côté, G.P. Cloning and Characterization of a Dictyostelium Myosin I Heavy Chain Kinase Activated by Cdc42 and Rac. J. Biol. Chem. 1996, 271, 27044-27048. [CrossRef]

211. Lee, S.-F.; Mahasneh, A.; de la Roche, M.; Côté, G.P. Regulation of the p21-activated Kinase-relatedDictyostelium Myosin I Heavy Chain Kinase by Autophosphorylation, Acidic Phospholipids, and Ca ${ }^{2+}$-Calmodulin. J. Biol. Chem. 1998, 273, 27911-27917. [CrossRef]

212. Phillips, J.E.; Gomer, R.H. The p21-Activated Kinase (PAK) Family Member PakD Is Required for Chemorepulsion and Proliferation Inhibition by Autocrine Signals in Dictyostelium discoideum. PLoS ONE 2014, 9, e96633. [CrossRef]

213. Garcia, M.; Ray, S.; Brown, I.; Irom, J.; Brazill, D. PakD, a Putative p21-Activated Protein Kinase in Dictyostelium discoideum, Regulates Actin. Eukaryot. Cell 2013, 13, 119-126. [CrossRef]

214. Suess, P.M.; Gomer, R.H. Extracellular Polyphosphate Inhibits Proliferation in an Autocrine Negative Feedback Loop in Dictyostelium discoideum. J. Biol. Chem. 2016, 291, 20260-20269. [CrossRef]

215. Suess, P.M.; Watson, J.; Chen, W.; Gomer, R.H. Extracellular polyphosphate signals through Ras and Akt to prime Dictyostelium discoideum cells for development. J. Cell Sci. 2017, 130, 2394-2404. [CrossRef] [PubMed]

216. Brill, S.; Li, S.; Lyman, C.W.; Church, D.M.; Wasmuth, J.J.; Weissbach, L.; Bernards, A.; Snijders, A.J. The Ras GTPase-activatingprotein-related human protein IQGAP2 harbors a potential actin binding domain and interacts with calmodulin and Rho family GTPases. Mol. Cell. Biol. 1996, 16, 4869-4878. [CrossRef] 
217. Hart, M.J.; Callow, M.G.; Souza, B.; Polakis, P. IQGAP1, a Calmodulin-Binding Protein with a RasGAP-Related Domain, Is a Potential Effector for Cdc42Hs. EMBO J. 1996, 15, 2997-3005. [CrossRef]

218. Kuroda, S.; Fukata, M.; Kobayashi, K.; Nakafuku, M.; Nomura, N.; Iwamatsu, A.; Kaibuchi, K. Identification of IQGAP as a Putative Target for the Small GTPases, Cdc42 and Rac1. J. Biol. Chem. 1996, 271, 23363-23367. [CrossRef] [PubMed]

219. McCallum, S.J.; Wu, W.J.; Cerione, R.A. Identification of a Putative Effector for Cdc42Hs with High Sequence Similarity to the RasGAP-related Protein IQGAP1 and a Cdc42Hs Binding Partner with Similarity to IQGAP2. J. Biol. Chem. 1996, 271, 21732-21737. [CrossRef] [PubMed]

220. Weissbach, L.; Settleman, J.; Kalady, M.F.; Snijders, A.J.; Murthy, A.E.; Yan, Y.X.; Bernards, A. Identification of a Human RasGAP-Related Protein Containing Calmodulin-Binding Motifs. J. Biol. Chem. 1994, 269, 20517-20521. [CrossRef]

221. Wang, S.; Watanabe, T.; Noritake, J.; Fukata, M.; Yoshimura, T.; Itoh, N.; Harada, T.; Nakagawa, M.; Matsuura, Y.; Arimura, N.; et al. IQGAP3, a novel effector of Rac1 and Cdc42, regulates neurite outgrowth. J. Cell Sci. 2007, 120, 567-577. [CrossRef] [PubMed]

222. Hedman, A.C.; Smith, J.M.; Sacks, D.B. The biology of IQGAP proteins: Beyond the cytoskeleton. EMBO Rep. 2015, 16, 427-446. [CrossRef]

223. White, C.D.; Erdemir, H.H.; Sacks, D.B. IQGAP1 and its binding proteins control diverse biological functions. Cell. Signal. 2012, 24, 826-834. [CrossRef]

224. Bashour, A.-M.; Fullerton, A.T.; Hart, M.J.; Bloom, G.S. IQGAP1, a Rac- and Cdc42-binding Protein, Directly Binds and Cross-links Microfilaments. J. Cell Biol. 1997, 137, 1555-1566. [CrossRef] [PubMed]

225. Erickson, J.W.; Cerione, R.A.; Hart, M.J. Identification of an Actin Cytoskeletal Complex That Includes IQGAP and the Cdc42 GTPase. J. Biol. Chem. 1997, 272, 24443-24447. [CrossRef] [PubMed]

226. Fukata, M.; Kuroda, S.; Fujii, K.; Nakamura, T.; Shoji, I.; Matsuura, Y.; Okawa, K.; Iwamatsu, A.; Kikuchi, A.; Kaibuchi, K. Regulation of Cross-linking of Actin Filament by IQGAP1, a Target for Cdc42. J. Biol. Chem. 1997, 272, 29579-29583. [CrossRef]

227. Roy, M.; Li, Z.; Sacks, D.B. IQGAP1 Binds ERK2 and Modulates Its Activity. J. Biol. Chem. 2004, 279, 17329-17337. [CrossRef]

228. Roy, M.; Li, Z.; Sacks, D.B. IQGAP1 Is a Scaffold for Mitogen-Activated Protein Kinase Signaling. Mol. Cell. Biol. 2005, 25, 7940-7952. [CrossRef] [PubMed]

229. Ho, Y.-D.; Joyal, J.L.; Li, Z.; Sacks, D.B. IQGAP1 Integrates $\mathrm{Ca}^{2+} /$ Calmodulin and Cdc42 Signaling. J. Biol. Chem. 1999, 274, 464-470. [CrossRef] [PubMed]

230. Joyal, J.L.; Annan, R.S.; Ho, Y.-D.; Huddleston, M.E.; Carr, S.A.; Hart, M.J.; Sacks, D.B. Calmodulin Modulates the Interaction between IQGAP1 and Cdc42. Identification of IQGAP1 by Nanoelectrospray Tandem Mass Spectrometry. J. Biol. Chem. 1997, 272, 15419-15425. [CrossRef]

231. Nojima, H.; Adachi, M.; Matsui, T.; Okawa, K.; Tsukita, S.; Tsukita, S. IQGAP3 regulates cell proliferation through the Ras/ERK signalling cascade. Nat. Cell Biol. 2008, 10, 971-978. [CrossRef]

232. Swart-Mataraza, J.M.; Li, Z.; Sacks, D.B. IQGAP1 Is a Component of Cdc42 Signaling to the Cytoskeleton. J. Biol. Chem. 2002, 277, 24753-24763. [CrossRef] [PubMed]

233. Fukata, M.; Watanabe, T.; Noritake, J.; Nakagawa, M.; Yamaga, M.; Kuroda, S.; Matsuura, Y.; Iwamatsu, A.; Perez, F.; Kaibuchi, K. Rac1 and Cdc42 Capture Microtubules through IQGAP1 and CLIP-170. Cell 2002, 109, 873-885. [CrossRef]

234. Kuroda, S.; Fukata, M.; Nakagawa, M.; Fujii, K.; Nakamura, T.; Ookubo, T.; Izawa, I.; Nagase, T.; Nomura, N.; Tani, H.; et al. Role of IQGAP1, a Target of the Small GTPases Cdc42 and Rac1, in Regulation of E-Cadherin- Mediated Cell-Cell Adhesion. Science 1998, 281, 832-835. [CrossRef] [PubMed]

235. Smith, J.M.; Hedman, A.C.; Sacks, D.B. IQGAPs choreograph cellular signaling from the membrane to the nucleus. Trends Cell Biol. 2015, 25, 171-184. [CrossRef] [PubMed]

236. Adachi, M.; Kawasaki, A.; Nojima, H.; Nishida, E.; Tsukita, S. Involvement of IQGAP family proteins in the regulation of mammalian cell cytokinesis. Genes Cells 2014, 19, 803-820. [CrossRef] [PubMed]

237. Brandt, D.T.; Grosse, R. Get to grips: Steering local actin dynamics with IQGAPs. EMBO Rep. 2007, 8, 1019-1023. [CrossRef] [PubMed]

238. Noritake, J.; Watanabe, T.; Sato, K.; Wang, S.; Kaibuchi, K. IQGAP1: A key regulator of adhesion and migration. J. Cell Sci. 2005, 118, 2085-2092. [CrossRef] [PubMed]

239. Watanabe, T.; Wang, S.; Kaibuchi, K. IQGAPs as key regulators of actin-cytoskeleton dynamics. Cell Struct. Funct. 2015, 40, 69-77. [CrossRef]

240. Shannon, K.B. IQGAP Family Members in Yeast, Dictyostelium, and Mammalian Cells. Int. J. Cell Biol. $2012,2012,894817$. [CrossRef]

241. Friedberg, F.; Rivero, F. Single and multiple CH (calponin homology) domain containing multidomain proteins in Dictyostelium discoideum: An inventory. Mol. Biol. Rep. 2009, 37, 2853-2862. [CrossRef] [PubMed]

242. Adachi, H.; Takahashi, Y.; Hasebe, T.; Shirouzu, M.; Yokoyama, S.; Sutoh, K. Dictyostelium IQGAP-related Protein Specifically Involved in the Completion of Cytokinesis. J. Cell Biol. 1997, 137, 891-898. [CrossRef] [PubMed]

243. Faix, J.; Clougherty, C.; Konzok, A.; Mintert, U.; Murphy, J.; Albrecht, R.; Muhlbauer, B.; Kuhlmann, J. The IQGAP-related protein DGAP1 interacts with Rac and is involved in the modulation of the F-actin cytoskeleton and control of cell motility. J. Cell Sci. 1998, 111 Pt 20, 3059-3071. [CrossRef] 
244. Kurella, V.B.; Richard, J.M.; Parke, C.L.; LeCour, L.F.; Bellamy, H.D.; Worthylake, D.K. Crystal Structure of the GTPase-activating Protein-related Domain from IQGAP1. J. Biol. Chem. 2009, 284, 14857-14865. [CrossRef] [PubMed]

245. Marinović, M.; Mijanović, L.; Šoštar, M.; Vizovišek, M.; Junemann, A.; Fonović, M.; Turk, B.; Weber, I.; Faix, J.; Filić, V. IQGAPrelated protein IqgC suppresses Ras signaling during large-scale endocytosis. Proc. Natl. Acad. Sci. USA 2019, 116, 1289-1298. [CrossRef]

246. Faix, J.; Weber, I.; Mintert, U.; Köhler, J.; Lottspeich, F.; Marriott, G. Recruitment of cortexillin into the cleavage furrow is controlled by Rac1 and IQGAP-related proteins. EMBO J. 2001, 20, 3705-3715. [CrossRef] [PubMed]

247. Mondal, S.; Burgute, B.; Rieger, D.; Müller, R.; Rivero, F.; Faix, J.; Schleicher, M.; Noegel, A.A. Regulation of the Actin Cytoskeleton by an Interaction of IQGAP Related Protein GAPA with Filamin and Cortexillin I. PLoS ONE 2010, 5, e15440. [CrossRef] [PubMed]

248. Faix, J.; Steinmetz, M.; Boves, H.; Kammerer, R.; Lottspeich, F.; Mintert, U.; Murphy, J.; Stock, A.; Aebi, U.; Gerisch, G. Cortexillins, Major Determinants of Cell Shape and Size, Are Actin-Bundling Proteins with a Parallel Coiled-Coil Tail. Cell 1996, 86, 631-642. [CrossRef]

249. Simson, R.; Wallraff, E.; Faix, J.; Niewöhner, J.; Gerisch, G.; Sackmann, E. Membrane Bending Modulus and Adhesion Energy of Wild-Type and Mutant Cells of Dictyostelium Lacking Talin or Cortexillins. Biophys. J. 1998, 74, 514-522. [CrossRef]

250. Lee, S.; Shen, Z.; Robinson, D.N.; Briggs, S.; Firtel, R.A. Involvement of the Cytoskeleton in Controlling Leading-Edge Function during Chemotaxis. Mol. Biol. Cell 2010, 21, 1810-1824. [CrossRef] [PubMed]

251. Shu, S.; Liu, X.; Kriebel, P.W.; Daniels, M.P.; Korn, E. Actin cross-linking proteins cortexillin I and II are required for cAMP signaling during Dictyostelium chemotaxis and development. Mol. Biol. Cell 2012, 23, 390-400. [CrossRef] [PubMed]

252. Dickinson, D.J.; Robinson, D.N.; Nelson, W.J.; Weis, W.I. $\alpha$-Catenin and IQGAP Regulate Myosin Localization to Control Epithelial Tube Morphogenesis in Dictyostelium. Dev. Cell 2012, 23, 533-546. [CrossRef]

253. BenseñorL, B.; Kan, H.-M.; Wang, N.; Wallrabe, H.; Davidson, L.A.; Cai, Y.; Schafer, D.A.; Bloom, G.S. IQGAP1 regulates cell motility by linking growth factor signaling to actin assembly. J. Cell Sci. 2007, 120, 658-669. [CrossRef]

254. Brandt, D.T.; Marion, S.; Griffiths, G.; Watanabe, T.; Kaibuchi, K.; Grosse, R. Dia1 and IQGAP1 interact in cell migration and phagocytic cup formation. J. Cell Biol. 2007, 178, 193-200. [CrossRef]

255. Le Clainche, C.; Schlaepfer, D.; Ferrari, A.; Klingauf, M.; Grohmanova, K.; Veligodskiy, A.; Didry, D.; Le, D.; Egile, C.; Carlier, M.-F.; et al. IQGAP1 Stimulates Actin Assembly through the N-Wasp-Arp2/3 Pathway. J. Biol. Chem. 2007, 282, 426-435. [CrossRef] [PubMed]

256. Sethi, K.; Cram, E.J.; Zaidel-Bar, R. Stretch-induced actomyosin contraction in epithelial tubes: Mechanotransduction pathways for tubular homeostasis. Semin. Cell Dev. Biol. 2017, 71, 146-152. [CrossRef]

257. Bañón-Rodríguez, I.; Gálvez-Santisteban, M.; Vergarajauregui, S.; Bosch, M.; Borreguero-Pascual, A.; Martín-Belmonte, F. EGFR controls IQGAP basolateral membrane localization and mitotic spindle orientation during epithelial morphogenesis. $E M B O J$. 2014, 33, 129-145. [CrossRef]

258. Nakamura, F.; Stossel, T.P.; Hartwig, J.H. The filamins. Cell Adhes. Migr. 2011, 5, 160-169. [CrossRef]

259. Stossel, T.P.; Condeelis, J.; Cooley, L.; Hartwig, J.H.; Noegel, A.; Schleicher, M.; Shapiro, S.S. Filamins as integrators of cell mechanics and signalling. Nat. Rev. Mol. Cell Biol. 2001, 2, 138-145. [CrossRef]

260. Popowicz, G.M.; Schleicher, M.; Noegel, A.A.; Holak, T.A. Filamins: Promiscuous Organizers of the Cytoskeleton. Trends Biochem. Sci. 2006, 31, 411-419. [CrossRef]

261. Cox, D.; Condeelis, J.; Wessels, D.; Soll, D.; Kern, H.; Knecht, D. Targeted disruption of the ABP-120 gene leads to cells with altered motility. J. Cell Biol. 1992, 116, 943-955. [CrossRef]

262. Cox, D.; Ridsdale, J.A.; Condeelis, J.; Hartwig, J. Genetic deletion of ABP-120 alters the three-dimensional organization of actin filaments in Dictyostelium pseudopods. J. Cell Biol. 1995, 128, 819-835. [CrossRef] [PubMed]

263. Cox, D.; Wessels, D.; Soll, D.R.; Hartwig, J.; Condeelis, J. Re-expression of ABP-120 rescues cytoskeletal, motility, and phagocytosis defects of ABP-120- Dictyostelium mutants. Mol. Biol. Cell 1996, 7, 803-823. [CrossRef] [PubMed]

264. Fisher, P.; Noegel, A.; Fechheimer, M.; Rivero, F.; Prassler, J.; Gerisch, G. Photosensory and thermosensory responses in Dictyostelium slugs are specifically impaired by absence of the F-actin cross-linking gelation factor (ABP-120). Curr. Biol. 1997, 7, 889-892. [CrossRef]

265. Del Valle-Pérez, B.; Martínez, V.G.; Lacasa-Salavert, C.; Figueras, A.; Shapiro, S.S.; Takafuta, T.; Casanovas, O.; Capella, G.; Ventura, F.; Viñals, F. Filamin B Plays a Key Role in Vascular Endothelial Growth Factor-induced Endothelial Cell Motility through Its Interaction with Rac-1 and Vav-2. J. Biol. Chem. 2010, 285, 10748-10760. [CrossRef]

266. Jacquemet, G.; Morgan, M.R.; Byron, A.; Humphries, J.D.; Choi, C.K.; Chen, C.; Caswell, P.T.; Humphries, M.J. Rac1 is deactivated at integrin activation sites via an IQGAP1/filamin-A/RacGAP1 pathway. J. Cell Sci. 2013, 126, 4121-4135. [CrossRef] [PubMed]

267. Jeon, Y.J.; Choi, J.S.; Lee, J.Y.; Yu, K.R.; Ka, S.H.; Cho, Y.; Choi, E.-J.; Baek, S.H.; Seol, J.H.; Park, D.; et al. Filamin B Serves as a Molecular Scaffold for Type I Interferon-induced c-Jun NH2-terminal Kinase Signaling Pathway. Mol. Biol. Cell 2008, 19, 5116-5130. [CrossRef] [PubMed]

268. Shifrin, Y.; Pinto, V.I.; Hassanali, A.; Arora, P.D.; McCulloch, C.A. Force-induced apoptosis mediated by the Rac/Pak/p38 signalling pathway is regulated by filamin A. Biochem. J. 2012, 445, 57-67. [CrossRef] [PubMed]

269. Rivero, F.; Albrecht, R.; Dislich, H.; Bracco, E.; Graciotti, L.; Bozzaro, S.; Noegel, A.A. RacF1, a Novel Member of the Rho Protein Family in Dictyostelium discoideum, Associates Transiently with Cell Contact Areas, Macropinosomes, and Phagosomes. Mol. Biol. Cell 1999, 10, 1205-1219. [CrossRef] 
270. Lee, E.; Seastone, D.J.; Harris, E.; Cardelli, J.A.; Knecht, D.A. RacB Regulates Cytoskeletal Function in Dictyostelium spp. Eukaryot. Cell 2003, 2, 474-485. [CrossRef] [PubMed]

271. Pang, K.M.; Dingermann, T.; Knecht, D.A. Regulated expression of myosin II heavy chain and RacB using an inducible tRNA suppressor gene. Gene 2001, 277, 187-197. [CrossRef]

272. Rivero, F.; Dislich, H.; Glöckner, G.; Noegel, A.A. The Dictyostelium discoideum family of Rho-related proteins. Nucleic Acids Res. 2001, 29, 1068-1079. [CrossRef]

273. Berthold, J.; Schenková, K.; Rivero, F. Rho GTPases of the RhoBTB subfamily and tumorigenesis. Acta Pharmacol. Sin. 2008, 29, 285-295. [CrossRef]

274. Ji, W.; Rivero, F. Atypical Rho GTPases of the RhoBTB Subfamily: Roles in Vesicle Trafficking and Tumorigenesis. Cells 2016, 5, 28. [CrossRef]

275. Aravind, L.; Koonin, E.V. Fold prediction and evolutionary analysis of the POZ domain: Structural and evolutionary relationship with the potassium channel tetramerization domain 1 1Edited by F. Cohen. J. Mol. Biol. 1999, 285, 1353-1361. [CrossRef]

276. Xu, L.; Wei, Y.; Reboul, J.; Vaglio, P.; Shin, T.-H.; Vidal, M.; Elledge, S.J.; Harper, J. BTB proteins are substrate-specific adaptors in an SCF-like modular ubiquitin ligase containing CUL-3. Nature 2003, 425, 316-321. [CrossRef] [PubMed]

277. Bridges, E.; Sheldon, H.; Kleibeuker, E.; Ramberger, E.; Zois, C.; Barnard, A.; Harjes, U.; Li, J.-L.; Masiero, M.; MacLaren, R.; et al. RHOQ is induced by DLL4 and regulates angiogenesis by determining the intracellular route of the Notch intracellular domain. Angiogenesis 2020, 23, 493-513. [CrossRef]

278. Hodge, R.G.; Ridley, A.J. Regulation and functions of RhoU and RhoV. Small GTPases 2017, 11, 8-15. [CrossRef]

279. Leszczynska, K.; Kaur, S.; Wilson, E.; Bicknell, R.; Heath, V.L. The role of RhoJ in endothelial cell biology and angiogenesis. Biochem. Soc. Trans. 2011, 39, 1606-1611. [CrossRef]

280. Nobes, C.D.; Hall, A. Rho, Rac, and Cdc42 GTPases regulate the assembly of multimolecular focal complexes associated with actin stress fibers, lamellipodia, and filopodia. Cell 1995, 81, 53-62. [CrossRef]

281. Etienne-Manneville, S. Cdc42-The centre of polarity. J. Cell Sci. 2004, 117, 1291-1300. [CrossRef] [PubMed]

282. Pichaud, F.; Walther, R.F.; de Almeida, F.N. Regulation of Cdc42 and its effectors in epithelial morphogenesis. J. Cell Sci. 2019, 132, jcs217869. [CrossRef] [PubMed]

283. Xiao, X.-H.; Lv, L.-C.; Duan, J.; Wu, Y.-M.; He, S.-J.; Hu, Z.-Z.; Xiong, L.-X. Regulating Cdc42 and Its Signaling Pathways in Cancer: Small Molecules and MicroRNA as New Treatment Candidates. Molcules 2018, 23, 787. [CrossRef] [PubMed]

284. Zhao, Z.; Manser, E. Myotonic dystrophy kinase-related Cdc42-binding kinases (MRCK), the ROCK-like effectors of Cdc42 and Rac1. Small GTPases 2015, 6, 81-88. [CrossRef] [PubMed]

285. Etienne-Manneville, S.; Hall, A. Integrin-Mediated Activation of Cdc42 Controls Cell Polarity in Migrating Astrocytes through

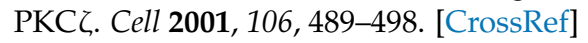

286. Etienne-Manneville, S.; Hall, A. Cdc42 regulates GSK-3 $\beta$ and adenomatous polyposis coli to control cell polarity. Nature 2003, 421, 753-756. [CrossRef]

287. LaRochelle, D.A.; Vithalani, K.K.; De Lozanne, A. Role of Dictyostelium racE in cytokinesis: Mutational analysis and localization studies by use of green fluorescent protein. Mol. Biol. Cell 1997, 8, 935-944. [CrossRef] [PubMed]

288. Seastone, D.J.; Lee, E.; Bush, J.; Knecht, D.; Cardelli, J. Overexpression of a Novel Rho Family GTPase, RacC, Induces Unusual Actin-based Structures and Positively Affects Phagocytosis in Dictyostelium discoideum. Mol. Biol. Cell 1998, 9, $2891-2904$. [CrossRef]

289. Erickson, J.W.; Zhang, C.-J.; Kahn, R.A.; Evans, T.; Cerione, R.A. Mammalian Cdc42 Is a Brefeldin A-sensitive Component of the Golgi Apparatus. J. Biol. Chem. 1996, 271, 26850-26854. [CrossRef] [PubMed]

290. Yang, L.; Wang, L.; Zheng, Y. Gene Targeting of Cdc42 and Cdc42GAP Affirms the Critical Involvement of Cdc42 in Filopodia Induction, Directed Migration, and Proliferation in Primary Mouse Embryonic Fibroblasts. Mol. Biol. Cell 2006, 17, 4675-4685. [CrossRef]

291. Chernichenko, N.; Omelchenko, T.; Deborde, S.; Bakst, R.L.; He, S.; Chen, C.-H.; Gusain, L.; Vakiani, E.; Katabi, N.; Hall, A.; et al. Cdc42 Mediates Cancer Cell Chemotaxis in Perineural Invasion. Mol. Cancer Res. 2020, 18, 913-925. [CrossRef] [PubMed]

292. Watson, J.; Owen, D.; Mott, H.R. Cdc42 in actin dynamics: An ordered pathway governed by complex equilibria and directional effector handover. Small GTPases 2017, 8, 237-244. [CrossRef]

293. Jeon, P.; Jeon, T.J. WasC, a WASP family protein, is involved in cell adhesion and migration through regulation of F-actin polymerization in Dictyostelium. J. Microbiol. 2020, 58, 696-702. [CrossRef]

294. Kriebel, P.W.; Barr, V.A.; Parent, C.A. Adenylyl Cyclase Localization Regulates Streaming during Chemotaxis. Cell 2003, 112, 549-560. [CrossRef]

295. Saran, S.; Meima, M.E.; Alvarez-Curto, E.; Weening, K.E.; Rozen, D.; Schaap, P. cAMP signaling in Dictyostelium. Complexity of CAMP Synthesis, Degradation and Detection. J. Muscle Res. Cell Motil. 2002, 23, 793-802. [CrossRef] [PubMed]

296. Harris, K.P.; Tepass, U. Cdc42 and Vesicle Trafficking in Polarized Cells. Traffic 2010, 11, 1272-1279. [CrossRef] [PubMed]

297. Luna, A.; Matas, O.B.; Martínez-Menárguez, J.A.; Mato, E.; Durán, J.M.; Ballesta, J.; Way, M.; Egea, G. Regulation of Protein Transport from the Golgi Complex to the Endoplasmic Reticulum by CDC42 and N-WASP. Mol. Biol. Cell 2002, 13, 866-879. [CrossRef]

298. Phillips, J.E.; Gomer, R.H. A secreted protein is an endogenous chemorepellant in Dictyostelium discoideum. Proc. Natl. Acad. Sci. USA 2012, 109, 10990-10995. [CrossRef] [PubMed] 
299. Rijal, R.; Consalvo, K.M.; Lindsey, C.K.; Gomer, R.H. An endogenous chemorepellent directs cell movement by inhibiting pseudopods at one side of cells. Mol. Biol. Cell 2019, 30, 242-255. [CrossRef]

300. Okuwa, T.; Morio, T.; Saito, T.; Masamune, Y.; Yasukawa, H. Complete Sequences and Expression Kinetics of racG, racH, racI and racJ Genes in Dictyostelium discoideum. Biol. Pharm. Bull. 2001, 24, 84-87. [CrossRef]

301. Somesh, B.P.; Neffgen, C.; Iijima, M.; Devreotes, P.; Rivero, F. Dictyostelium RacH regulates endocytic vesicular trafficking and is required for localization of vacuolin. Traffic 2006, 7, 1194-1212. [CrossRef]

302. Balest, A.; Peracino, B.; Bozzaro, S. Legionella pneumophila infection is enhanced in a RacH-null mutant of Dictyostelium. Commun. Integr. Biol. 2011, 4, 194-197. [CrossRef]

303. Hagedorn, M.; Soldati, T. Flotillin and RacH modulate the intracellular immunity of Dictyostelium to Mycobacterium marinum infection. Cell. Microbiol. 2007, 9, 2984. [CrossRef]

304. Hagedorn, M.; Rohde, K.H.; Russell, D.G.; Soldati, T. Infection by Tubercular Mycobacteria Is Spread by Nonlytic Ejection from Their Amoeba Hosts. Science 2009, 323, 1729-1733. [CrossRef]

305. Humphries, A.C.; Donnelly, S.K.; Way, M. Cdc42 and the RhoGEF Intersectin-1 collaborate with Nck to promote N-WASPdependent actin polymerisation. J. Cell Sci. 2014, 127, 673-685. [CrossRef]

306. Gouin, E.; Welch, M.D.; Cossart, P. Actin-based motility of intracellular pathogens. Curr. Opin. Microbiol. 2005, 8, 35-45. [CrossRef]

307. Gerald, N.; Dai, J.; Ting-Beall, H.P.; De Lozanne, A. A Role for Dictyostelium RacE in Cortical Tension and Cleavage Furrow Progression. J. Cell Biol. 1998, 141, 483-492. [CrossRef]

308. Robinson, D.N.; Spudich, J.A. Dynacortin, a Genetic Link between Equatorial Contractility and Global Shape Control Discovered by Library Complementation of a Dictyostelium discoideum Cytokinesis Mutant. J. Cell Biol. 2000, 150, 823-838. [CrossRef]

309. West-Foyle, H.; Kothari, P.; Osborne, J.; Robinson, D.N. 14-3-3 proteins tune non-muscle myosin II assembly. J. Biol. Chem. 2018, 293, 6751-6761. [CrossRef] [PubMed]

310. Zhou, Q.; Kee, Y.-S.; Poirier, C.C.; Jelinek, C.; Osborne, J.; Divi, S.; Surcel, A.; Will, M.E.; Eggert, U.S.; Müller-Taubenberger, A.; et al. 14-3-3 Coordinates Microtubules, Rac, and Myosin II to Control Cell Mechanics and Cytokinesis. Curr. Biol. 2010, 20, 1881-1889. [CrossRef] [PubMed]

311. Kee, Y.-S.; Ren, Y.; Dorfman, D.; Iijima, M.; Firtel, R.; Iglesias, P.A.; Robinson, D.N. A mechanosensory system governs myosin II accumulation in dividing cells. Mol. Biol. Cell 2012, 23, 1510-1523. [CrossRef]

312. Ramalingam, N.; Franke, C.; Jaschinski, E.; Winterhoff, M.; Lü, Y.; Brühmann, S.; Junemann, A.; Meier, H.; Noegel, A.A.; Weber, I.; et al. A resilient formin-derived cortical actin meshwork in the rear drives actomyosin-based motility in 2D confinement. Nat. Commun. 2015, 6, 8496. [CrossRef] [PubMed]

313. Litschko, C.; Brühmann, S.; Csiszár, A.; Stephan, T.; Dimchev, V.; Damiano-Guercio, J.; Junemann, A.; Körber, S.; Winterhoff, M.; Nordholz, B.; et al. Functional integrity of the contractile actin cortex is safeguarded by multiple Diaphanous-related formins. Proc. Natl. Acad. Sci. USA 2019, 116, 3594-3603. [CrossRef] [PubMed]

314. Senoo, H.; Cai, H.; Wang, Y.; Sesaki, H.; Iijima, M. The novel RacE-binding protein GflB sharpens Ras activity at the leading edge of migrating cells. Mol. Biol. Cell 2016, 27, 1596-1605. [CrossRef]

315. Senoo, H.; Kamimura, Y.; Kimura, R.; Nakajima, A.; Sawai, S.; Sesaki, H.; Iijima, M. Phosphorylated Rho-GDP directly activates mTORC2 kinase towards AKT through dimerization with Ras-GTP to regulate cell migration. Nature 2019, 21, 867-878. [CrossRef]

316. Hoxhaj, G.; Manning, B.D. The PI3K-AKT network at the interface of oncogenic signalling and cancer metabolism. Nat. Rev. Cancer 2019, 20, 74-88. [CrossRef]

317. Laplante, M.; Sabatini, D.M. mTOR signaling at a glance. J. Cell Sci. 2009, 122, 3589-3594. [CrossRef]

318. Senoo, H.; Wai, M.; Matsubayashi, H.T.; Sesaki, H.; Iijima, M. Hetero-oligomerization of Rho and Ras GTPases Connects GPCR Activation to mTORC2-AKT Signaling. Cell Rep. 2020, 33, 108427. [CrossRef]

319. Lammers, M.; Meyer, S.; Kühlmann, D.; Wittinghofer, A. Specificity of Interactions between mDia Isoforms and Rho Proteins. J. Biol. Chem. 2008, 283, 35236-35246. [CrossRef]

320. Maiti, S.; Michelot, A.; Gould, C.; Blanchoin, L.; Sokolova, O.; Goode, B.L. Structure and activity of full-length formin mDia1. Cytoskeleton 2012, 69, 393-405. [CrossRef] [PubMed]

321. Sakamoto, S.; Thumkeo, D.; Ohta, H.; Zhang, Z.; Huang, S.; Kanchanawong, P.; Fuu, T.; Watanabe, S.; Shimada, K.; Fujihara, Y.; et al. mDia1/3 generate cortical F-actin meshwork in Sertoli cells that is continuous with contractile F-actin bundles and indispensable for spermatogenesis and male fertility. PLoS Biol. 2018, 16, e2004874. [CrossRef] [PubMed]

322. Chen, A.; Arora, P.D.; Lai, C.C.; Copeland, J.W.; Moraes, T.F.; McCulloch, C.A.; Lavoie, B.D.; Wilde, A. The scaffold-protein IQGAP1 enhances and spatially restricts the actin-nucleating activity of Diaphanous-related formin 1 (DIAPH1). J. Biol. Chem. 2020, 295, 3134-3147. [CrossRef]

323. Brandwein, D.; Wang, Z. Interaction between Rho GTPases and 14-3-3 Proteins. Int. J. Mol. Sci. 2017, 18, 2148. [CrossRef] [PubMed]

324. Abdrabou, A.; Brandwein, D.; Liu, C.; Wang, Z. Rac1 S71 Mediates the Interaction between Rac1 and 14-3-3 Proteins. Cells 2019, 8 , 1006. [CrossRef] [PubMed]

325. Obšilová, V.; Kopecka, M.; Kosek, D.; Kacirova, M.; Kylarová, S.; Rezabkova, L.; Obsil, T. Mechanisms of the 14-3-3 protein function: Regulation of protein function through conformational modulation. Physiol. Res. 2014, 63, 155-164. [CrossRef] 
326. Rios, A.; Hernández-Ramírez, V.I.; Moguel, M.; Bahena, A.I.Z.; Rosales-Encina, J.L.; Vargas, M. Ángel; Talamás-Rohana, P. Participation of Rho, ROCK-2, and GAP activities during actin microfilament rearrangements in Entamoeba histolytica induced by fibronectin signaling. Cell Biol. Int. 2008, 32, 984-1000. [CrossRef]

327. Amano, M.; Nakayama, M.; Kaibuchi, K. Rho-kinase/ROCK: A key regulator of the cytoskeleton and cell polarity. Cytoskeleton 2010, 67, 545-554. [CrossRef] [PubMed]

328. Narumiya, S.; Tanji, M.; Ishizaki, T. Rho Signaling, ROCK and MDia1, in Transformation, Metastasis and Invasion. Cancer Metastasis Rev. 2009, 28, 65-76. [CrossRef] [PubMed]

329. Bosgraaf, L.; van Haastert, P.J. The regulation of myosin II in Dictyostelium. Eur. J. Cell Biol. 2006, 85, 969-979. [CrossRef] [PubMed]

330. Basant, A.; Glotzer, M. Spatiotemporal Regulation of RhoA during Cytokinesis. Curr. Biol. 2018, 28, R570-R580. [CrossRef] [PubMed]

331. Maddox, A.S.; Burridge, K. RhoA is required for cortical retraction and rigidity during mitotic cell rounding. J. Cell Biol. 2003, 160, 255-265. [CrossRef]

332. Wheeler, A.P.; Ridley, A.J. Why three Rho proteins? RhoA, RhoB, RhoC, and cell motility. Exp. Cell Res. 2004, 301 , 43-49. [CrossRef]

333. Filić, V.; Marinović, M.; Faix, J.; Weber, I. The IQGAP-related protein DGAP1 mediates signaling to the actin cytoskeleton as an effector and a sequestrator of Rac1 GTPases. Cell. Mol. Life Sci. 2014, 71, 2775-2785. [CrossRef]

334. Somesh, B.P.; Vlahou, G.; Iijima, M.; Insall, R.H.; Devreotes, P.; Rivero, F. RacG Regulates Morphology, Phagocytosis, and Chemotaxis. Eukaryot. Cell 2006, 5, 1648-1663. [CrossRef]

335. Amos, L.A.; Löwe, J. Overview of the Diverse Roles of Bacterial and Archaeal Cytoskeletons. Subcell. Biochem. 2017, 84, 1-26. [CrossRef] [PubMed]

336. Stoddard, P.R.; Williams, T.A.; Garner, E.; Baum, B. Evolution of polymer formation within the actin superfamily. Mol. Biol. Cell 2017, 28, 2461-2469. [CrossRef]

337. Wagstaff, J.; Löwe, J. Prokaryotic cytoskeletons: Protein filaments organizing small cells. Nat. Rev. Microbiol. 2018, 16, 187-201. [CrossRef]

338. Wickstead, B.; Gull, K. The evolution of the cytoskeleton. J. Cell Biol. 2011, 194, 513-525. [CrossRef]

339. Akıl, C.; Robinson, R.C. Genomes of Asgard archaea encode profilins that regulate actin. Nature 2018, 562, 439-443. [CrossRef] [PubMed]

340. Akıl, C.; Tran, L.T.; Orhant-Prioux, M.; Baskaran, Y.; Manser, E.; Blanchoin, L.; Robinson, R.C. Insights into the evolution of regulated actin dynamics via characterization of primitive gelsolin/cofilin proteins from Asgard archaea. Proc. Natl. Acad. Sci. USA 2020, 117, 19904-19913. [CrossRef] [PubMed]

341. Izoré, T.; Kureisaite-Ciziene, D.; McLaughlin, S.H.; Löwe, J. Crenactin forms actin-like double helical filaments regulated by arcadin-2. eLife 2016, 5, e21600. [CrossRef] [PubMed]

342. Merino, F.; Raunser, S. The mother of all actins? eLife 2016, 5, 161. [CrossRef] [PubMed]

343. Velle, K.B.; Fritz-Laylin, L.K. Diversity and evolution of actin-dependent phenotypes. Curr. Opin. Genet. Dev. 2019, 58-59, 40-48. [CrossRef]

344. Velle, K.B.; Fritz-Laylin, L.K. Conserved actin machinery drives microtubule-independent motility and phagocytosis in Naegleria. J. Cell Biol. 2020, 219, 219. [CrossRef]

345. Fritz-Laylin, L.; Lord, S.J.; Mullins, R.D. Our evolving view of cell motility. Cell Cycle 2017, 16, 1735-1736. [CrossRef]

346. Fritz-Laylin, L.K. The evolution of animal cell motility. Curr. Biol. 2020, 30, R477-R482. [CrossRef]

347. Kameritsch, P.; Renkawitz, J. Principles of Leukocyte Migration Strategies. Trends Cell Biol. 2020, 30, 818-832. [CrossRef] [PubMed]

348. Moreau, H.D.; Piel, M.; Voituriez, R.; Lennon-Duménil, A.-M. Integrating Physical and Molecular Insights on Immune Cell Migration. Trends Immunol. 2018, 39, 632-643. [CrossRef]

349. Spang, A.; Saw, J.H.; Jørgensen, S.L.; Zaremba-Niedzwiedzka, K.; Martijn, J.; Lind, A.E.; Van Eijk, R.; Schleper, C.; Guy, L.; Ettema, T.J.G. Complex archaea that bridge the gap between prokaryotes and eukaryotes. Nature 2015, 521, 173-179. [CrossRef] [PubMed]

350. Zaremba-Niedzwiedzka, K.; Caceres, E.F.; Saw, J.H.; Bäckström, D.; Juzokaite, L.; Vancaester, E.; Seitz, K.W.; Anantharaman, K.; Starnawski, P.; Kjeldsen, K.U.; et al. Asgard archaea illuminate the origin of eukaryotic cellular complexity. Nature 2017, 541, 353-358. [CrossRef] [PubMed]

351. Dey, G.; Thattai, M.; Baum, B. On the Archaeal Origins of Eukaryotes and the Challenges of Inferring Phenotype from Genotype. Trends Cell Biol. 2016, 26, 476-485. [CrossRef]

352. Kessin, R.H. Dictyostelium: Evolution, Cell Biology, and the Development of Multicellularity; Bard, J.B.L., Barlow, P.W., Kirk, D.L., Eds.; Developmental and Cell Biology Series; Cambridge University Press: Cambridge, UK, 2001.

353. Martín-González, J.; Montero-Bullón, J.; Lacal, J. Dictyostelium discoideum as a non-mammalian biomedical model. Microb. Biotechnol. 2021, 14, 111-125. [CrossRef]

354. Eichinger, L.; Noegel, A.A. Comparative genomics of Dictyostelium discoideum and Entamoeba histolytica. Curr. Opin. Microbiol. 2005, 8, 606-611. [CrossRef] [PubMed]

355. Siddiqui, R.; Khan, N.A. Biology and pathogenesis of Acanthamoeba. Parasites Vectors 2012, 5, 6. [CrossRef] [PubMed]

356. Hillmann, F.; Forbes, G.; Novohradská, S.; Ferling, I.; Riege, K.; Groth, M.; Westermann, M.; Marz, M.; Spaller, T.; Winckler, T.; et al. Multiple Roots of Fruiting Body Formation in Amoebozoa. Genome Biol. Evol. 2018, 10, 591-606. [CrossRef] 
357. Eichinger, L.; Rivero, F. (Eds.) Dictyostelium Discoideum Protocols, 2nd ed.; Methods in Molecular Biology Series 983; Humana Press: Totowa, NJ, USA, 2013.

358. Manich, M.; Hernandez-Cuevas, N.; Villa, J.D.O.; Syan, S.; Marchat, L.A.; Olivo-Marin, J.-C.; Guillén, N. Morphodynamics of the Actin-Rich Cytoskeleton in Entamoeba histolytica. Front. Cell. Infect. Microbiol. 2018, 8, 179. [CrossRef]

359. Fritz-Laylin, L.; Prochnik, S.E.; Ginger, M.; Dacks, J.B.; Carpenter, M.; Field, M.C.; Kuo, A.; Paredez, A.; Chapman, J.; Pham, J.; et al. The Genome of Naegleria gruberi Illuminates Early Eukaryotic Versatility. Cell 2010, 140, 631-642. [CrossRef]

360. Paredez, A.; Assaf, Z.J.; Sept, D.; Timofejeva, L.; Dawson, S.C.; Wang, C.-J.R.; Cande, W.Z. An actin cytoskeleton with evolutionarily conserved functions in the absence of canonical actin-binding proteins. Proc. Natl. Acad. Sci. USA 2011, 108, $6151-6156$. [CrossRef] [PubMed]

361. Krtková, J.; Xu, J.; Lalle, M.; Steele-Ogus, M.; Alas, G.C.M.; Sept, D.; Paredez, A.R. 14-3-3 Regulates Actin Filament Formation in the Deep-Branching Eukaryote Giardia lamblia. mSphere 2017, 2, e00248-17. [CrossRef]

362. Fort, P.; Blangy, A. The Evolutionary Landscape of Dbl-Like RhoGEF Families: Adapting Eukaryotic Cells to Environmental Signals. Genome Biol. Evol. 2017, 9, 1471-1486. [CrossRef] [PubMed]

363. Agarwal, M.; Guerin, N.A.; Larochelle, D.A. Chimeric analysis of the small GTPase RacE in cytokinesis signaling in Dictyostelium discoideum. Exp. Cell Res. 2004, 295, 226-235. [CrossRef]

364. Charest, P.G.; Firtel, R.A. Big roles for small GTPases in the control of directed cell movement. Biochem. J. 2006, 401, 377-390. [CrossRef] [PubMed]

365. Stairs, C.W.; Ettema, T.J. The Archaeal Roots of the Eukaryotic Dynamic Actin Cytoskeleton. Curr. Biol. 2020, 30 , R521-R526. [CrossRef] 